\title{
The lon Channel and GPCR Toolkit of Brain Capillary Pericytes
}

\author{
Ashwini Hariharan ${ }^{1 \dagger}$, Nick Weir ${ }^{1 \dagger}$, Colin Robertson ${ }^{1}$, Liqun $\mathrm{He}^{2}$, Christer Betsholtz ${ }^{2,3}$ and \\ Thomas A. Longden ${ }^{1 *}$
}

${ }^{1}$ Department of Physiology, School of Medicine, University of Maryland, Baltimore, MD, United States, ${ }^{2}$ Rudbeck Laboratory, Department of Immunology, Genetics and Pathology, Uppsala University, Uppsala, Sweden, ${ }^{3}$ Department of Medicine Huddinge (MedH), Karolinska Institutet \& Integrated Cardio Metabolic Centre, Huddinge, Sweden

\section{OPEN ACCESS}

Edited by:

Fabrice Dabertrand

University of Colorado, United States

Reviewed by:

Chiara Bianca Maria Platania

University of Catania, Italy

Frank Faraci,

The University of lowa, United States

*Correspondence:

Thomas A. Longden

thomas.longden@som.umaryland.edu

†These authors have contributed equally to this work

Specialty section:

This article was submitted to Non-Neuronal Cells,

a section of the journal

Frontiers in Cellular Neuroscience

Received: 31 August 2020 Accepted: 13 November 2020 Published: 18 December 2020

Citation:

Hariharan A, Weir N, Robertson C, He L, Betsholtz $C$ and Longden TA (2020) The Ion Channel and GPCR Toolkit of Brain Capillary Pericytes. Front. Cell. Neurosci. 14:601324. doi: 10.3389/fncel.2020.601324
Brain pericytes reside on the abluminal surface of capillaries, and their processes cover $\sim 90 \%$ of the length of the capillary bed. These cells were first described almost 150 years ago (Eberth, 1871; Rouget, 1873) and have been the subject of intense experimental scrutiny in recent years, but their physiological roles remain uncertain and little is known of the complement of signaling elements that they employ to carry out their functions. In this review, we synthesize functional data with single-cell RNAseq screens to explore the ion channel and G protein-coupled receptor (GPCR) toolkit of mesh and thin-strand pericytes of the brain, with the aim of providing a framework for deeper explorations of the molecular mechanisms that govern pericyte physiology. We argue that their complement of channels and receptors ideally positions capillary pericytes to play a central role in adapting blood flow to meet the challenge of satisfying neuronal energy requirements from deep within the capillary bed, by enabling dynamic regulation of their membrane potential to influence the electrical output of the cell. In particular, we outline how genetic and functional evidence suggest an important role for $\mathrm{G}_{\mathrm{S}}$-coupled GPCRs and ATP-sensitive potassium (K $\mathrm{K}_{\text {ATP }}$ ) channels in this context. We put forth a predictive model for long-range hyperpolarizing electrical signaling from pericytes to upstream arterioles, and detail the TRP and $\mathrm{Ca}^{2+}$ channels and $\mathrm{G}_{\mathrm{q}}, \mathrm{G}_{\mathrm{i} / \mathrm{o}}$, and $\mathrm{G}_{12 / 13}$ signaling processes that counterbalance this. We underscore critical questions that need to be addressed to further advance our understanding of the signaling topology of capillary pericytes, and how this contributes to their physiological roles and their dysfunction in disease.

Keywords: pericytes, ion channels, GPCRs (G protein coupled receptors), neurovascular coupling (NVC), cerebral blood flow (CBF), $\mathrm{K}_{\text {ATP }}$ channels, brain metabolism

\section{INTRODUCTION}

A combination of autonomic signaling (Cipolla et al., 2004; Hamel, 2006) and intrinsic pressure sensing and metabolic autoregulatory mechanisms (Bayliss, 1902; Paulson et al., 1990) drives continual adjustments in global and local blood flow in the brain. Importantly, as the brain lacks substantial energy stores it must be able to rapidly adapt local blood flow to fluctuating neuronal metabolic needs to provide adequate oxygen and glucose delivery. This is achieved through the ondemand process of functional hyperemia (FH), where increases in neural activity-which can span orders of magnitude in milliseconds-are met with an increase in local blood flow within seconds. This call-and-response phenomenon is underlain by a complex range of stratified mechanisms, collectively termed neurovascular coupling (NVC), which have inbuilt redundancy to ensure the fidelity of the blood flow response. 
Significant inroads toward a full understanding of these NVC mechanisms have been made in recent years (Iadecola, 2017), and in particular ion channel and GPCR signaling networks within and between the cells of the neurovascular unit [NVU; neurons, astrocytes, smooth muscle cells (SMCs), endothelial cells (ECs), and pericytes] are emerging as major contributors (Longden et al., 2016). However, capillary pericytes represent a relative blind spot in our knowledge, and our understanding of their involvement in brain blood flow control is less well-developed than that for other cells of the NVU. Accordingly, the purpose of this review is to survey the signaling toolkit that mesh and thinstrand pericytes may employ to contribute to the control of blood flow throughout the brain. To this end, we leverage data from recent brain single-cell RNAseq (scRNAseq) screens (He et al., 2018; Vanlandewijck et al., 2018; Zeisel et al., 2018) to profile the expression of ion channels (Table 1) and GPCRs (Table 2) in brain capillary pericytes which, when synthesized with functional results, may aid in delineating their physiological roles.

An important caveat with this approach is that mRNA expression does not necessarily predict protein levels (Liu et al., 2016), and we thus stress that it is essential that the hypotheses generated by transcriptomic data be subject to further experimental scrutiny. Accordingly, while the following discussion is based on robust mRNA expression data, we highlight where there is question of whether gene expression translates into functional channels or receptors. A second putative caveat relates to the quality of the scRNAseq data. Specifically, it is important to ask if low-level mRNA counts reflect true and physiologically meaningful expression or artifacts such as contamination of the pericyte transcriptomes by mRNA from other cell types. Pericytes in particular are sensitive to endothelial contamination because of the tight physical association between these two cell types. With these caveats in mind, to arrive at a list of genes with reasonable likelihood of pericyte expression we first selected genes detected at levels $>1$ average count per cell in the 1,088 adult brain pericytes present in the Vanlandewijck et al. dataset (http:// betsholtzlab.org/VascularSingleCells/database.html; He et al., 2018; Vanlandewijck et al., 2018) and compared this to their expression in the Zeisel dataset (http://mousebrain.org; Zeisel et al., 2018). In the latter, three pericyte clusters are provided (PER1, PER2, PER3) of which PER1 and PER2 are endothelial cell contaminated, whereas PER3 appears pure. After manually checking for signs of contamination by comparing the expression level in pericytes with expression in other brain cell types, we selected the following criteria as qualifying: (i) expression in $>3 \%$ of the pericytes in the Vanlandewijck dataset and; (ii) detectable expression ( $>0$ ) in the Zeisel et al. PER3 dataset (Figure 1).

Below, we focus our discussion on the ion channels and GPCRs that are likely to be most pertinent to blood flow control. We center our discussion on studies using acute and in vivo preparations, as cultured pericytes may exhibit phenotypic drift which confounds interpretation. Accordingly, we note instances in which we refer to cultured pericytes. We begin by briefly reviewing the key features of the brain vasculature and pericytes before exploring their ion channel and GPCR complement in detail.

\section{THE VASCULAR NETWORK OF THE BRAIN}

\section{Fundamental Angioarchitecture}

From pial arteries on the brains surface, penetrating arterioles branch orthogonally and dive into the parenchyma (Duvernoy et al., 1981; Cipolla, 2009; Figure 2). Arteries and arterioles are composed of a lumen lined by electrically-coupled cobblestonemorphology ECs (Haas and Duling, 1997) that directly interface with the blood. These ECs are surrounded by a fenestrated internal elastic lamina (IEL), composed mainly of elastin and collagen (Schwartz et al., 1981), through which they extend projections to directly contact overlying contractile smooth muscle cells (SMCs) (Aydin et al., 1991).

As the penetrating arteriole extends deeper into the tissue, further vessels sprout from its length at regular intervals (Blinder et al., 2013). These initial branch points are sites of precapillary sphincters which are regulated over short time scales to control blood flowing into the capillary bed (Grubb et al., 2020). From this point, extensive ramification of the vascular bed greatly expands the surface area of the network, facilitating efficient exchange of nutrients and waste to rapidly satisfy the intense metabolic requirements of every neuron. The capillary bedconsisting of capillary ECs (cECs; Garcia and Longden, 2020) and overlying pericytes (see below) embedded in the basement membrane (a dense network of glycoproteins, collagens and secreted factors; Pozzi et al., 2017) - is incredibly dense, and each microliter of cortex holds approximately $1 \mathrm{~m}$ of blood vessels (Shih et al., 2015). Of these, around $90 \%$ by volume are capillaries (Gould et al., 2017). Accordingly, ECs are estimated to comprise around $30 \%$ of the non-neuronal cell mass in the gray matter, forming a network of 20-25 billion ECs throughout the entire human brain (von Bartheld et al., 2016). This places cECs in close apposition with all neurons, with each neuronal cell body lying within $\sim 15 \mu \mathrm{m}$ of a vessel (Tsai et al., 2009). Red blood cells (RBCs) traverse this network, releasing oxygen to diffuse down its concentration gradient into the tissue, while glucose is transported by ECs from the blood plasma into the parenchyma. After negotiating the capillary bed, oxygen-depleted RBCs eventually reach a vertically-oriented venule, which drain to veins at the cortical surface on the path back to the heart.

\section{Mural Cell Properties Transition Gradually With Increasing Branch Order}

As the vascular bed ramifies from the penetrating arteriole, there is gradation in the morphology and functional characteristics of the mural cells associated with vessels. The first 3-4 branches of the vascular network (1st to 4th order) originating from the penetrating arteriole constitute a "transitional zone" (Ratelade et al., 2020). These vessels are covered by cells expressing high levels of $\alpha$-smooth muscle actin ( $\alpha$-SMA) with ovoid cell bodies and multiple broad processes that almost completely ensheathe the underlying vessel (Grant et al., 2019; Figure 3A). Given that the identity of these cells is unresolved, and that they have been referred to as both pericytes (Peppiatt et al., 2006; Hall et al., 2014; Attwell et al., 2016; Grant et al., 2019) and SMCs (Hill et al., 2015; Grutzendler and Nedergaard, 2019), we refer to these cells here as "contractile mural cells" and to the segments of the vasculature 
TABLE 1 | lon channels expressed by CNS capillary pericytes.

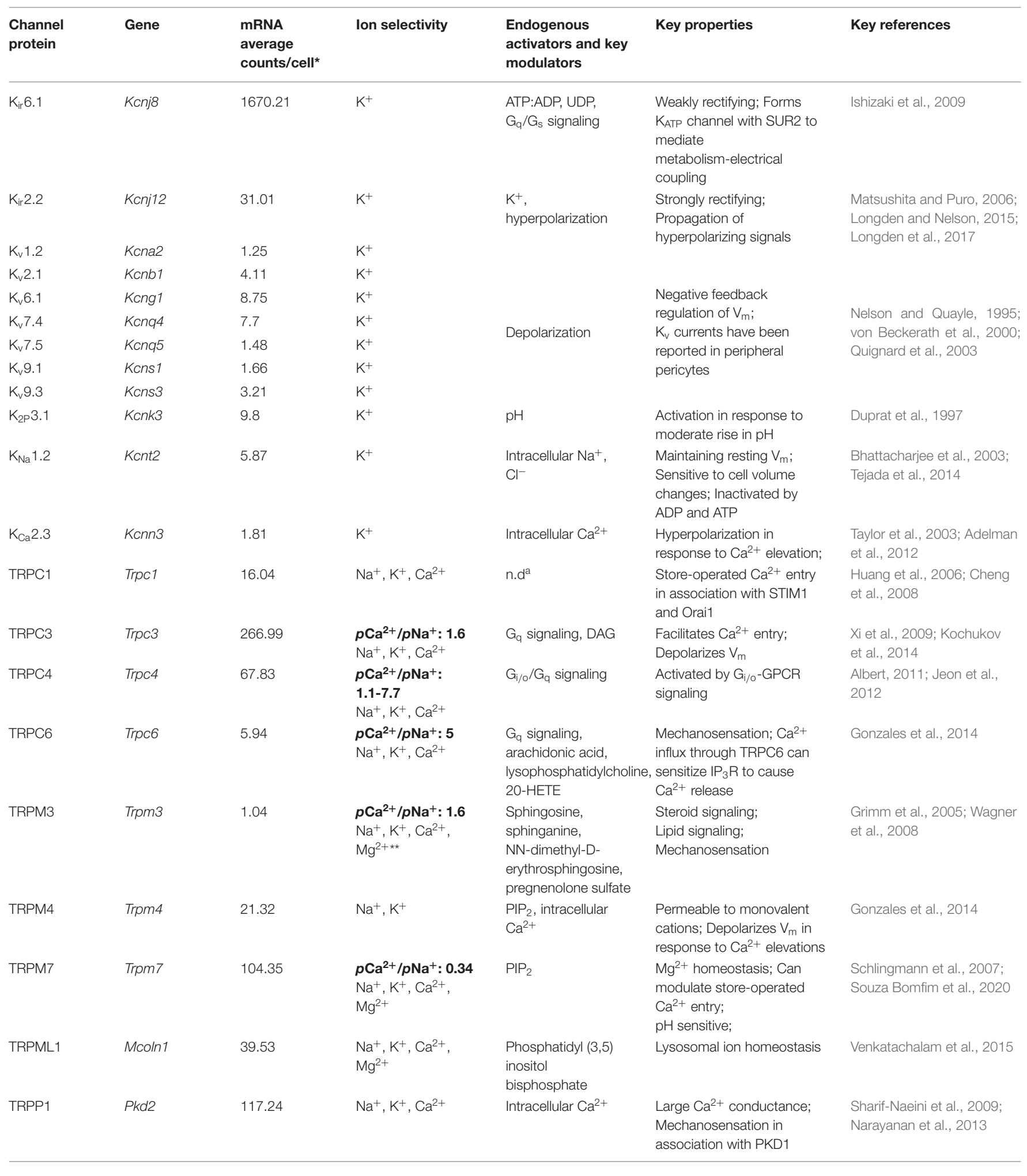


TABLE 1 | Continued

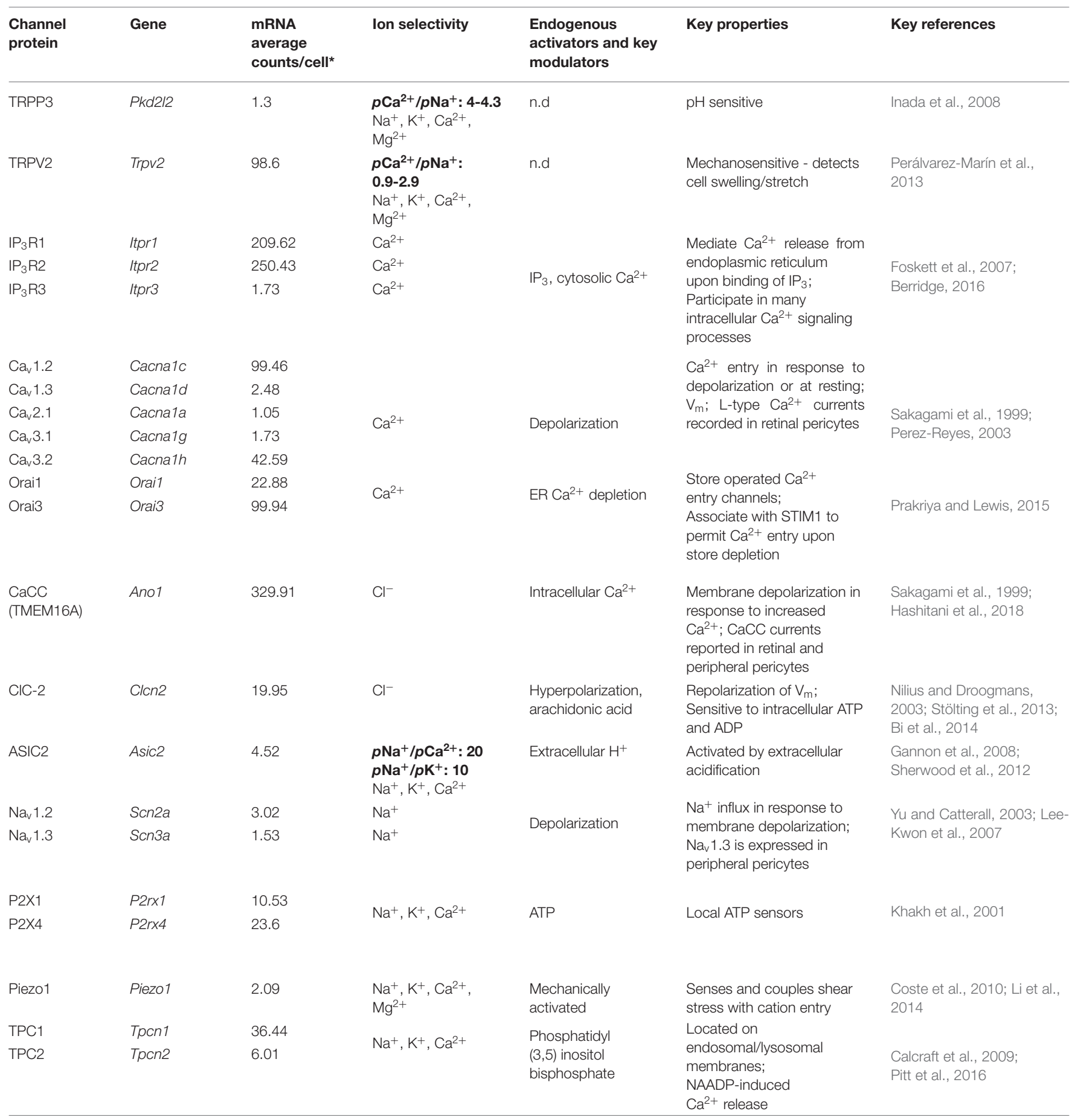

Naming conventions used throughout conform to those outlined in the IUPHAR/BPS Guide to Pharmacology (Armstrong et al., 2020). Permeability ratios are noted in bold where appropriate. Abbreviations not used elsewhere: NAADP, nicotinic acid adenine dinucleotide phosphate.

an.d., no data.

*Data from He et al. (2018) and Vanlandewijck et al. (2018), expressed as average counts per cell annotated as a brain pericyte. Cells were isolated from adult mice of either sex aged

10-19 weeks.

${ }^{\star *}$ Permeability for short-pore sequence isoform TRPM3 $\alpha 2$. 
TABLE 2 | G protein coupled receptors expressed by CNS capillary pericytes.

\begin{tabular}{|c|c|c|c|c|c|c|c|}
\hline Receptor & Gene & $\begin{array}{c}\text { mRNA } \\
\text { average } \\
\text { counts/cell* }\end{array}$ & $\begin{array}{l}\text { Principal } \\
\text { G-protein }\end{array}$ & $\begin{array}{c}\text { GPCR } \\
\text { sub-class }\end{array}$ & $\begin{array}{l}\text { Endogenous } \\
\text { agonists }\end{array}$ & $\begin{array}{l}\text { Signal transduction } \\
\text { effects; roles }\end{array}$ & Key references \\
\hline$A_{1}$ receptor & Adora1 & 1.96 & $\mathrm{G}_{\mathrm{i} / \mathrm{o}}$ & A & Adenosine & $\begin{array}{l}\downarrow \text { CAMP; } \\
\text { Arterial vasoconstriction }\end{array}$ & Borea et al., 2018 \\
\hline $\mathrm{A}_{2 \mathrm{~A}}$ receptor & Adora2a & 85.45 & $\mathrm{G}_{\mathrm{s}}$ & & & $\begin{array}{l}\uparrow \text { cAMP; } \\
\text { Arterial vasorelaxation }\end{array}$ & \\
\hline \multicolumn{8}{|l|}{ Adrenoceptors } \\
\hline $\begin{array}{l}\alpha_{1 \mathrm{~A}} \text {-adrenoreceptor } \\
\alpha_{1 \mathrm{~B}} \text {-adrenoreceptor }\end{array}$ & $\begin{array}{l}\text { Adra1a } \\
\text { Adra1b }\end{array}$ & $\begin{array}{l}1.44 \\
1.29\end{array}$ & $\begin{array}{l}\mathrm{G}_{\mathrm{q}} \\
\mathrm{G}_{\mathrm{q}}\end{array}$ & A & $\begin{array}{l}\text { Epinephrine > } \\
\text { norepinephrine }\end{array}$ & $\begin{array}{l}\uparrow \mathrm{IP}_{3} / \mathrm{DAG} ; \\
\text { Arterial vasoconstriction }\end{array}$ & $\begin{array}{l}\text { Hieble and Ruffolo, 1997; } \\
\text { Guimarães and Moura, }\end{array}$ \\
\hline$\alpha_{2 A}$-adrenoreceptor & Adra2a & 1.73 & $\mathrm{G}_{\mathrm{i} / \mathrm{o}}$ & & & $\downarrow$ CAMP; & 2001; Muszkat et al., 2005; \\
\hline Chemerin receptor 1 & Cmklr1 & 3.49 & $\mathrm{G}_{\mathrm{i} / \mathrm{o}}$ & A & $\begin{array}{l}\text { Resolvin E1 > } \\
\text { Chemerin }\end{array}$ & $\begin{array}{l}\downarrow \mathrm{CAMP} \text {; Vasoconstrictor } \\
\text { with a role in inflammation }\end{array}$ & $\begin{array}{l}\text { De Henau et al., 2016; } \\
\text { Kennedy et al., } 2016\end{array}$ \\
\hline \multicolumn{8}{|c|}{ Chemokine receptors } \\
\hline CCR9 & Cor9 & 25.5 & $\mathrm{G}_{\mathrm{i} / \mathrm{o}}$ & A & CCL25 & $\begin{array}{l}\uparrow \mathrm{Ca}^{2+} \text {; } \\
\text { Activation of adaptive } \\
\text { immune response; } \\
\text { Leukocyte recruitment }\end{array}$ & $\begin{array}{l}\text { Watts et al., 2013; Mazzotti } \\
\text { et al., } 2017\end{array}$ \\
\hline CXCR4 & Cxcr4 & 1.44 & $\mathrm{G}_{\mathrm{i} / \mathrm{o}}$ & & CXCL12 & & \\
\hline $\mathrm{ET}_{\mathrm{B}}$ receptor & Ednrb & 20.99 & $\mathrm{G}_{\mathrm{s}}, \mathrm{G}_{\mathrm{i} / \mathrm{o}}, \mathrm{G}_{\mathrm{q}}$ & & & $\begin{array}{l}\uparrow \mathrm{IP}_{3} / \mathrm{DAG} / \mathrm{PLA} \mathrm{A}_{2} / \mathrm{PLD} ; \\
\text { Vasodilation in ECs, } \\
\text { vasoconstriction in SMCs }\end{array}$ & \\
\hline FFA2 receptor & Ffar2 & 6.47 & $\mathrm{G}_{\mathrm{q}}$ & A & Free fatty acids & $\begin{array}{l}\uparrow \mathrm{IP}_{3} / \mathrm{DAG} ; \\
\text { Roles in metabolism and } \\
\text { inflammation }\end{array}$ & Li et al., 2018 \\
\hline GIP receptor & Gipr & 8.48 & $\mathrm{G}_{\mathrm{s}}$ & $\mathrm{B}$ & $\begin{array}{l}\text { Gastric inhibitory } \\
\text { polypeptide }\end{array}$ & $\begin{array}{l}\uparrow \text { cAMP; } \\
\text { Increases blood flow in } \\
\text { adipose microvessels }\end{array}$ & Asmar et al., 2019 \\
\hline GPER & Gper1 & 716.19 & $\mathrm{G}_{\mathrm{i} / \mathrm{o}}$ & $A$ & $17 \beta$-estradiol & $\begin{array}{l}\text { Diverse genomic and } \\
\text { non-genomic roles; } \\
\text { Vasodilation, likely via } \\
\text { secondary } G_{s} \text { coupling }\end{array}$ & $\begin{array}{l}\text { Prossnitz and Arterburn, } \\
\text { 2015; Evans et al., } 2016\end{array}$ \\
\hline Kisspeptin receptor & Kiss1r & 1.93 & $\mathrm{G}_{\mathrm{q}}$ & A & $\begin{array}{l}\text { Kisspeptin- } \\
10,-13,-14,-54,-52\end{array}$ & $\begin{array}{l}\uparrow \mathrm{IP}_{3} / \mathrm{DAG} ; \\
\text { Vasoconstrictor, inhibits } \\
\text { angiogenesis }\end{array}$ & $\begin{array}{l}\text { Sawyer et al., 2011; } \\
\text { Cvetković et al., } 2013\end{array}$ \\
\hline
\end{tabular}


TABLE 2 | Continued

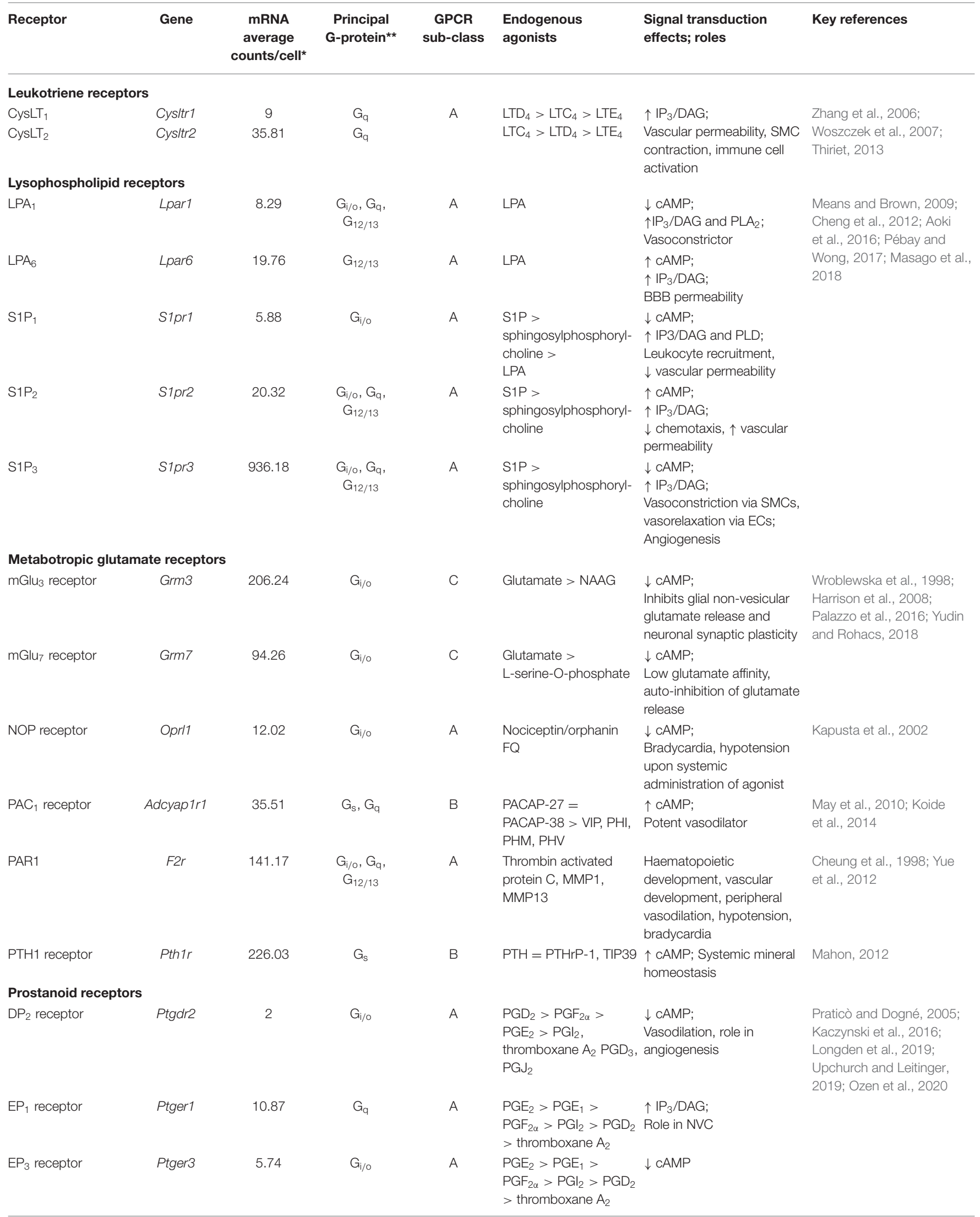


TABLE 2 | Continued

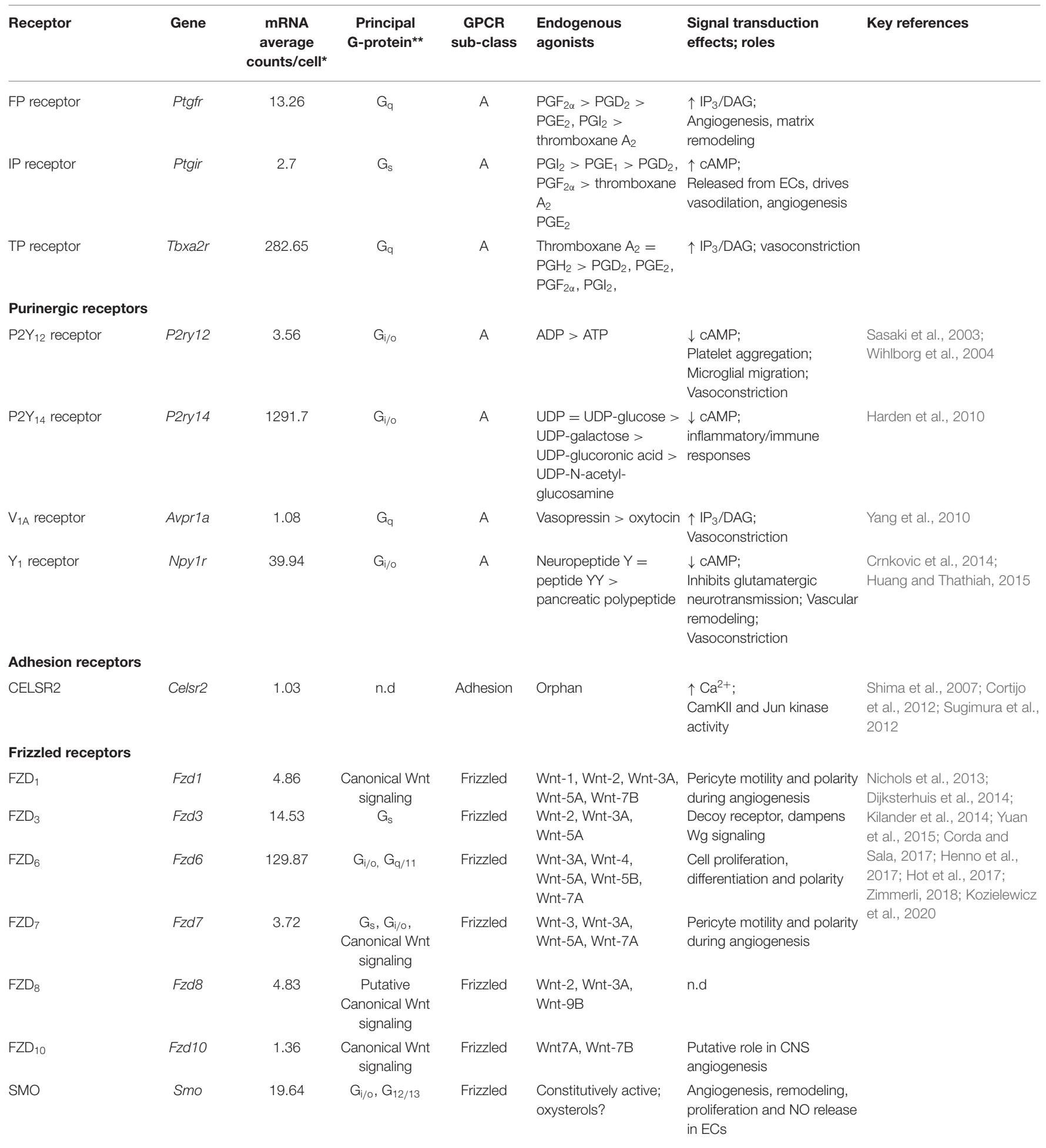


TABLE 2 | Continued

\begin{tabular}{|c|c|c|c|c|c|c|c|}
\hline Receptor & Gene & $\begin{array}{c}\text { mRNA } \\
\text { average } \\
\text { counts/cell* }\end{array}$ & $\begin{array}{l}\text { Principal } \\
\text { G-protein }{ }^{\star \star}\end{array}$ & $\begin{array}{c}\text { GPCR } \\
\text { sub-class }\end{array}$ & $\begin{array}{l}\text { Endogenous } \\
\text { agonists }\end{array}$ & $\begin{array}{l}\text { Signal transduction } \\
\text { effects; roles }\end{array}$ & Key references \\
\hline GPR4 & Gpr4 & 85.06 & $\begin{array}{c}\mathrm{G}_{\mathrm{s}}, \mathrm{G}_{\mathrm{i} / \mathrm{o}}, \mathrm{G}_{\mathrm{q}} \\
\mathrm{G}_{12 / 13}\end{array}$ & A & $\mathrm{H}^{+}$ & $\begin{array}{l}\uparrow \mathrm{cAMP} \\
\uparrow \mathrm{IP}_{3} / \mathrm{DAG} \\
\text { Pro-inflammatory in ECs }\end{array}$ & $\begin{array}{l}\text { Tobo et al., 2007; Li et al., } \\
\text { 2015; Weiß et al., } 2017 \text {; } \\
\text { Carvalho et al., } 2020\end{array}$ \\
\hline GPR20 & Gpr20 & 4.93 & n.d & A & n.d & n.d & \\
\hline GPR157 & Gpr157 & 1.18 & n.d & None & n.d & n.d & \\
\hline GPR182 & Gpr182 & 17.83 & n.d & A & Adrenomedullin & n.d & \\
\hline GPRC5B & Gprc5b & 1.04 & n.d & $\mathrm{C}$ & n.d & $\begin{array}{l}\text { Regulation of vascular SMC } \\
\text { tone }\end{array}$ & \\
\hline OPN3 & Opn3 & 1.59 & n.d & A & n.d & n.d & \\
\hline TPRA1 & Tpra1 & 52.7 & $\mathrm{G}_{\mathrm{i} / \mathrm{o}}$ & 7TM & $N / A$ & n.d & Singh et al., 2015 \\
\hline
\end{tabular}

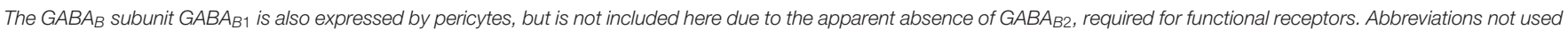

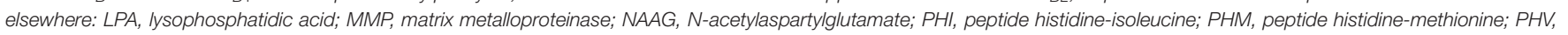
peptide histidine-valine; PLD, phospholipase D; TIP39, Tuberoinfundibular peptide of 39 residues; VIP, vasoactive intestinal peptide.

an.d, no data.

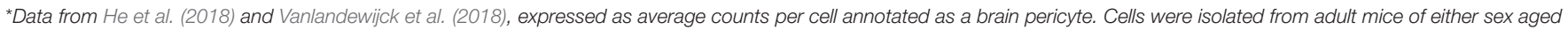
10-19 weeks.

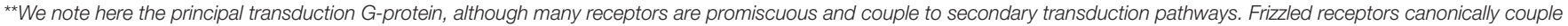

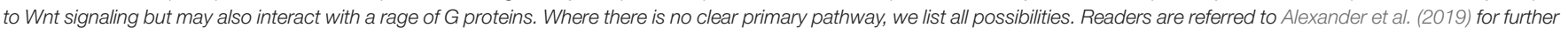
details.

that they cover as "vessels." Expression of $\alpha$-SMA permits these cells to rapidly regulate the diameter of the underlying vessel and therefore blood flow. Indeed, multiple studies have illustrated the importance of contractile mural cells in mediating dilation (of 10-30\%) in response to neuronal stimulation (Hill et al., 2015; Mishra et al., 2016; Kisler et al., 2017; Cai et al., 2018; Rungta et al., 2018).

Beyond this point in the vasculature, mural cells do not express high levels of $\alpha$-SMA, although one recent study suggested that retinal mural cells retain expression of a low level of this protein (Alarcon-Martinez et al., 2018) and they do express very low levels of the Acta2 gene in the brain (He et al., 2018; Vanlandewijck et al., 2018). As a result, these cells are not equipped to regulate vessel diameter over abrupt time scales, but there is clear evidence that they may contract slowly under certain circumstances (reducing the diameter of the underlying vessel by up to $\sim 25 \%$; Fernández-Klett et al., 2010; Gonzales et al., 2020). Thus, we consider the relatively static diameter vessels downstream of the $\alpha$-SMA terminus (which typically occurs between the 1st and 4th order branch in immunostaining experiments; Grant et al., 2019) to be capillaries. The identity of mural cells on these so-defined capillaries is unambiguous, and there is consensus that these cells are pericytes.

The pericytes residing on capillaries display at least two distinct morphologies: (i) Immediately adjacent to the $\alpha$-SMA terminus, pericytes take on a mesh-like appearance, and are thus known as "mesh pericytes" (Figure 3B); (ii) beyond these are cells that project long, thin processes along the vasculature, and accordingly these are referred to as "thin-strand pericytes" (Grant et al., 2019; Figures 3C,D).

\section{CELLULAR ANATOMY OF MESH AND THIN-STRAND PERICYTES}

Despite differing morphologies (Figure 3), mesh and thinstrand pericytes are indistinguishable at the level of singlecell transcriptomics, possibly due to the fact that mesh pericytes represent only a small fraction of capillary pericytes (Chasseigneaux et al., 2018). Pericyte cell bodies have a highly stereotyped shape, appearing as a large ovoid that protrudes from the wall of the capillary, which is often referred to as a "bump-on-a-log" (Grant et al., 2019). Mesh pericytes are few in number relative to thin-strand pericytes and have fewer, shorter longitudinal processes (their primary trunks averaging $40 \mu \mathrm{m}$ in length; Hartmann et al., 2015) that cover $\sim 70 \%$ of the underlying capillary. This contrasts with upstream contractile mural cells which cover 95\% of the underlying vessel (Grant et al., 2019). Thin-strand pericytes extend long, thin, strand-like processes that are $\sim 1.5 \mu \mathrm{m}$ in diameter and cover on average around $250 \mu \mathrm{m}$ in total capillary distance, in some instances 
A

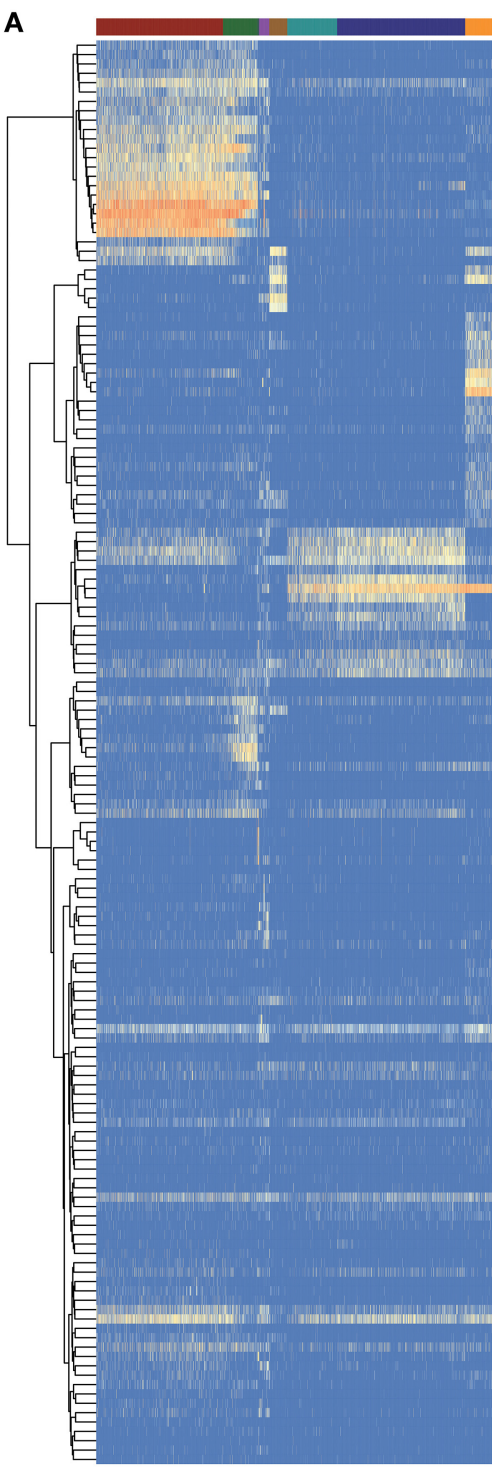

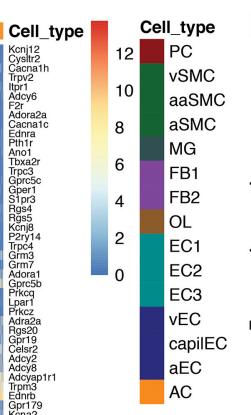

B

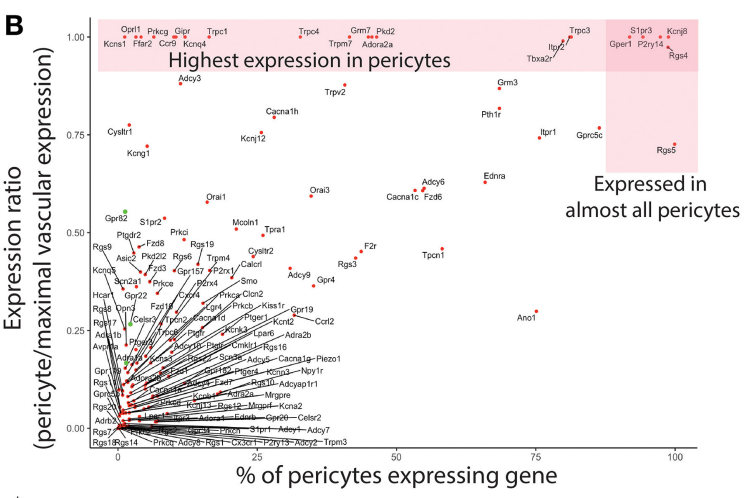

C

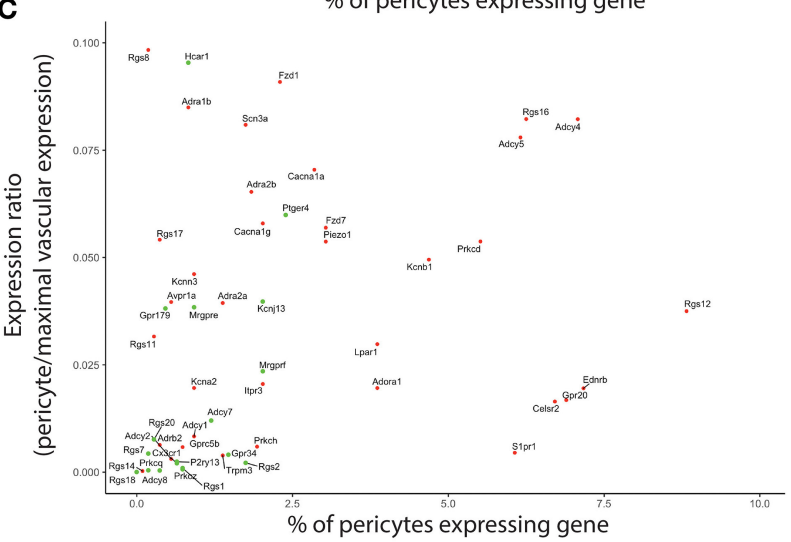

FIGURE 1 | Overview of gene qualification process for pericyte ion channels and GPCRs and other genes of interest. An initial filter of 1 average count/cell was applied to exclude genes with extremely low expression. (A) Heatmap of expression of the remaining genes throughout the neurovascular unit. A small subset of these genes were highly enriched in pericytes (top left), while many showed higher expression in other cell types. To filter out potential contamination, genes that were expressed in $<3 \%$ of pericytes, and were absent from the PER3 cluster of Zeisel et al. (2018) were excluded. (B) Relationship between pericyte-specificity of expression and fraction of pericytes expressing each gene considered. Genes represented by green circles were excluded according to the above criteria. (C) High resolution view of genes with a $<0.1$ expression ratio in pericytes, that were expressed in fewer than $10 \%$ of pericytes, corresponding to the bottom left corner in (B). Genes represented by green circles were excluded from further consideration as potential contamination.

exceeding $300 \mu \mathrm{m}$ (Berthiaume et al., 2018). Together, the thinstrand pericyte cell body and its processes cover between one third (Mathiisen et al., 2010) and one half (Grant et al., 2019) of the abluminal surface area of the endothelium. A typical thinstrand process has a stable "non-terminal core" of $\sim 50 \mu \mathrm{m}$ in length that bifurcates into slightly shorter, dynamic terminal processes that may extend or retract up to $20 \mu \mathrm{m}$ over the course of days to weeks (Berthiaume et al., 2018). At their terminal ends, thin-strand processes appear to come into close proximity with those of neighboring pericytes (Berthiaume et al., 2018), possibly allowing for direct contact between adjacent pericytes, although this awaits direct experimental confirmation. Changes in the length of processes of one cell appear to evoke opposite changes in the length of adjacent pericyte processes, preventing the formation of substantial gaps (Berthiaume et al., 2018).

These processes are for the most part prevented from making direct contact with the underlying endothelium by the basement membrane. However, electron microscopy has revealed thatsimilar to the IEL of arteries and arterioles-the capillary basement membrane is dotted with many fenestrations, with an average area of $1.5 \mu \mathrm{m}^{2}$, ranging from 100 to $450 \mathrm{~nm}$ in diameter (Carlson, 1989; Figure 3D). In arteries, similar fenestrations are 




the sites of myoendothelial junctions, optimized for EC-SMC communication by the presence of a number of key enzymes, ion channels, and gap junction (GJ) proteins (Straub et al., 2014). In the capillary bed, these fenestrations are the site of "peg-socket" interdigitations where either the pericyte or the EC sends a projection to make contact with the adjacent cell (Tilton et al., 1979; Cuevas et al., 1984; Armulik et al., 2005). These contact points are thought to be the sites of GJ communication between the two cell types (see Box 1), and may be the location of key signaling events, such as local calcium $\left(\mathrm{Ca}^{2+}\right)$ or cyclic adenosine monophosphate (cAMP) elevations. Moreover, they may be sites of macromolecular signaling complex assembly, containing ion channels, and GPCRs positioned to facilitate cell-cell communication.

\section{ION CHANNEL EXPRESSION IN BRAIN CAPILLARY PERICYTES}

A cursory review of the brain capillary pericyte ion channel expression data provided by He et al. (2018) and Vanlandewijck et al. (2018) reveals that potassium $\left(\mathrm{K}^{+}\right)$channels are the dominant ion channel species in pericytes. Remarkably, this is due to the adenosine triphosphate (ATP)-sensitive $\mathrm{K}^{+}\left(\mathrm{K}_{\mathrm{ATP}}\right)$ channel inward rectifier $\left(\mathrm{K}_{\mathrm{ir}}\right)$ subunit, $\mathrm{K}_{\mathrm{ir}} 6.1$, accounting for nearly half of the total ion channel gene expression in these cells. Transient receptor potential (TRP), $\mathrm{Ca}^{2+}$, and chloride $\left(\mathrm{Cl}^{-}\right)$channels make up the remaining half, along with lower expression of a handful of other channel subunits including two-pore channels (TPCs), voltagegated sodium $\left(\mathrm{Na}^{+} ; \mathrm{Na}_{\mathrm{v}}\right)$ channels, P2X receptors, acid sensing ion channels (ASICs), and Piezol (Table 1 and Figure 4).

\section{PERICYTE K ${ }^{+}$CHANNELS}

Focusing initially on the $\mathrm{K}^{+}$channel superfamily, capillary pericytes express $\mathrm{K}_{\mathrm{ir}}$, two-pore domain $\left(\mathrm{K}_{2 \mathrm{P}}\right)$, voltage-gated $\left(\mathrm{K}_{\mathrm{V}}\right), \mathrm{Na}^{+}$-activated $\left(\mathrm{K}_{\mathrm{Na}}\right)$, and $\mathrm{Ca}^{2+}$-activated $\left(\mathrm{K}_{\mathrm{Ca}}\right) \mathrm{K}^{+}$ channel genes.

 Metabolism-Electrical Coupling and Facilitate Rapid, Long-Range Electrical Signaling}

$\mathrm{K}_{\mathrm{ir}}$ channels have the defining biophysical property of inward rectification, preferentially conducting large currents into the cell at voltages negative to the $\mathrm{K}^{+}$equilibrium potential $\left(\mathrm{E}_{\mathrm{K}}\right)$, the magnitude of which depend on the electrochemical gradient for $\mathrm{K}^{+}$[i.e., the difference between $\mathrm{V}_{\mathrm{m}}$ and $\mathrm{E}_{\mathrm{K}}$ ] (Katz, 1949; Hibino et al., 2010). At potentials positive to $\mathrm{E}_{\mathrm{K}}$ some degree of rectification occurs, ranging from strong-in which almost no current passes from the interior of the cell to the exteriorto weak, in which rectification is only seen at very positive potentials. Accordingly, $\mathrm{K}_{\mathrm{ir}}$ channels can be classified by their 

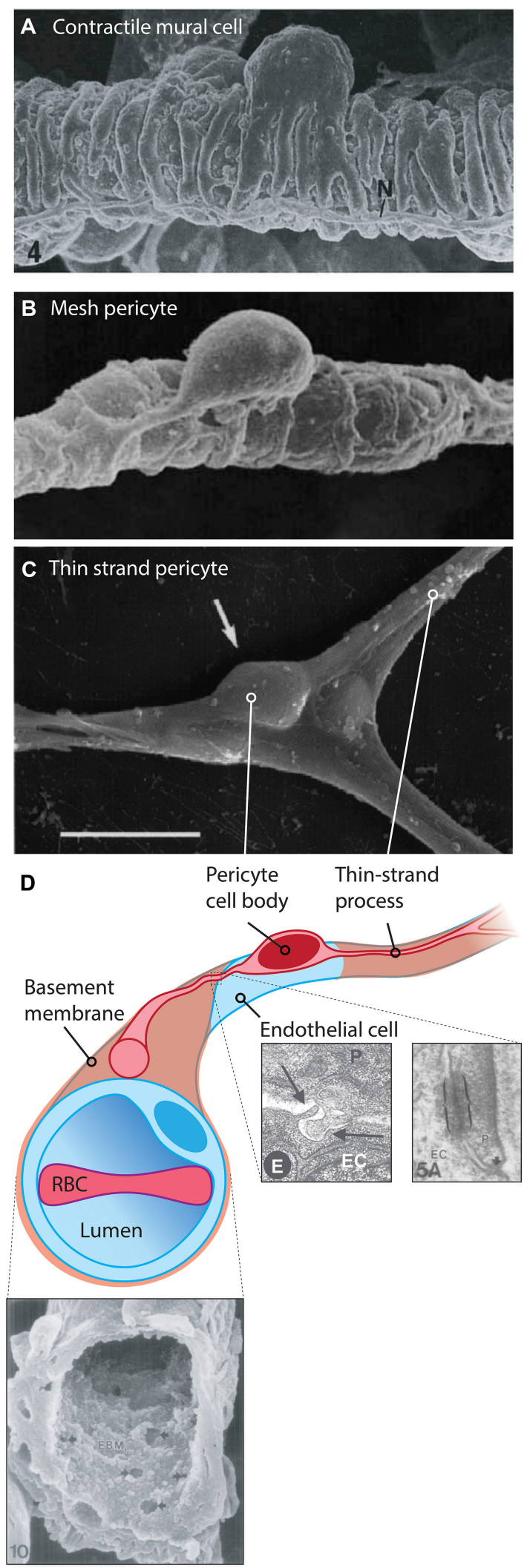

FIGURE 3 | Cytoarchitecture and microenvironment of pericytes. (A) Mural cells with a 'bump-on-a-log' cell body, with multiple contractile processes that

(Continued)
FIGURE 3 | almost completely encase the underlying vessel. 6,000x, rat mammary gland vasculature. Reproduced with permission from Fujiwara and Uehara (1984). (B) A 4,400x magnification scanning electron micrograph of a putative mesh pericyte of the rat mammary gland. Multiple sparse processes enwrap the underlying capillary. Reproduced with permission from Fujiwara and Uehara (1984). (C) A thin-strand pericyte atop a rat retinal capillary, extending fine processes away from the ovoid cell body. Adapted with permission from Sakagami et al. (1999). Scale bar: $10 \mu \mathrm{m}$. (D) Illustration of a thin-strand pericyte. The bulk of the volume of the cell body is occupied by the nucleus. The pericyte is prevented from making direct contact with the underlying EC by the basement membrane, shown in the SEM at bottom left, reproduced with permission from Carlson (1989). Multiple small fenestrations are seen in this structure, allowing for pericyte and endothelial projections to make direct contact with one another, forming so-called 'peg-socket junctions' which are also sites of gap junction formation. At bottom right electron micrographs depicting a peg-socket junction (left) and a pericyte-endothelial gap junction (right) are shown, reproduced with permission from Díaz-Flores et al. (2009) and Carlson (1989). Abbreviations in micrographs: EC, endothelial cell; N, nerve; P, pericyte.

degree of rectification as strongly-rectifying $\left(\mathrm{K}_{\mathrm{ir}} 2 . \mathrm{x}, \mathrm{K}_{\mathrm{ir}} 3 . \mathrm{x}\right)$, intermediately-rectifying $\left(\mathrm{K}_{\mathrm{ir}} 4 . \mathrm{x}\right)$ or weakly-rectifying $\left(\mathrm{K}_{\mathrm{ir}} 1.1\right.$, $\left.\mathrm{K}_{\mathrm{ir}} 6 . \mathrm{x}, \mathrm{K}_{\mathrm{ir}} 7 . \mathrm{x}\right)$. Alternatively, this group of channels can be classified according to function into classic $\left(\mathrm{K}_{\mathrm{ir}} 2 . \mathrm{x}\right)$, G-protein sensitive $\left(\mathrm{K}_{\mathrm{ir}} 3 . \mathrm{x}\right), \mathrm{K}_{\mathrm{ATP}}\left(\mathrm{K}_{\mathrm{ir}} 6 . \mathrm{x}\right)$, or $\mathrm{K}^{+}$transport $\left(\mathrm{K}_{\mathrm{ir}} 1 . \mathrm{x}, \mathrm{K}_{\mathrm{ir}} 4 . \mathrm{x}\right.$, $K_{i r} 5 . x, K_{i r} 7 . x$ ) channels (Hibino et al., 2010). Of the $K_{i r}$ channel family, capillary pericytes express extremely high levels of $\mathrm{K}_{\mathrm{ir}} 6.1$-far exceeding that of any other ion channel gene expressed by brain pericytes-and to a lesser extent $\mathrm{K}_{\mathrm{ir}} 2.2$ (Bondjers et al., 2006; He et al., 2018; Vanlandewijck et al., 2018).

As $\mathrm{K}_{\mathrm{ir}} 6.1$ is a component of $\mathrm{K}_{\mathrm{ATP}}$ channels, this suggests that the two key roles of these channels-providing membrane hyperpolarization and coupling metabolism to membrane electrical activity-could be major contributors to pericyte physiology. Functional $\mathrm{K}_{\mathrm{ATP}}$ channels are hetero-octameric assemblies of four two-transmembrane spanning pore-forming $\mathrm{K}_{\mathrm{ir}} 6 . \mathrm{x}$ subunits (either $\mathrm{K}_{\mathrm{ir}} 6.1$ or $\mathrm{K}_{\mathrm{ir}} 6.2$, encoded by Kcnj8 and Kcnj11, respectively), each associated with a regulatory 17-transmembrane spanning ATP-binding cassette subfamily sulfonylurea subunit (SUR1 or SUR2, respectively encoded by $A b c c 8$ and $A b c c 9$-the latter of which is also highly expressed in brain pericytes; Figure 5A; Seino and Miki, 2003; Li et al., 2017). SURs are required for membrane trafficking of the channel (Burke et al., 2008) and impart sensitivity to $\mathrm{K}_{\mathrm{ATP}}$ agonists and antagonists and intracellular nucleotides. Alternative splicing yields a number of SUR2 variants with SUR2A and SUR2B as the major forms, differing by just 42 amino acids in their C-terminal domains (Seino and Miki, 2003). Thus, the available expression data suggest that $\mathrm{K}_{\mathrm{ATP}}$ channels native to brain pericytes are composed of $\mathrm{K}_{\mathrm{ir}} 6.1$ and SUR2 - often referred to as the "vascular" form of $\mathrm{K}_{\mathrm{ATP}}$-and indicates that these are expressed much more highly in pericytes than they are in cerebral SMCs and ECs (Figure 4C).

$\mathrm{K}^{+}$currents through $\mathrm{K}_{\mathrm{ATP}}$ channels are weakly rectifying at potentials very positive to $\mathrm{E}_{\mathrm{K}}$-the result of voltagedependent intracellular magnesium $\left(\mathrm{Mg}^{2+}\right)$ block (Findlay, 1987). The defining biophysical feature of $\mathrm{K}_{\mathrm{ATP}}$ channels is that open probability $\left(\mathrm{P}_{\mathrm{O}}\right)$ decreases with increasing 
BOX 1 | Potential gap junction configurations between capillary pericytes and $\mathrm{CECs}$.

According to expression data (He et al., 2018; Vanlandewijck et al., 2018), pericytes predominantly express mRNA for connexin (Cx)37 and Cx45, along with much lower expression of Cx26 and Cx43. Capillary ECs, on the other hand, robustly express $\mathrm{C} \times 43$ and $\mathrm{C} \times 45$, with low levels of $\mathrm{C} \times 37$, whereas $\mathrm{Cx} 26$ is undetectable (see Figure). Electron microscopy has been used to visualize putative GJ sites between pericytes and ECs at pegsocket interdigitations. In contrast, similar sites between the processes of neighboring pericytes have yet to be clearly demonstrated. Nonetheless, a recent dye transfer study (Kovacs-Oller et al., 2020), has shown that the cells of the capillary bed form a syncytium. Accordingly, two configurations for cell-cell communication can be postulated: (i) Pericyte-EC GJs alone permit bidirectional transfer of intracellular materials and charge between cells of the capillary wall; (ii) both pericyte-EC GJs and pericyte-pericyte GJs permit intercellular communication along two parallel, closely adjacent paths. The latter configuration would provide redundancy in the event of cell-cell communication failing in one cell type.

GJs are homo- or hetero-dodecameric assemblies of Cx subunits (Koval et al., 2014), formed from two hexameric hemichannels that dock to yield intercellular channels. GJs can be homotypic, with both hemichannels composed of the same $\mathrm{Cx}$ isoform(s), or heterotypic, with each hemichannel consisting of a distinct assembly of $6 \mathrm{Cx}$ subunits. Moreover, a given hemichannel may be homomeric (composed $\mathrm{Cx}$ monomers of the same isoform) or heteromeric (consisting of multiple $\mathrm{Cx}$ isoforms), a property that depends on the propensity of the locally expressed Cxs to co-assemble. These complexities yield channels with distinct attributes, which may further oligomerize into large GJ plaques with discrete population characteristics.

Considering pericyte connexins in isolation, $\alpha$-class Cxs 37 and 45 are not known to assemble into heteromers, but both of these will heteromerize with the much more modestly expressed $\alpha \mathrm{Cx} 43$. The $\beta \mathrm{Cx} 26$, on the other hand, is not compatible with $\alpha \mathrm{Cx}$ isoforms. Thus, the available data suggest that the typical pericyte hemichannel is most likely to be a homomeric assembly of $\mathrm{C} \times 37$ or $\mathrm{C} \times 45$, with perhaps a low level of heteromerization involving $\mathrm{C} \times 43$. Similarly, the EC-expressed Cx43 will form heteromers with Cx37 and Cx45, but again the latter are not compatible with one another. Thus, the possibility of heteromerization appears to be higher for ECs. In terms of heterotypic compatibility in the formation of GJs, Cx37, Cx43, and Cx45 are known to readily assemble together, whereas $\mathrm{C} \times 26$ hemichannels will not dock with any of these.

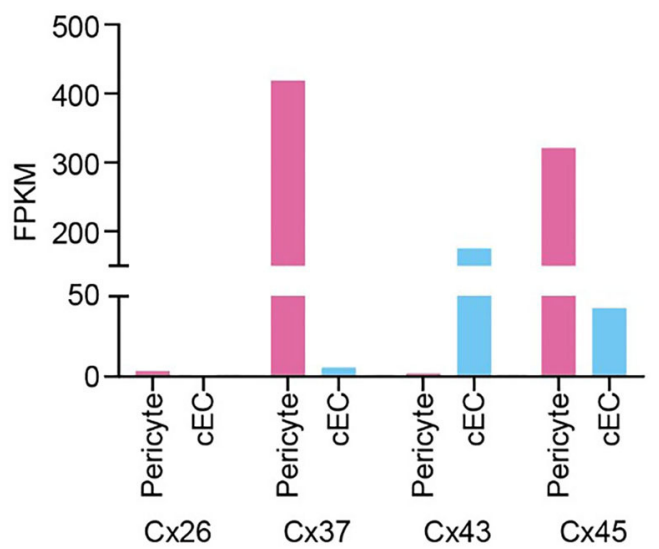

Taken together, this complexity underscores the great deal of further work needed to firmly establish the nature and properties of GJs in the capillary wall. intracellular ATP levels, with ATP stabilizing the closed state of the channel (Enkvetchakul and Nichols, 2003). Thus, when cellular ATP demands are low and free cytosolic ATP is high, the channel is closed. In contrast, when cell activity increases or metabolism drops, the ADP:ATP ratio rises and the channel may open to hyperpolarize the membrane (Quayle et al., 1997). Consistent with these channels being saturated by ATP to keep them closed under resting conditions, the $\mathrm{K}_{\mathrm{ATP}}$ channel blocker glibenclamide has no effects on resting CBF but levcromakalim, a $\mathrm{K}_{\mathrm{ATP}}$ channel opener, increases global CBF by $14 \%$ (Al-Karagholi et al., 2020).

Nucleotide regulation of $\mathrm{K}_{\mathrm{ATP}}$ channels is complex and has been best characterized for $\mathrm{K}_{\mathrm{ir}} 6.2 / \mathrm{SUR} 1$-containing channels, which we review briefly here. Intracellular nucleotides are sensed by an array of sites throughout the channel complex: ATP has been shown to bind to an inhibitory site of the $K_{\text {ir }} 6.2$ subunit (Tucker et al., 1997; Tanabe et al., 2000) with just one of four subunits of the channel needing to bind ATP to effect closure (Markworth et al., 2000). The SUR1 subunit has two nucleotide binding domains (Li et al., 2017), where $\mathrm{Mg}^{2+}$-bound adenosine diphosphate (MgADP) occupancy increases channel activity (Tung and Kurachi, 1991; Gribble et al., 1997; Shyng et al., 1997). MgATP also has a stimulatory effect here, likely through hydrolysis to MgADP, although this is normally masked by the much more potent inhibitory effect of free ATP (Gribble et al., 1998; Proks et al., 2010). Thus, as might be expected, increasing intracellular $\mathrm{Mg}^{2+}$ antagonizes the inhibitory effect of free ATP (Gribble et al., 1998). Conversely, in the absence of $\mathrm{Mg}^{2+}$, ADP may have an inhibitory effect (Findlay, 1988). Comparatively less is known about the fine details of nucleotide regulation of $\mathrm{K}_{\mathrm{ir}} 6.1 / \mathrm{SUR} 2 \mathrm{~B}$ channels, which have a smaller conductance than their $\mathrm{K}_{\mathrm{ir}} 6.2$-containing counterparts $(\sim 15-30$ $\mathrm{pS}$ for $\mathrm{K}_{\mathrm{ir}} 6.1 / \mathrm{SUR} 2 \mathrm{~B}$-containing channels vs. $\sim 50-90 \mathrm{pS}$ for the $\mathrm{K}_{\mathrm{ir}} 6.2 / \mathrm{SUR} 2 \mathrm{~A}$ form, for example; Hibino et al., 2010). However, it is clear that the presence of a nucleotide diphosphate and $\mathrm{Mg}^{2+}$ is a requirement for channel activity, and that these channels are also sensitive to ATP inhibition (Kajioka et al., 1991; Kovacs and Nelson, 1991; Beech et al., 1993; Kamouchi and Kitamura, 1994; Nelson and Quayle, 1995; Zhang and Bolton, 1996; Yamada et al., 1997).

One of the consequences of the nucleotide sensitivity of $\mathrm{K}_{\mathrm{ATP}}$ channels is that they may act as sensors of the metabolic state of the cell and transduce changes in this parameter into adjustments of membrane voltage. This is perhaps best characterized in pancreatic $\beta$ cells, where $\mathrm{K}_{\mathrm{ATP}}$ channels composed of $\mathrm{K}_{\mathrm{ir}} 6.2$ and SUR1 subunits couple glucose concentration with insulin secretion (Tarasov et al., 2004). Here, elevated glucose leads to an increase in intracellular ATP due to increased glucose metabolism. This closes $\mathrm{K}_{\mathrm{ATP}}$ channels, which depolarizes the cell and drives $\mathrm{Ca}^{2+}$-mediated insulin secretion through the activation of L-type voltage-dependent $\mathrm{Ca}^{2+}$ channels (VDCCs; MacDonald et al., 2005). Conversely, if glucose concentrations decrease the channel opens, hyperpolarizing the membrane to 
A

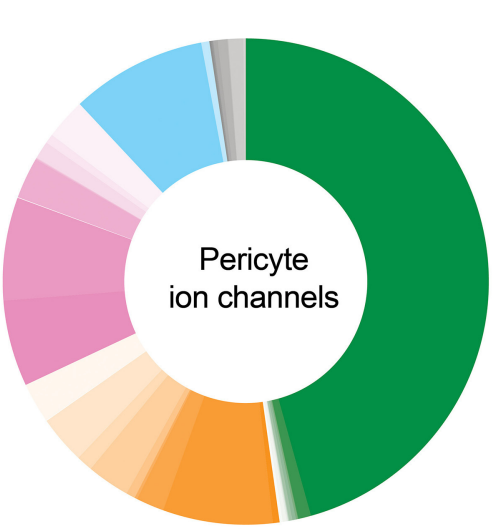

:

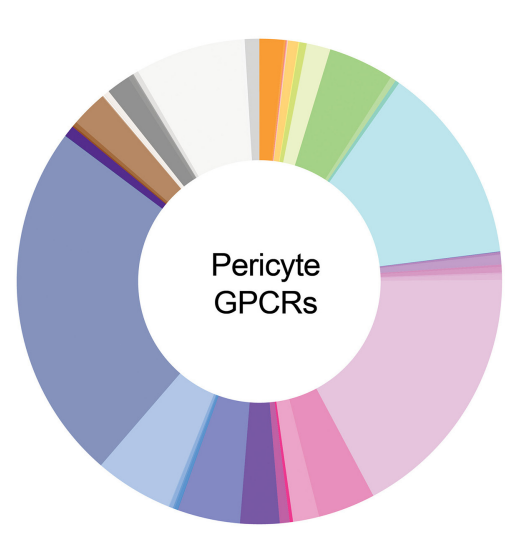

Adenosine receptors

$A_{1}$
$A_{2 A}$
$A_{2 B}$

Adrenergic receptors

$a_{1 \mathrm{~A}}$

$a_{1 B}$

$a_{2 A}$

$\alpha_{2 B}$

Calcitonin receptor-lik receptor

Chemerin receptor 1

Chemokine receptors

CCR9

CXCR4

CCRL2

C

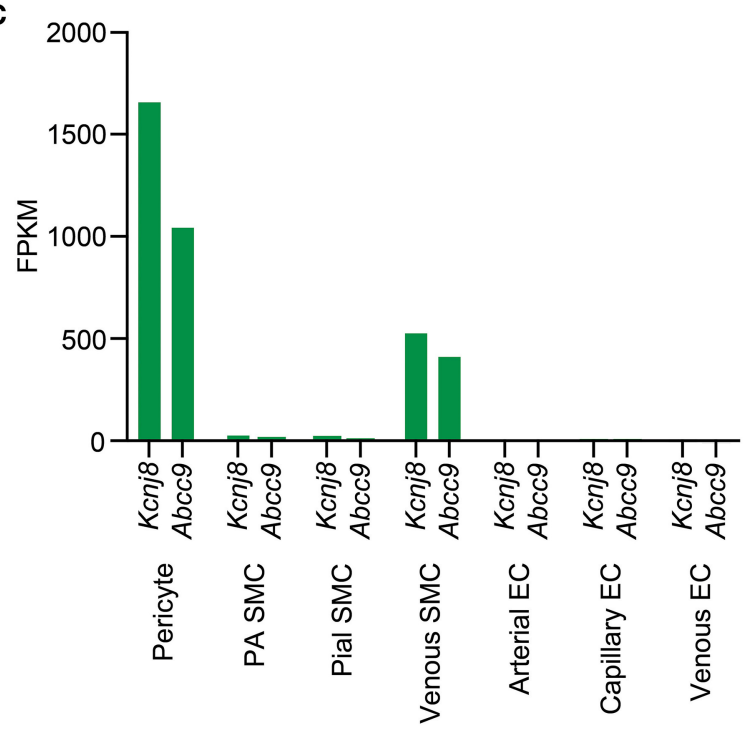

TRP channels

$\mathrm{Ca}^{2+}$ channels $\mathrm{Cl}^{-}$channels

Other

channels

\begin{tabular}{|l|l|}
\hline $\mathrm{IP}_{3} \mathrm{R} 1$ & $\mathrm{CaCC}$ \\
\hline $\mathrm{IP}_{3} \mathrm{R} 2$ & $\mathrm{ClC}-2$ \\
\hline $\mathrm{IP}_{3} \mathrm{R} 3$ & \\
$\mathrm{Ca}_{\mathrm{v}} 1.2$ & \\
$\mathrm{Ca} 1.3$ & \\
$\mathrm{Ca} 2.1$ & \\
$\mathrm{Ca} a_{\mathrm{v}} 3.1$ & \\
$\mathrm{Ca} 3.2$ & \\
Orai1 \\
Orai3
\end{tabular}

Endothe
$\mathrm{ET}_{\mathrm{A}}$
$\mathrm{ET}_{\mathrm{B}}$

FFA2 receptor

GIP receptor

GPER

Kisspeptin receptor

Leukotriene receptors

- CysLT,

- CysLT

Lysophospholipid receptors

LPA $_{1}$

- LPA $_{6}$

- $\mathrm{S}_{1 \mathrm{P}_{1}}$

$\mathrm{S}_{\mathrm{S}} \mathrm{P}_{2}$

Metabotropic glutamate rs

$\mathrm{mGlu}_{3}$

- $\mathrm{mGlu}_{7}$

- NOP receptor

- $\mathrm{PAC}_{1}$ receptor

PAR1

\section{PTH1 receptor}

Prostanoid receptors

$\mathrm{DP}_{2}$
$\mathrm{EP}_{1}$
$\mathrm{EP}_{3}$
$\mathrm{FP}$
$\mathrm{IP}$
$\mathrm{TP}$
$\mathrm{P} \mathrm{Y}_{14}$

- $V_{1 \mathrm{~A}}$ receptor

- $\mathrm{Y}_{1}$ receptor

CELSR2

\section{Frizzled receptors}

FZD

$\mathrm{FZD}_{3}$

FZD $_{6}$

$\mathrm{FZD}_{7}$

$\mathrm{FZD}_{8}$

FZD $_{10}$

$\mathrm{SMO}^{10}$

Orphan receptors

GPR4

GPR19

GPR20

GPR157

GPR182

GPRC5B

GPRC5C

LGR4

OPN3

\section{Other}

TPRA1

FIGURE 4 | Overview of CNS pericyte ion channel and GPCR expression. (A) Relative abundance of mRNA for all ion channel subunits meeting our inclusion criteria. The size of each segment represents the relative expression of the underlying gene. Channels are clustered on the basis of the ion species that the corresponding 
FIGURE 4 | functional channel conducts (denoted by shading of the same color) and are then grouped by family/subfamily. $\mathrm{K}^{+}$channels are the predominant ion channel class due to extremely high expression of Kcnj8 which forms the pore of vascular $K_{\text {ATP }}$ channels. The non-selective TRP channels are the next highest expressed, followed by $\mathrm{Ca}^{2+}$ channels, $\mathrm{Cl}^{-}$channels, and lower expression of other channels. (B) Relative expression of pericyte GPCRs. Here, receptors are organized by ligand sensitivity or class. (C) Expression of the $\mathrm{K}_{\text {ATP }}$ channel genes Kcnj8 and Abcc 9 throughout the brain vasculature. Pericytes express both genes at much higher levels than arterial SMCs or ECs. However, venous SMCs also express high levels of K $\mathrm{K}_{\text {ATP }}$ channel-forming genes.

prevent insulin release. In an analogous situation, $\mathrm{K}_{\mathrm{ATP}}$ channels composed of $\mathrm{K}_{\mathrm{ir}} 6.2$ and SUR1 are involved in glucose sensing and glucagon secretion in the ventromedial hypothalamic neurons of the hypothalamus (Miki et al., 2001).

Like many other channels (Hille et al., 2015; Dickson and Hille, 2019), $\mathrm{K}_{\mathrm{ATP}}$ channels containing $\mathrm{K}_{\mathrm{ir}} 6.2$ poreforming subunits are also influenced by the concentration of intracellular phosphoinositides, such as phosphoinositol4,5-bisphosphate (PIP 2 ; Fan and Makielski, 1997). In $\mathrm{K}_{\mathrm{ir}} 6.2-$ containing channels, ATP and $\mathrm{PIP}_{2}$ compete for residues on overlapping binding sites on the pore forming subunit, each subtly altering channel conformation to stabilize closed or open states, respectively (Enkvetchakul and Nichols, 2003), with $\mathrm{PIP}_{2}$ additionally uncoupling the pore-forming subunit from its SUR companion (Li et al., 2017). Exposure of these $\mathrm{K}_{\text {ATP }}$ channels to $\mathrm{PIP}_{2}$ decreases ATP affinity $\left(\mathrm{K}_{0.5}\right)$ in excess of two orders of magnitude from $\sim 10 \mu \mathrm{M}$ to $\sim 3.5 \mathrm{mM}$, and furthermore in the absence of ATP increases channel $\mathrm{P}_{\mathrm{o}}$ (Shyng and Nichols, 1998). As the abundance of $\mathrm{PIP}_{2}$ thus regulates $\mathrm{P}_{\mathrm{O}}$, this raises the possibility that cell signaling that impinges upon $\mathrm{PIP}_{2}$ levels may subsequently affect channel activity. $\mathrm{K}_{\mathrm{ir}} 6.1 / \mathrm{SUR} 2 \mathrm{~B}$ channels, in contrast, appear to have a much higher affinity for $\mathrm{PIP}_{2}$ than $\mathrm{K}_{\mathrm{ir}} 6.2$ channels. Accordingly, $\mathrm{PIP}_{2}$ is thought to bind so tightly here as to be saturating, and thus physiological fluctuations of this phospholipid do not influence channel activity (Quinn et al., 2003; Harraz et al., 2020). However, a number of intracellular signaling pathways have been established to dramatically influence vascular $\mathrm{K}_{\mathrm{ATP}}$ activity. Indeed, phosphorylation by protein kinase C (PKC), lying downstream of DAG, decreases the $\mathrm{P}_{\mathrm{o}}$ of $\mathrm{K}_{\mathrm{ir}} 6.1$ /SUR2B channels (Bonev and Nelson, 1996; Shi et al., 2008b) and in stark contrast, protein kinase A (PKA), which is stimulated as a result of $\mathrm{G}_{\mathrm{s}}$-coupled GPCR engagement, phosphorylates $\mathrm{K}_{\mathrm{ATP}}$ to increase $\mathrm{P}_{\mathrm{o}}$ (Kleppisch and Nelson, 1995; Bonev and Nelson, 1996; Quinn et al., 2004; Shi et al., 2007, 2008a).

Accordingly, there appear to be two major possible avenues through which vascular $K_{\text {ATP }}$ channels could be engaged in pericytes:

i) Changes in metabolism may couple $K_{A T P}$ channel activity to membrane hyperpolarization.

It is possible that brain pericyte $\mathrm{K}_{\mathrm{ATP}}$ channels act as sensors of the metabolic state of the cell and adjust membrane potential in response to perturbations in energy supply. Notably, the expression of the glucose transporter GLUT1 is incredibly high in astrocytes and brain ECs compared to pericytes, which express much lower levels of GLUTs 1, 3 and 4 (He et al., 2018; Vanlandewijck et al., 2018). Therefore, while astrocytes and capillary endothelial cells are well equipped for glucose import, the comparatively lower expression of
GLUTs in the pericytes situated between them could make them more sensitive to subtle changes in glucose levels, such as local depletions that occur during neural activity ( $\mathrm{Hu}$ and Wilson, 1997; Paulson et al., 2010; Li and Freeman, 2015; Pearson-Leary and McNay, 2016). Such decreases in glucose could impact pericyte metabolism, increasing the ADP:ATP ratio to open $\mathrm{K}_{\mathrm{ATP}}$ channels and hyperpolarize the membrane.

However, as glucose can be transmitted via gap junctions (Rouach et al., 2008) it is possible that pericyte glucose needs are instead satisfied directly by the underlying ECs, enabling them to continually maintain a high level of cytosolic ATP. This latter possibility, coupled with evidence that metabolic regulation of vascular $\mathrm{K}_{\mathrm{ATP}}$ channels in arteriolar SMCs requires either anoxia or extreme ATP consumption (Quayle et al., 2006)-circumstances of energetic compromise that are unlikely to be seen under physiological conditions (Quayle et al., 1997)-suggests that $\mathrm{K}_{\mathrm{ATP}}$ metabolism-electrical coupling may be primarily relevant in pathological situations (e.g., stroke). In this context, metabo-electrical coupling may represent a last-ditch effort to stimulate blood flow and therefore replenish $\mathrm{O}_{2}$ and glucose to regions in deep metabolic crisis. Further studies are needed to understand metabolic contributions to the control of pericyte K ATP channels.

ii) Molecules that stimulate $G_{s}$ signaling may engage pericyte $K_{\text {ATP }}$ channels.

Pericytes express a broad repertoire of receptors that couple to the $G_{s}$ signaling pathway, including those for purines, polyadenylate cyclase activating peptide (PACAP), parathyroid hormone (PTH) and prostaglandins (discussed in detail below, see Table 2). The release of these molecules into the paravascular space during neuronal activity could thus engage $G_{s}$ signaling in local pericytes, culminating in the phosphorylation of $\mathrm{K}_{\mathrm{ATP}}$ and channel opening. Indeed, in the retina (often used as a model of the NVU; see Box 2) the inhibitory neurotransmitter and metabolic byproduct adenosine hyperpolarizes the rat retinal pericyte membrane potential by $\sim 30 \mathrm{mV}$ through $\mathrm{K}_{\mathrm{ATP}}$ channel engagement resulting from $A_{1}$ and $A_{2 a}$ adenosine receptor activation (Li and Puro, 2001), likely through engagement of cAMP and PKA.

What would be the physiological consequence of such profound membrane hyperpolarization in pericytes? It has been proposed that $\mathrm{K}_{\mathrm{ATP}}$-generated hyperpolarization of pericytes in the retinal vasculature could be transmitted over long distances to close VDCCs in the mural cells of upstream vessels, thereby causing vasorelaxation and an increase in blood flow (Ishizaki et al., 2009). Such a mechanism could 
A

$\mathrm{K}_{\text {ATP }}$

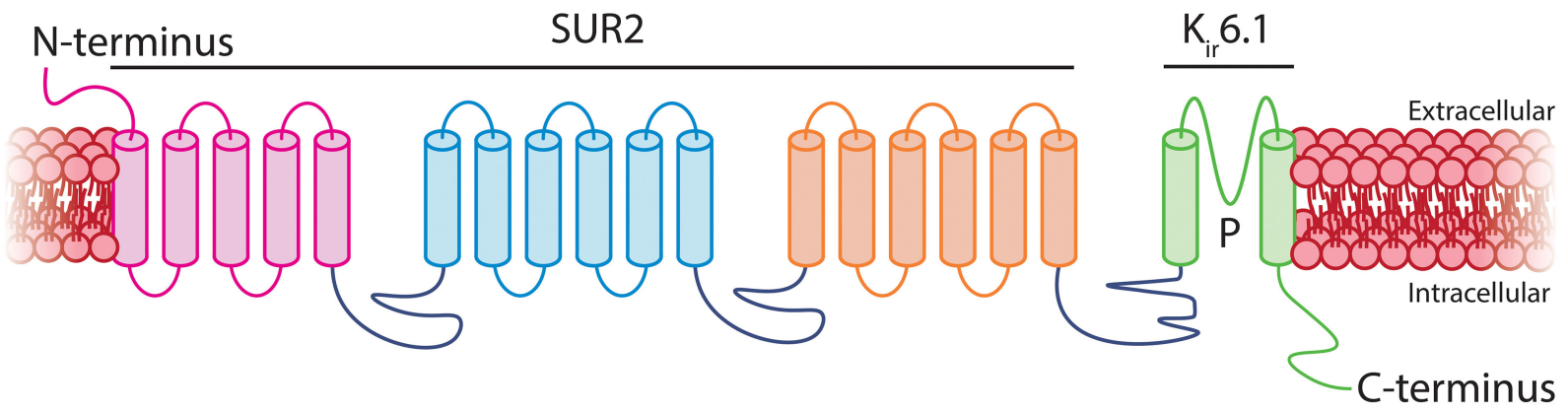

B



D

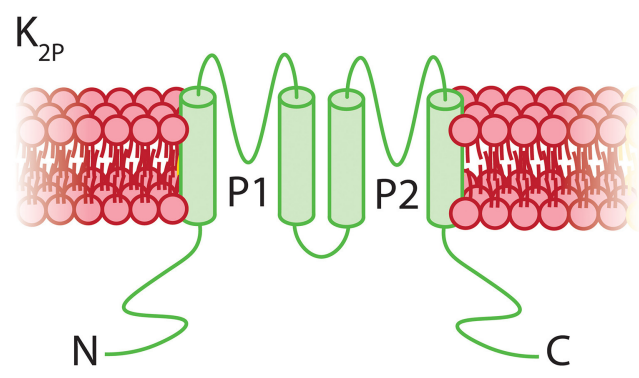

F

\section{$\mathrm{K}_{\mathrm{Ca}} 2.3$}



CaM
C

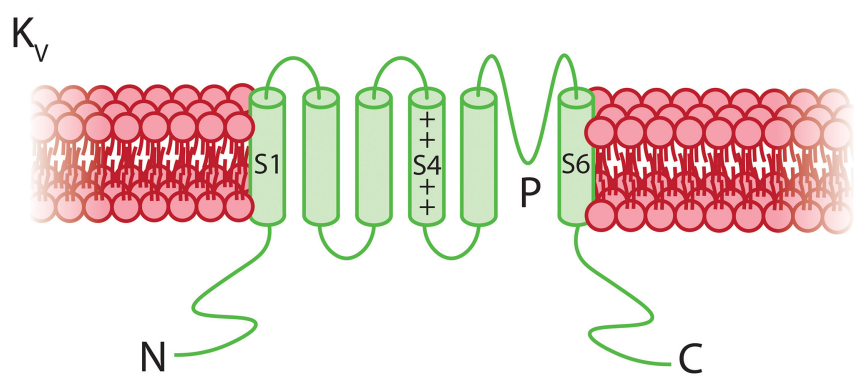

E

\section{$\mathrm{K}_{\mathrm{Na}} 1.2$}

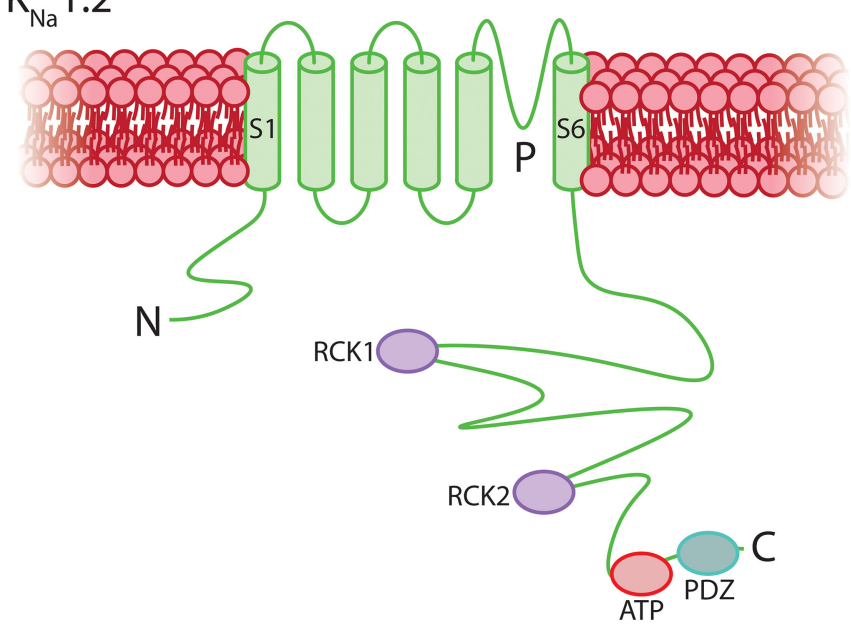

FIGURE 5 | Structural topology of $\mathrm{K}^{+}$channels expressed by pericytes. (A) Vascular $\mathrm{K}_{\text {ATP }}$ channels are octamers consisting of four 17 -transmembrane SUR2 subunits associated with four 2-transmembrane pore-forming $K_{i r} 6.1$ subunits. (B) $K_{\text {ir }} 2.2$ channels consist of homo or heteromeric assemblies of four 2-transmembrane subunits. (C) $K_{v}$ channels are composed of four 6-transmembrane alpha subunits with a positively charged voltage sensor at S4 which transduces changes in $V_{m}$ into conformational alterations. (D) $K_{2 P}$ channels are tetramers of two-pore domain four-transmembrane subunits. (E) $K_{\mathrm{Na}}$ channels have a 6-transmembrane structure that lacks a voltage sensor, with multiple regulatory sites in the long intracellular $\mathrm{COOH}$-terminus including two RCK domains, an ATP binding site, and a PDZ domain. (F) $\mathrm{K}_{\mathrm{Ca}} 2.3$ channels consist of four 6-transmembrane domains which lack a voltage-sensor at $\mathrm{S} 4$. The $\mathrm{COOH}$-terminus of each is associated with a calmodulin monomer, which imparts $\mathrm{Ca}^{2+}$ sensitivity to the channel. 
BOX 2 | A brief comparison of retinal and brain vasculatures.

The retinal vasculature consists of two vascular beds - the outer layer of retinal photoreceptors is nourished by the choroidal vasculature, and the multilayered inner retinal vasculature provides oxygen and nutrients to the inner cell layers. The latter has a tightly regulated blood-retinal barrier, akin to the BBB, which pericytes help to maintain (Trost et al., 2016). Vascular density in the cerebral cortex varies according to the metabolic demand of the brain region it supplies (e.g., white vs. gray matter), whereas in the retina, capillary density tends to be greater in the center of the tissue and decreases toward the periphery (Patton et al., 2005). Both retinal and cerebral vascular cells have identical embryological origins: pericytes and SMCs derive from neuroectodermal neural crest cells and ECs derive from mesodermal hemangioblasts (Kurz, 2009; Dyer and Patterson, 2010). Structurally, the cortical and inner retinal vascular beds share a similar overall architecture, with a post-arteriolar transitional zone of 3-4 branches that are covered by contractile mural cells, leading to thin strand pericyte-covered deep capillaries (Ratelade et al., 2020). A distinction between these vascular beds is that the retinal vasculature is highly organized into two parallel plexi (Ramos et al., 2013), whereas cerebral capillaries form more elaborate three-dimensional geometries (Blinder et al., 2013). These structural differences could dictate differences in the flow of blood through each circulation and may necessitate distinctions in the signaling mechanisms that are utilized to direct blood flow through either bed. However, the vasculatures in both retina and cortex respond similarly to neuronal activity with elevations in blood flow (Newman, 2013), and similar mechanisms underpinning these responses appear to be at play in either bed. $\mathrm{K}^{+}, \mathrm{PGE}_{2}$, and EETs, for example, have been implicated in control of blood flow in both circulations (Newman, 2013; Longden et al., 2017; Gonzales et al., 2020). Recent studies have also indicated the utility of non-invasive examinations of the retinal vasculature as a marker for detecting cerebrovascular diseases, due to a similar susceptibility of both circulations to vascular risk factors such as hypertension or diabetes (Patton et al., 2005; van de Kreeke et al., 2018; McGrory et al., 2019; Querques et al., 2019). Data on gene expression in vascular cells of the retina are currently lacking, but would provide a useful standpoint for deeper comparisons of the similarities and differences between these vascular beds.

Studies on retinal pericytes (Li and Puro, 2001; Kawamura et al., 2002, 2003; Wu et al., 2003; Matsushita and Puro, 2006), on cerebral pericytes (Peppiatt et al., 2006; Fernández-Klett et al., 2010; Hill et al., 2015; Rungta et al., 2018), or both (Gonzales et al., 2020; Kovacs-Oller et al., 2020) have thus informed our current understanding of blood flow control and pericyte physiology. Although it is clear that a high degree of similarity exists between these vascular beds, the possibility of yet-to-be-identified differences between these networks should be borne in mind when attempting to draw generalizations from data from both vascular beds. To this end, we note explicitly where data on pericytes in this review were drawn from studies performed in retina.

be enabled by transmission of hyperpolarizing signals either between pericytes themselves, or between pericytes and ECs. Indeed, hyperpolarizations transmitted to cECs are predicted to engage $\mathrm{K}_{\mathrm{ir}} 2.1$ channels, which we have recently shown to rapidly propagate hyperpolarizing signals over long distances through the brain endothelium to upstream arterioles, causing their dilation and an increase in blood flow (Longden and Nelson, 2015; Longden et al., 2017). A similar mechanism involving both $\mathrm{K}_{\mathrm{ATP}}$ and $\mathrm{K}_{\mathrm{ir}} 2.1$ channels has also recently been shown to be critical for control of blood flow in the heart (Zhao et al., 2020). In the brain, connexin (Cx)37, and $\mathrm{Cx} 45$ are highly expressed in pericytes (He et al., 2018; Vanlandewijck et al., 2018; see Box 1), and thus these likely form cell-cell GJs that facilitate long-range transmission of $\mathrm{K}_{\mathrm{ATP}}$-mediated electrical signals (Figure 6).

$\mathrm{K}_{\mathrm{ir}} 2$ channels are activated not only by membrane hyperpolarization, but also by external $\mathrm{K}^{+}$, which is an important mediator of NVC (Filosa et al., 2006; Longden and Nelson, 2015; Longden et al., 2017). Neurons or astrocytes release $\mathrm{K}^{+}$into the perivascular space during NVC, and its concentration can reach $\sim 10 \mathrm{mM}$ during concerted activity (Orkand et al., 1966; Newman, 1986; Ballanyi et al., 1996; Kofuji and Newman, 2004). Interestingly, $\mathrm{K}_{\mathrm{ir}} 2.2$ channels are expressed in pericytes (Table $\mathbf{1}$ and Figure 5B) and $K_{i r}$ currents with the expected biophysical characteristics and sensitivity to micromolar barium $\left(\mathrm{Ba}^{2+}\right)$ have been reported in cultured retinal and heart pericytes (von Beckerath et al., 2000; Quignard et al., 2003), and retinal and kidney pericytes from microvessels (Cao et al., 2006; Matsushita and Puro, 2006). Strong rectification in $\mathrm{K}_{\mathrm{ir}} 2$ channels results from intracellular polyamine and $\mathrm{Mg}^{2+}$ block of the channel pore at depolarized membrane potentials, limiting outward current. This block is relieved by elevating external $\mathrm{K}^{+}$to levels that are typically seen during neuronal activity, initiating rapid and self-perpetuating hyperpolarization that drives $V_{m}$ toward
$\mathrm{E}_{\mathrm{K}}$ (Longden and Nelson, 2015). Thus, pericyte $\mathrm{K}_{\mathrm{ir}} 2.2$ channels could contribute to transmitted hyperpolarizations in several ways. On one hand, $\mathrm{K}^{+}$elevations resulting from neural activity may directly activate $\mathrm{K}_{\mathrm{ir}} 2.2$ channels on pericytes (Figure 6). Alternatively, engagement of pericyte $\mathrm{K}_{\mathrm{ATP}}$ channels could cause a $\mathrm{K}^{+}$or hyperpolarization-mediated recruitment of $\mathrm{K}_{\mathrm{ir}} 2.2$ channels, which would serve to amplify hyperpolarization. $\mathrm{K}_{\mathrm{ir}} 2.2$ channels could then propagate hyperpolarizing signals from capillary pericytes to upstream vessels by means of pericyte-pericyte communication through their thin-strand processes or by passing hyperpolarization to neighboring ECs via pericyte-endothelial GJs. $\mathrm{PIP}_{2}$ is also central to $\mathrm{K}_{\mathrm{ir}} 2$ channel function (D'Avanzo et al., 2010; Hansen et al., 2011), and its depletion via $G_{\mathrm{q}}$ PCR signaling has recently been shown to play an important role in regulating $\mathrm{K}_{\mathrm{ir}} 2.1$ channel activity in cECs (Harraz et al., 2018). Accordingly, signaling processes that influence PIP 2 levels are anticipated to factor in to $\mathrm{K}_{\mathrm{ir}} 2.2$ channel activity in pericytes.

Collectively, genetic and functional data to date argue for an important role of $\mathrm{K}_{\mathrm{ATP}}$ and $\mathrm{K}_{\mathrm{ir}} 2.2$ channels in regulating pericyte electrical activity, and we thus propose that the activity of these channels plays a central role in the control of capillary blood flow (Figure 6).

\section{Voltage-Gated $\mathrm{K}^{+}\left(\mathrm{K}_{\mathrm{v}}\right)$ Channels Provide Graded Opposition to Membrane Depolarization}

$\mathrm{K}_{\mathrm{v}}$ channels are formed by 4 identical subunits that surround a central pore. Each subunit is composed of six transmembrane segments (S1-S6) of which four form the voltage sensor domain (S1-S4) with several regularly spaced positively-charged amino acids in the S4 helix playing a central role in transducing voltage into conformational changes that gate the channel. The 


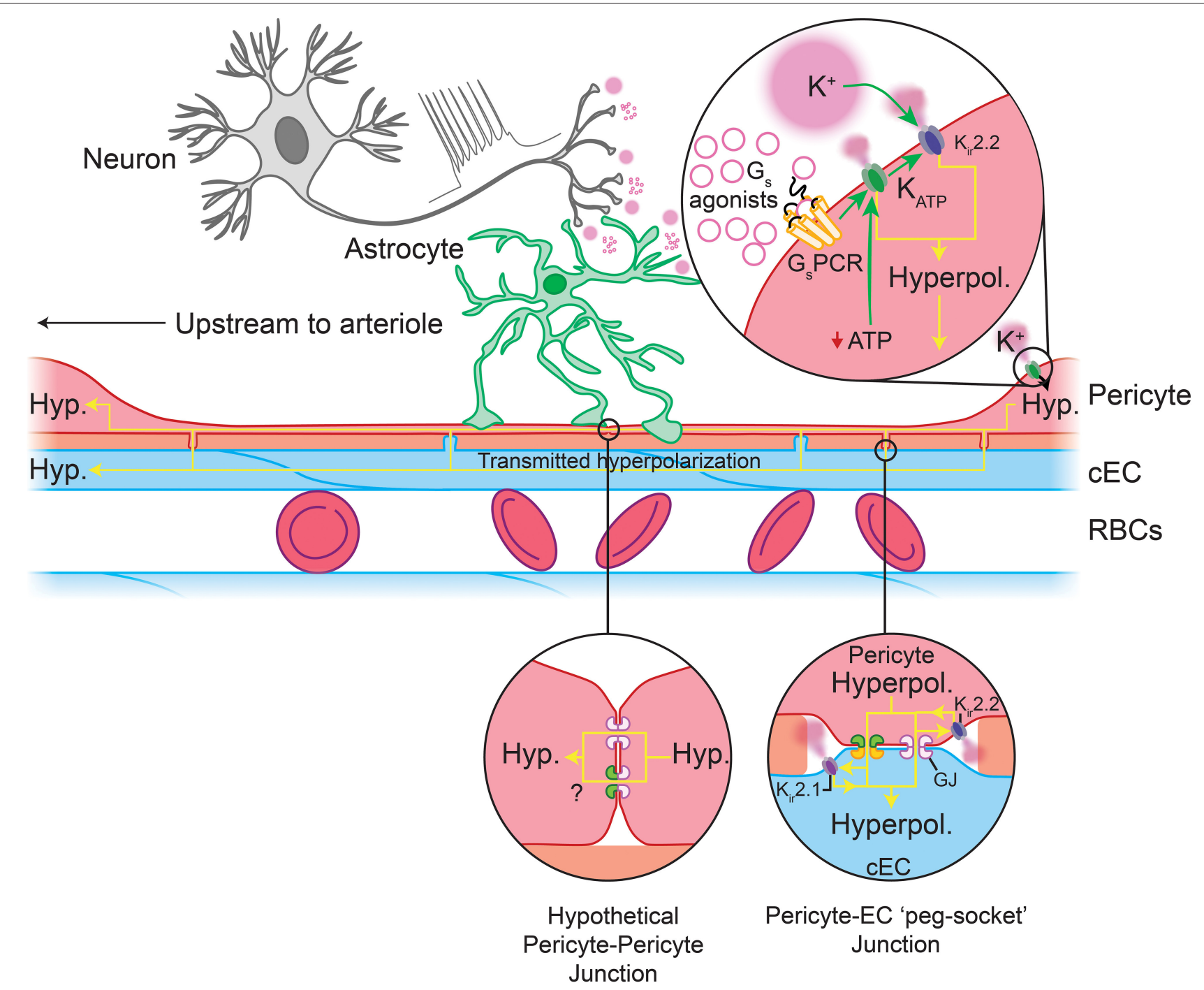

FIGURE 6 | Predicted capillary pericyte-EC interactions to control local blood flow. Neuronal activity drives the release of $\mathrm{K}^{+}$and $\mathrm{G}_{\mathrm{S}} \mathrm{PCR}$ agonists. Top inset: These are predicted to engage pericyte $\mathrm{K}_{\mathrm{i}} 2.2$ and their cognate GPCRs, respectively. $\mathrm{G}_{\mathrm{s}} \mathrm{PCR}$ activity activates $\mathrm{K}_{\mathrm{ATP}}$ channels, the hyperpolarization by which may feed forward to evoke further $\mathrm{K}_{\mathrm{ir}} 2.2$ activity (a sufficient fall in ATP:ADP would also engage $\mathrm{K}_{\text {ATP }}$ channels). The hyperpolarization generated by these channels may then be passed via gap junctions to cECs (bottom right inset) or possibly to adjacent pericytes, though direct pericyte-pericyte gap junctions have not been observed to date. In cECs, the incoming hyperpolarization will engage $\mathrm{K}_{\mathrm{i}} 2.1$ channels to amplify hyperpolarization to a sufficient level to pass to adjacent cECs and pericytes. Hyperpolarization-mediated activation of $\mathrm{K}_{\mathrm{i}} 2.1$ and $\mathrm{K}_{\mathrm{ir}} 2.2$ in these cells will rapidly regenerate the current so that it can be passed to the next cell, and so on upstream to the arteriole. Upon arrival at the arteriole and its first few offshoots, hyperpolarization will be passed via GJs at MEPs to SMCs and to contractile mural cells, which will close VDCCs, leading to a fall in intracellular $\mathrm{Ca}^{2+}$, relaxation of their actin-myosin contractile machinery, vasodilation, and an increase in blood flow.

remaining two transmembrane regions line the $\mathrm{K}^{+}$-selective pore (S5-S6; Figure 5C; Jiang et al., 2003; Chen et al., 2010).

In order of mRNA abundance, cerebral pericytes express modest to low levels of genes encoding: $\mathrm{K}_{\mathrm{v}} 6.1, \mathrm{~K}_{\mathrm{v}} 7.4, \mathrm{~K}_{\mathrm{v}} 2.1$, $\mathrm{K}_{\mathrm{v}} 9.3, \mathrm{~K}_{\mathrm{v}} 9.1, \mathrm{~K}_{\mathrm{v}} 7.5$, and $\mathrm{K}_{\mathrm{v}} 1.2$, in the absence of $\mathrm{K}_{\mathrm{v}}$ beta subunits (Table 1). Outward $\mathrm{K}^{+}$currents attributable to $\mathrm{K}_{\mathrm{v}}$ channels have been measured in these cells, for example in guinea pig cochlear stria vascularis and cultured bovine retinal pericytes (von Beckerath et al., 2000; Quignard et al., 2003; Liu et al., 2018). $K_{v}$ channels are crucial for negative feedback regulation of $V_{m}$, their $P_{o}$ and unitary currents increasing with membrane depolarization to provide a counterbalancing hyperpolarizing influence (Nelson and Quayle, 1995; Koide et al., 2018). Their activity can also be modulated by a range of intracellular signaling cascades that engage varied effectors such as PKC, cSRC or Rho-kinase (which inhibit $\mathrm{K}_{\mathrm{V}}$ channels) or cAMP-PKA and cyclic guanosine monophosphate(cGMP)-protein kinase G (PKG) signaling pathways (which promote channel activity) (Jackson, 2018). Of note, nitric oxide (NO) can exert major signaling effects via soluble guanylate cyclase (sGC) and cGMPPKG in pericytes (Denninger and Marletta, 1999). As adjacent cECs are a major source of local NO (Longden et al., 2019), its 
elevation may be sufficient to engage pericyte PKG signaling to promote activity of $\mathrm{K}_{\mathrm{V}}$ and other PKG-sensitive channels.

Cerebral arteriolar SMCs are each estimated to express $\sim 3,000$ $\mathrm{K}_{\mathrm{v}}$ channels/cell (Dabertrand et al., 2015) composed principally of $\mathrm{K}_{\mathrm{v}} 1.2$ and $\mathrm{K}_{\mathrm{v}} 1.5$ (Straub et al., 2009) with activation initially detectable above $-40 \mathrm{mV}$ and increasing e-fold per $11-13 \mathrm{mV}$, exhibiting half-activation between approximately -10 and $0 \mathrm{mV}$ (Robertson and Nelson, 1994; Straub et al., 2009). These channels also exhibit substantial steady-state inactivation over the physiological voltage range (Robertson and Nelson, 1994). $\mathrm{K}_{\mathrm{v}}$ currents with similar characteristics have been described in cultured retinal pericytes (Quignard et al., 2003), whereas the half-maximal activation of $\mathrm{K}_{\mathrm{V}}$ channels recorded in cultured coronary pericytes is substantially more negative at $-40.9 \mathrm{mV}$, along with a steeper voltage-dependence of activation (e-fold per $4.6 \mathrm{mV}$ ) and only modest inactivation at physiological membrane potentials (von Beckerath et al., 2000). Thus, $\mathrm{K}_{\mathrm{V}}$ current characteristics in pericytes appear to be regionally dependent, likely a result of differential expression and assembly of distinct $\mathrm{K}_{\mathrm{V}}$ isoforms. Direct characterization of $\mathrm{K}_{\mathrm{v}}$ currents in native brain pericytes is therefore critical to furthering our understanding of their role in the control of pericyte $V_{m}$, where these channels are anticipated to provide negative feedback to limit depolarization effected by the activity of depolarizing ion channels in pericytes, such as those of the TRP family.

\section{$\mathrm{K}_{2 \mathrm{P}}$ 3.1 Channels Provide a Background $\mathrm{K}^{+}$ Conductance and May Impart pH Sensitivity}

$\mathrm{K}_{2 \mathrm{P}}$ channels contribute to maintenance of resting membrane potential due to steady outward $\mathrm{K}^{+}$"leak" at potentials positive to $\mathrm{E}_{\mathrm{K}}$. They comprise a family of 15 members, and are composed of two identical subunits, each with four transmembrane domains with two pore-forming loops making up a central $\mathrm{K}^{+}$conducting pore (Figure 5D; Miller and Long, 2012; Lolicato et al., 2014). $\mathrm{K}_{2 \mathrm{P}} 3.1$, also known as the two-pore domain weakly inwardly-rectifying $\mathrm{K}^{+}$channel (TWIK)-related acidsensitive $K^{+}$(TASK)-1 channel (Duprat et al., 1997), is the only $\mathrm{K}_{2 \mathrm{P}}$ isoform expressed in capillary pericytes, and is also expressed in cerebral SMCs (He et al., 2018; Vanlandewijck et al., 2018). In SMCs, its steady current contributes to maintaining a relatively negative $\mathrm{V}_{\mathrm{m}}$ by counterbalancing depolarizing influences (Gurney et al., 2003).

Perhaps the most well-studied characteristic of TASK-1 is its sensitivity to $\mathrm{pH}$ within the range of $\sim 6.5-8$. Acidic $\mathrm{pH}$ inhibits channel activity while alkaline $\mathrm{pH}$ increases it, with half-maximal activation occurring at $\mathrm{pH} 7.4$ and $\sim 90 \%$ of maximal TASK-1 current recorded at pH 7.7 (Duprat et al., 1997). Synchronous neuronal activity can cause rapid changes in $\mathrm{pH}$. For example, alkalization in extracellular $\mathrm{pH}$ has been observed in the hippocampus, cerebellum and some cortical areas, by up to 0.2 units (Chesler and Kaila, 1992; Makani and Chesler, 2010). Thus, it is possible that in addition to setting resting $\mathrm{V}_{\mathrm{m}}, \mathrm{K}_{2 \mathrm{P}} 3.1$ imparts sensitivity to pericytes in these regions to such shifts, which could hyperpolarize $\mathrm{V}_{\mathrm{m}}$ to modulate blood flow through the mechanisms described above.

\section{$\mathrm{Na}^{+}$- and $\mathrm{Ca}^{2+}$-Activated $\mathrm{K}^{+}$Channels Are Expressed at Low Levels in Pericytes}

Capillary pericytes also express low levels of genes encoding the $\mathrm{Na}^{+}$-activated $\mathrm{K}_{\mathrm{Na}} 1.2$ channel and the $\mathrm{Ca}^{2+}$-activated $\mathrm{K}_{\mathrm{Ca}} 2.3$ channel (Table 1). $\mathrm{K}_{\mathrm{Na}} 1.2$ channels (Figure 5E) are sensitive to intracellular $\mathrm{Na}^{+}$and $\mathrm{Cl}^{-}$, and are dramatically stimulated by cell swelling and inhibited by a decrease in cell volume (Bhattacharjee et al., 2003; Tejada et al., 2014). Thus, they could impart sensitivity to pericyte volume changes, and may respond to fluctuations in intracellular ion concentrations or metabolic state.

$\mathrm{K}_{\mathrm{Ca}} 2.3$ (also known as SK3) belongs to the family of smallconductance $\mathrm{Ca}^{2+}$-activated $\mathrm{K}^{+}(\mathrm{SK})$ channels that share overall transmembrane topology with $\mathrm{K}_{\mathrm{V}}$ channels, yet lack a functional voltage-sensor at S4 (Figure 5F; Adelman et al., 2012). Each subunit in the tetrameric channel is associated with a calmodulin (CaM) monomer via a CaM binding domain in the C-terminal region. $\mathrm{Ca}^{2+}$ binding to $\mathrm{CaM}$ induces a conformational change which leads to rapid channel opening, with an $\mathrm{EC}_{50}$ for $\mathrm{Ca}^{2+}$ of 300-500 nM (Ledoux et al., 2006; Adelman et al., 2012). If functional SK channels in native pericytes are confirmed, they are expected to facilitate coupling between $\mathrm{Ca}^{2+}$ elevations and membrane hyperpolarization.

\section{PERICYTE TRP CHANNELS}

The TRP channel family mediates cellular responses to a wide range of stimuli (Clapham, 2003). These are non-selective cation channels that depolarize the membrane upon activation and, in many cases, conduct significant amounts of $\mathrm{Ca}^{2+}$. In mammals there are six subfamilies of TRP channels encoded by 28 genes, 11 of which are expressed by capillary pericytes. These are canonical (TRPC1, TRPC3, TRPC4, TRPC6), melastatin (TRPM3, TRPM4, TRPM7), mucolipin (TRPML1), poly-cystin (TRPP1, TRPP3), and vanilloid (TRPV2) channels (Earley and Brayden, 2010; He et al., 2018; Vanlandewijck et al., 2018). Functional TRP channels are tetramers of subunits with a common six transmembrane structure, which can assemble into homomeric or heteromeric functional channels. Their tendency to heteromerize, generally with closely related members, can give rise to channels with unique sensing capabilities and biophysical properties (Venkatachalam and Montell, 2007). Overall, subfamily members share $\sim 35 \%$ amino acid sequence homology, with the majority of this diversity arising from differences in their cytoplasmic domains (Figure 7; Clapham, 2003; Nilius and Owsianik, 2011). While they have been traditionally described as "non-selective," the pattern of ion selectivity for different cations varies between subfamilies (Hill-Eubanks et al., 2014; see Table 1).

Broadly speaking, TRP channels are major downstream effectors for GPCR signaling (Clapham, 2003; Veldhuis et al., 2015), with particular second messenger systems both activating or sensitizing some TRP channels, and decreasing the activity of others. TRPC channels are $\mathrm{Ca}^{2+}$ permeable and typically activated by plasmalemmal GPCRs or tyrosine kinase receptors that activate PLC isoforms (Albert, 2011). TRPC3/6 channels are directly activated by DAG, which is liberated by $\mathrm{G}_{\mathrm{q}}$ signaling, and inhibited by $\mathrm{PIP}_{2}$, which decreases during $\mathrm{G}_{\mathrm{q}}$ 


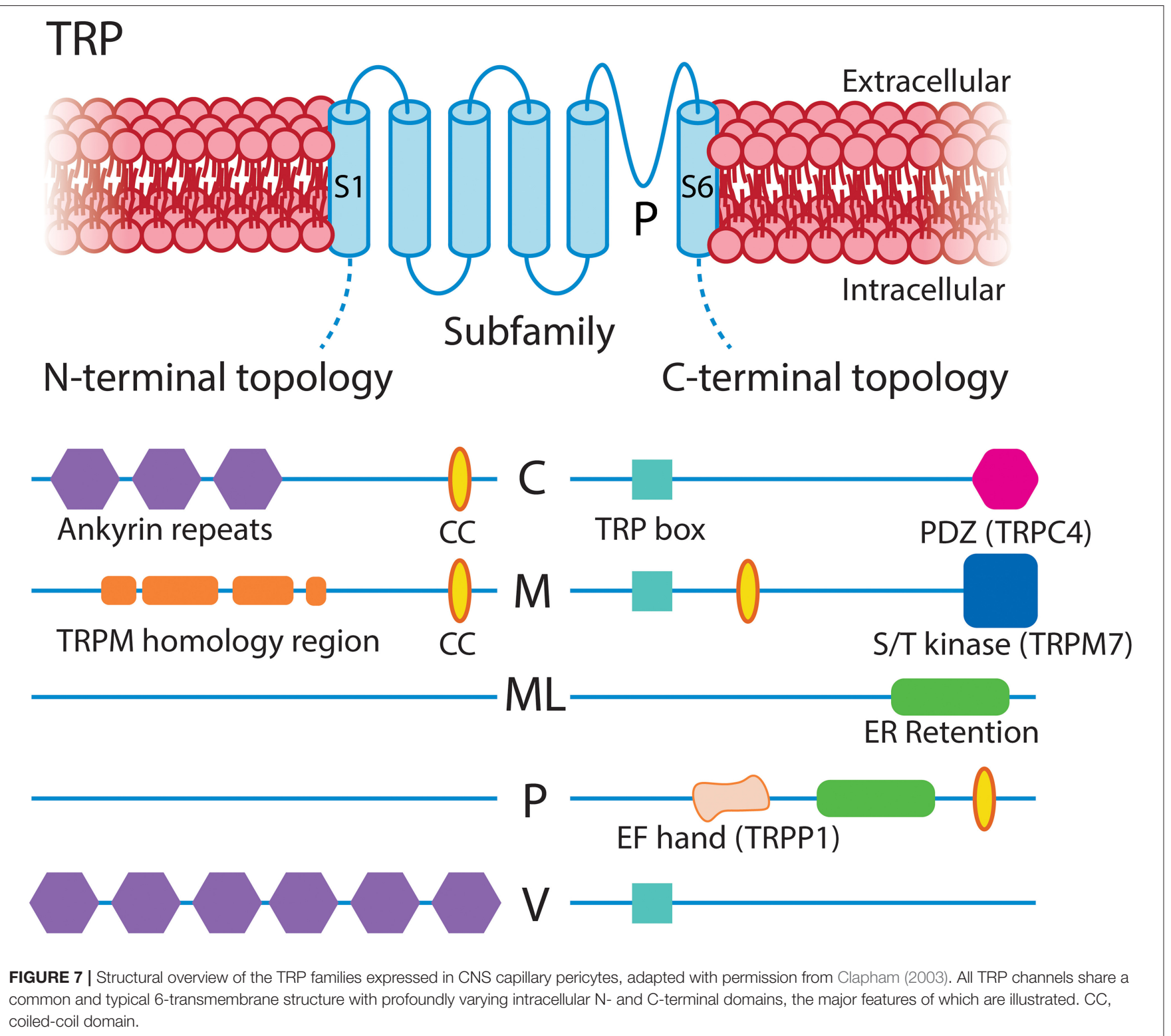

activity (Hofmann et al., 1999; Albert, 2011). The activation mechanisms of TRPC4 are less clear, whereas TRPC1-containing channels are unresponsive to DAG and are instead gated by $\mathrm{PIP}_{2}$ in a PKC-dependent manner (Hofmann et al., 1999; Albert, 2011), although heteromultimerization with TRPC3 can convey DAG sensitivity (Lintschinger et al., 2000). TRPC3 is the most robustly expressed TRP channel in capillary pericytes (Table 1) and is thus likely to be engaged during $\mathrm{G}_{\mathrm{q}}$ PCRDAG signaling. This channel permits robust $\mathrm{Ca}^{2+}$ entry, although it has relatively low selectivity for $\mathrm{Ca}^{2+}$ over $\mathrm{Na}^{+}$ $\left(p \mathrm{Ca}^{2+}: \mathrm{pNa}^{+} \sim 1.5\right.$; Pedersen et al., 2005). At the arteriolar level, TRPC3 has been implicated in mediating vasodilation through elevations of $\mathrm{EC} \mathrm{Ca}^{2+}$ leading to $\mathrm{K}_{\mathrm{Ca}} 2.3$ activation (Kochukov et al., 2014), whereas its activation in SMCs mediates arteriolar constriction through a mechanism involving an $\mathrm{IP}_{3} \mathrm{R}$-activated (sarcoplasmic reticulum (SR) $\mathrm{Ca}^{2+}$ release independent) TRPC3-dependent $\mathrm{Na}^{+}$current that depolarizes $\mathrm{V}_{\mathrm{m}}$ and activates VDCCs (Xi et al., 2009). Similar couplings may occur in capillary pericytes, likely depending on the macromolecular organization of TRPC3 with other local signaling elements.

Members of the TRPC subfamily, in particular TRPC1, have also been suggested to participate in store-operated $\mathrm{Ca}^{2+}$ entry (SOCE) - an event activated by the depletion of endoplasmic reticulum (ER) $\mathrm{Ca}^{2+}$ stores that depends on Orail and the ER-Ca ${ }^{2+}$ status sensing protein stromal interaction molecule 1 (STIM1; Huang et al., 2006; Soboloff et al., 2006; Cheng et al., 2008, 2013). Capillary pericytes express STIM1 and Orai1 and 3 (Table 1), and thus a functional interaction between TRPC1 and these proteins could be important for SOCE in pericytes. Recent work also shows TRPM7 activation, although not essential, can positively modulate SOCE (Souza Bomfim et al., 2020). 
The melastatin channel TRPM4 is unique in its exclusive permeability to monovalent cations. $\mathrm{Na}^{+}$currents through TRPM4 are voltage-dependent and activated by intracellular $\mathrm{Ca}^{2+}\left(\mathrm{EC}_{50} \sim 20 \mu \mathrm{M}\right)$ with the $\mathrm{Ca}^{2+}$ sensitivity of the channel regulated by multiple factors including cytosolic ATP, PKCdependent phosphorylation and calmodulin (Nilius et al., 2005; Ullrich et al., 2005). In cerebral SMCs, membrane stretch indirectly activates TRPM4 (and TRPC6) current through angiotensin II $\mathrm{AT}_{1}$ receptor activation and a resultant $\mathrm{IP}_{3}$ mediated $\mathrm{Ca}^{2+}$ elevation (Gonzales et al., 2014). Pericytes also express the $\mathrm{AT}_{1}$ receptor, and thus a similar mechanism may be present in capillary pericytes which could contribute to the mild, slow constrictions these cells are capable of FernándezKlett et al. (2010). In contrast to the monovalent conductance of TRPM4, the closely related TRPM3 and TRPM7 channels are also permeable to $\mathrm{Ca}^{2+}$ and $\mathrm{Mg}^{2+}$ (Pedersen et al., 2005). TRPM3 is activated by cell swelling, the neurosteroid pregnenolone sulfate, and the metabolite D-erythro-sphingosine and related sphingosine analogs and thus may impart sensitivity to steroid and lipid signals to pericytes (Grimm et al., 2005; Wagner et al., 2008). As pericytes also robustly express the $\mathrm{S}_{1} \mathrm{P}_{3}$ receptor (discussed below), it is likely that TRPM3 and $\mathrm{S}_{1} \mathrm{P}_{3}$ respond in concert to locally released lipids, such as those released constitutively by ECs and RBCs (Selim et al., 2011; Ksiazek et al., 2015). TRPM7, in contrast, is ubiquitously expressed and plays a major role in $\mathrm{Mg}^{2+}$ homeostasis (Schlingmann et al., 2007).

Functional TRPP1 channels (encoded by the $P k d 2$ gene) have a large conductance and conduct a significant amount of $\mathrm{Ca}^{2+}$ (Earley and Brayden, 2015). This channel has been implicated in mechanosensation when expressed alongside polycystic kidney disease (PKD)1 (Giamarchi and Delmas, 2007; Sharif-Naeini et al., 2009; Narayanan et al., 2013). As PKD1 is also present in pericytes, these channels may aid in the detection of local mechanical forces, such as paravascular fluid shear from the glymphatic system (Mestre et al., 2018), or those imparted through the very thin endothelium by changes in blood flow during neuronal activity, or through subtle changes in diameter of the underlying capillary. Similarly, the vanilloid family member TRPV2, also expressed in SMCs throughout the vasculature (Muraki et al., 2003), has been suggested to play a role in mechanosensation-evoked $\mathrm{Ca}^{2+}$ entry (PerálvarezMarín et al., 2013). Continuing this theme, mechanosensory contributions have also been reported for TRPC1, TRPC6, and TRPM4 (Yin and Kuebler, 2010). Combined with the fact that pericytes also express Piezol (see below), this represents a broad mechanosensing repertoire, suggesting that pericytes may be exquisitely sensitive to a range of mechanical perturbations. The resultant $\mathrm{Ca}^{2+}$ elevation and depolarizing currents through the activity of these channels could couple to a number of processes, including driving further $\mathrm{Ca}^{2+}$ release from stores, and activation of VDCCs, $\mathrm{K}_{\mathrm{Ca}} 2.3$ channels, or $\mathrm{Ca}^{2+}$-activated $\mathrm{Cl}^{-}$channels (CaCCs; discussed below). As recent work demonstrates that pericytes can subtly influence tone throughout the capillary bed (Fernández-Klett et al., 2010), mechanosensing and $\mathrm{Ca}^{2+}$. mediated mechanisms may play an important role in influencing this process.

\section{PERICYTE $\mathrm{Ca}^{2+}$ CHANNELS}

The overall expression level of $\mathrm{Ca}^{2+}$ channels is similar to that of TRP channels in pericytes, composed of message for $\operatorname{IP}_{3} R$ subtypes and a range of VDCCs.

\section{$\mathrm{IP}_{3}$ Rs Permit a Versatile Range of $\mathrm{Ca}^{2+}$ Signaling Behaviors in Response to Extracellular Signals}

The vast majority of intracellular $\mathrm{Ca}^{2+}$ signals arise from either $\mathrm{Ca}^{2+}$ influx across the plasmalemma, or release from the SR/ER via $\mathrm{IP}_{3} \mathrm{Rs}$ or ryanodine receptors (RyRs). $\mathrm{IP}_{3} \mathrm{Rs}$ are enormous proteins $(\sim 1.3 \mathrm{MDa})$ formed by four $\mathrm{IP}_{3} \mathrm{R}$ subunits. Three subunit isoforms- $\mathrm{IP}_{3} \mathrm{R} 1-3$ - exist, which are able to homo- or heterotetramize. Each individual subunit has six transmembrane segments: The fifth and sixth segments form a central ionconducting pore that is connected via a linker to the peripheral bundle formed by transmembrane domains 1-4. The large cytoplasmic $\mathrm{N}$-terminal domain contains the $\mathrm{IP}_{3}$ binding site and a putative $\mathrm{Ca}^{2+}$ sensor region, and binding of $\mathrm{IP}_{3}$ and $\mathrm{Ca}^{2+}$ leads to conformational changes which are transmitted to the pore to gate the channel (Figure 8; Fan et al., 2015; Baker et al., 2017; Hamada et al., 2017). IP 3 R subtypes share $~ 70 \%$ homology and differ in their affinity for $\mathrm{IP}_{3}$, with $\mathrm{IP}_{3} \mathrm{R} 2$ being more sensitive than $\mathrm{IP}_{3} \mathrm{R} 1$, and both of these subtypes being more sensitive than $\mathrm{IP}_{3} \mathrm{R} 3$ (Tu et al., 2005; Iwai et al., 2007). Brain capillary pericytes express the genes encoding $\mathrm{IP}_{3} \mathrm{Rs} 1$ and 2 robustly, and a much lower level of $\mathrm{IP}_{3} \mathrm{R} 3$, whereas RyRs are not appreciably expressed by these cells (He et al., 2018; Vanlandewijck et al., 2018; Table 1).

As described briefly above, $\mathrm{G}_{\mathrm{q}}$ PCRs activating phospholipase C $\beta$ (PLC $\beta$ ) (Fisher et al., 2020), or receptor tyrosine kinases (RTKs) activating PLC $\gamma$, can mediate the formation of $\mathrm{IP}_{3}$ and DAG from $\mathrm{PIP}_{2}$. $\mathrm{IP}_{3}$ then binds to $\mathrm{IP}_{3} \mathrm{Rs}$ on the ER membrane, leading to $\mathrm{Ca}^{2+}$ release from the ER lumen (where $\mathrm{Ca}^{2+}$ is maintained between 100 and $800 \mu \mathrm{M}$; Burdakov et al., 2005) down its electrochemical gradient into the cytosol $(<100 \mathrm{nM}$ basal $\mathrm{Ca}^{2+}$; Berridge, 2016). $\mathrm{IP}_{3}$ and $\mathrm{Ca}^{2+}$ act as co-agonists at $\mathrm{IP}_{3} \mathrm{Rs}$ (Bezprozvanny et al., 1991; Finch et al., 1991; Foskett et al., 2007) and channels display a biphasic sensitivity to $\mathrm{Ca}^{2+}$, resulting in a characteristic bell-shaped concentration-response curve. In the presence of very low $\mathrm{IP}_{3}$ levels, $\mathrm{IP}_{3}$ Rs are extremely sensitive to $\mathrm{Ca}^{2+}$ inhibition. However, a small increase in $\mathrm{IP}_{3}$ concentration (to $\sim 100 \mathrm{nM}$ ) profoundly reduces the sensitivity of the channel to $\mathrm{Ca}^{2+}$ inhibition, permitting dramatic increases in activity (Iino, 1990; Bezprozvanny et al., 1991; Finch et al., 1991; Foskett et al., 2007).

The resultant release of stored $\mathrm{Ca}^{2+}$ can take on a broad range of spatiotemporal profiles, which depend on many factors. To name just a few, these include the concentration of local $\mathrm{IP}_{3}$ and $\mathrm{Ca}^{2+}, \mathrm{ER} \mathrm{Ca}^{2+}$ load, the type, and number of $\mathrm{IP}_{3} \mathrm{Rs}$ expressed, their splice variation, whether they are homomers or heteromers, and the topology of the local microenvironment. Such intricacies provide the versatility to potentially generate a huge variety of $\mathrm{Ca}^{2+}$ signals that encode information through their amplitudes, 


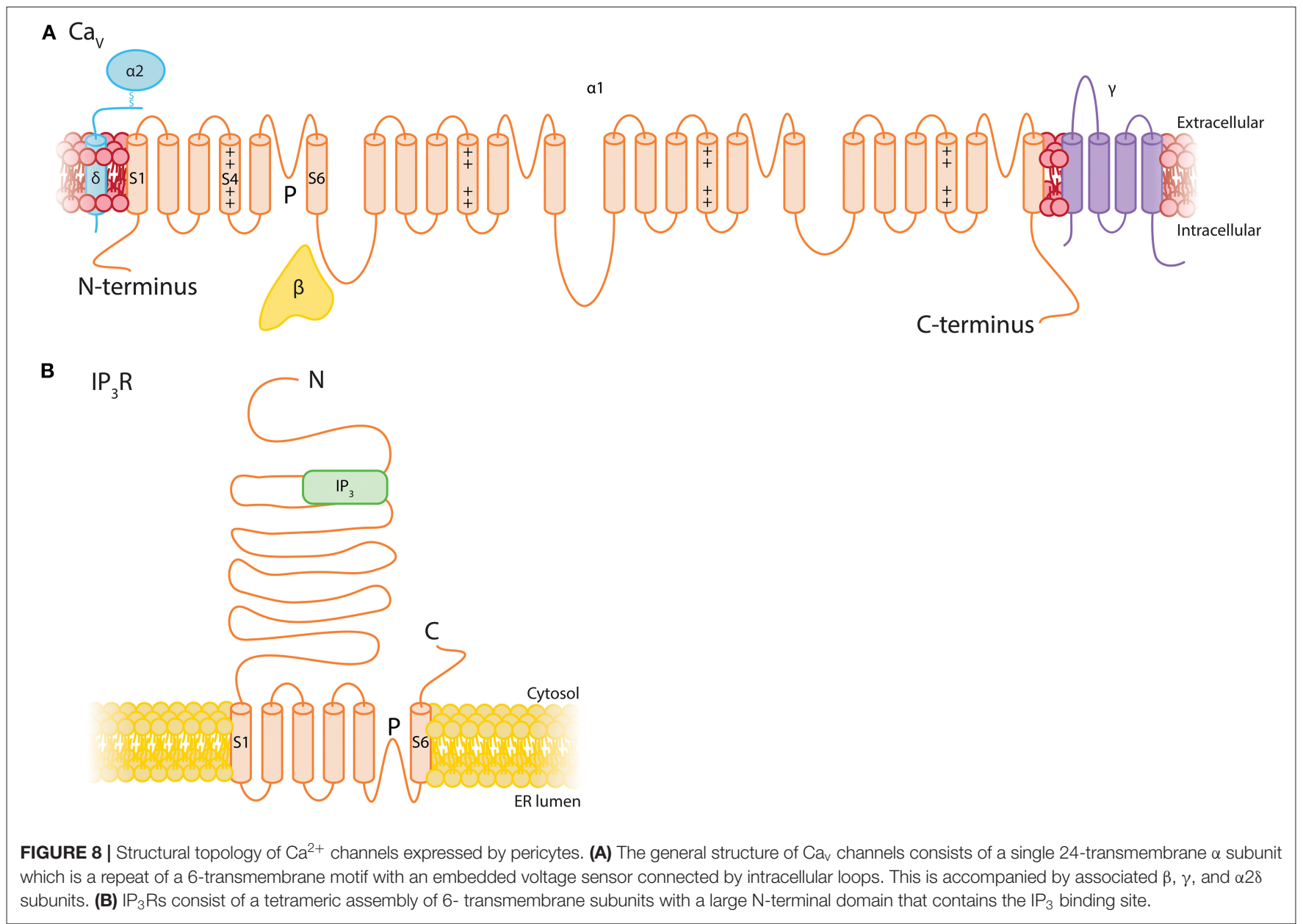

durations, frequencies, and spatial characteristics (Bootman and Bultynck, 2020). Despite these inherent complexities, a range of stereotyped $\mathrm{IP}_{3} \mathrm{R}$-mediated $\mathrm{Ca}^{2+}$ signals typically emerge. These range from the opening of single $\mathrm{IP}_{3} \mathrm{R}$ (termed a "blip"), to the coordinated, weakly cooperative openings of a cluster of around $6 \mathrm{IP}_{3}$ Rs within a release site (a "puff"), to finally-with sufficient $\mathrm{IP}_{3}$-a long-range regenerative $\mathrm{Ca}^{2+}$ "wave" arising due to the recruitment of successive sites through the process of $\mathrm{Ca}^{2+}$ induced $\mathrm{Ca}^{2+}$ release (CICR) (Berridge et al., 2000; Smith and Parker, 2009; Lock and Parker, 2020).

Store-mediated $\mathrm{Ca}^{2+}$ release has been observed in pericytes in a range of contexts. For example, pericytes of the ureter display long-duration $\mathrm{IP}_{3} \mathrm{R}$-mediated $\mathrm{Ca}^{2+}$ transients in response to the $\mathrm{G}_{\mathrm{q}} \mathrm{PCR}$ agonists endothelin-1 and arginine vasopressin. These signals are suppressed by elevations of $\mathrm{Ca}^{2+}$ in adjacent cECs, which are suggested to inhibit $\mathrm{IP}_{3} \mathrm{R}$ activity through a NO-dependent mechanism (Borysova et al., 2013). Spontaneous ER $\mathrm{Ca}^{2+}$ release-dependent $\mathrm{Ca}^{2+}$ transients have also been observed in suburothelial capillary pericytes, which activate CaCCs to depolarize the membrane, subsequently recruiting VDCCs (Hashitani et al., 2018).

In the brain, recent studies have revealed that capillary pericytes generate microdomain $\mathrm{Ca}^{2+}$ oscillations under ambient conditions, and that neural activity evoked by odor leads to a transient cessation of these signals and a decrease in basal $\mathrm{Ca}^{2+}$, which correlates with an increase in $\mathrm{RBC}$ velocity (Hill et al., 2015; Rungta et al., 2018). However, it is worthy of note that a decrease was not observed in similar experiments in which whisker stimulation was used to drive activity (Hill et al., 2015), suggesting the possibility of heterogeneity in the $\mathrm{Ca}^{2+}$ signaling machinery deployed by pericytes in different regions of the cortex. The specific ion channels and broader mechanisms that underlie these ambient signals have not yet been delineated, but $\mathrm{IP}_{3} \mathrm{Rs}$ are obvious potential candidates. Elucidation of the mechanistic basis and roles of these $\mathrm{Ca}^{2+}$ signals in brain capillaries is critical, and awaits further experimentation.

\section{Voltage-Dependent $\mathrm{Ca}^{2+}$ Channels Directly Link $\mathbf{V}_{\mathbf{m}}$ to $\mathrm{Ca}^{2+}$ Entry}

VDCCs are composed of four to five distinct subunits $\left(\alpha_{1}\right.$, $\beta, \alpha_{2} \delta$, and $\gamma$; Figure 7). The $\alpha_{1}$ subunits are pore forming and responsible for the pharmacological diversity of different VDCC subtypes. These are associated with an intracellular $\beta$ subunit, a disulphide-linked $\alpha_{2} \delta$ subunit, and in some cases a transmembrane $\gamma$ subunit, each of which regulate surface 
expression and tune the biophysical properties of the channel (Catterall et al., 2005). The large $\alpha_{1}$ subunit is organized into four homologous domains, each comprising six transmembrane segments (S1-S6) with intracellular N- and C- termini. Similar to $\mathrm{K}_{\mathrm{V}}$ channels, the $\mathrm{S} 4$ segment of each of these domains comprises the voltage sensor and the S5-S6 regions form the ion conducting pore (Catterall et al., 2005). Capillary pericytes express genes encoding the $\alpha$ subunits for L-type $\left(\mathrm{Ca}_{\mathrm{v}} 1.2, \mathrm{Ca}_{\mathrm{v}} 1.3\right), \mathrm{P} / \mathrm{Q}$-type $\left(\mathrm{Ca}_{\mathrm{v}} 2.1\right)$, and T-type $\left(\mathrm{Ca}_{\mathrm{v}} 3.1, \mathrm{Ca}_{\mathrm{v}} 3.2\right)$ channels and thus we briefly review the salient properties of these here. They also express low levels of several genes encoding $\beta$ and $\alpha_{2} \delta$ auxiliary subunits (He et al., 2018; Vanlandewijck et al., 2018).

As with $\mathrm{K}_{\mathrm{v}}$ channels, VDCC activity depends on membrane potential: $\mathrm{P}_{\mathrm{o}}$ steeply increases with depolarization, balanced by multiple feedback mechanisms that act to limit $\mathrm{Ca}^{2+}$ entry at depolarized potentials. Prominent among these are voltage- and $\mathrm{Ca}^{2+}$-dependent inactivation. Voltage-dependent inactivation (VDI) is inherent to the $\alpha_{1}$ subunit but is modulated by the ancillary $\beta$ subunit and others, whereas $\mathrm{Ca}^{2+}$-dependent inactivation (CDI) is conferred by a CaM monomer associated with the $\alpha_{1}$ carboxy tail (Peterson et al., 1999; An and Zamponi, 2005; Dick et al., 2008; Tadross and Yue, 2010; Tadross et al., 2010). Regulation is additionally complicated by the panoply of alternative splice variants that can be expressed, which impact the biophysical properties of the functional channel, including sensitivity to CDI and VDI.

L-type channels are widely expressed, including in the heart, in skeletal and smooth muscle, and in neurons (Zamponi et al., 2015). $\mathrm{Ca}_{\mathrm{v}} 1.2$ and $\mathrm{Ca}_{\mathrm{v}} 1.3$ have distinct biophysical and pharmacological differences (Lipscombe et al., 2004)- $\mathrm{Ca}_{\mathrm{v}} 1.3$ channels open and close on faster timescales than $\mathrm{Ca}_{\mathrm{v}} 1.2$ (Helton et al., 2005), and are less sensitive to inhibition by dihydropyridines (Xu and Lipscombe, 2001). A C-terminal modulatory (CTM) domain can structurally interfere with CaM binding to decrease $\mathrm{P}_{\mathrm{o}}$ and reduce CDI, an effect that is more pronounced in $\mathrm{Ca}_{\mathrm{v}} 1.3$ than $\mathrm{Ca}_{\mathrm{v}} 1.2$ (Striessnig et al., 2014). Moreover, in alternatively spliced $\mathrm{Ca}_{\mathrm{v}} 1.3$ channels, the absence of a CTM domain can shift the voltage of half-maximal activation by $\sim+10 \mathrm{mV}$ by decreasing the slope factor of the activation curve without any effects on activation threshold (Singh et al., 2008). At physiological extracellular $\mathrm{Ca}^{2+}$ levels, the activation threshold of $\mathrm{Ca}_{\mathrm{v}} 1.3$ is much more negative $(-55 \mathrm{mV})$ than $\mathrm{Ca}_{\mathrm{v}} 1.2(-25$ to $-30 \mathrm{mV}$ ) (Xu and Lipscombe, 2001). Thus, at pericyte resting $\mathrm{V}_{\mathrm{m}}$ of around $-45 \mathrm{mV}$, as measured in the retina (Zhang et al., 2011), $\mathrm{Ca}_{\mathrm{v}} 1.3$ channels could be active and contribute to $\mathrm{Ca}^{2+}$ entry.

In addition to voltage- and $\mathrm{Ca}^{2+}$-dependent inhibition, $\mathrm{L}$ type VDCC activity is heavily regulated by GPCR signaling. Prominent among these, $\mathrm{G}_{\mathrm{s}}$-cAMP-PKA signaling has long been known to play an important role in stimulating channel activity, and has been studied extensively in the heart. Here, it was recently shown that the target of PKA phosphorylation is not the core channel itself, as mutation of all PKA consensus phosphorylation sites to alanine resulted in channels that retained PKA regulation. Rather, PKA acts via the small G protein Rad, a constitutive inhibitor of VDCCs. Phosphorylation of Rad relieves its interaction with $\beta$ subunits, and allows channel activity (Liu et al., 2020). Further regulation of L-type channels by
PKC, stimulated by DAG liberated as a result of $\mathrm{G}_{\mathrm{q}}$ PCR activity, is also a possibility, with both inhibitory and potentiating effects having been observed (Kamp and Hell, 2000).

P- and Q-type currents are both attributable to $\mathrm{Ca}_{\mathrm{v}} 2.1$, with the $\beta$ subunit accompanying the pore-forming subunit thought to account for their differences (Zamponi et al., 2015). These channels have been best characterized in the nerve terminals and dendrites of neurons where they couple $\mathrm{Ca}^{2+}$ entry with neurotransmitter release (Zamponi et al., 2015) and also play a role in coupling $\mathrm{Ca}^{2+}$ entry to gene transcription via engagement of CaM kinase II (Wheeler et al., 2012). They open in response to similar depolarization levels as $\mathrm{Ca}_{\mathrm{v}} 1.2$ channels, with an activation threshold of approximately $-40 \mathrm{mV}$ (Adams et al., 2009). Upon repetitive/tetanic stimulation, as occurs during neuronal activity, CaM can bind to two adjacent sites on the $\mathrm{Ca}_{\mathrm{v}} 2.1 \alpha_{1}$ subunit to mediate an initial $\mathrm{Ca}^{2+}$-dependent facilitation (CDF) of P/Q-type current, followed by progressive CDI, with a relatively slow $(30 s-1 \mathrm{~min})$ recovery from this (Lee et al., 1999, 2000). While CDI of $\mathrm{Ca}_{\mathrm{v}} 2.1$ requires a global $\mathrm{Ca}^{2+}$ increase, $\mathrm{CDF}$ can be promoted by $\mathrm{Ca}^{2+}$ entry through an individual $\mathrm{Ca}_{\mathrm{v}} 2.1$ channel and results in an enhancement of channel $\mathrm{P}_{\mathrm{o}}$, enabling stimulation-evoked increases in amplitude and duration of $\mathrm{Ca}^{2+}$ currents (Chaudhuri et al., 2007). Slow and fast modes of $\mathrm{Ca}_{\mathrm{v}} 2.1$ gating have been proposed. The slow mode exhibits longer mean closed times and latency to first opening, slower kinetics of inactivation, and necessitates larger depolarizations to open the channel. Inactivation also occurs at more depolarized potentials in the slow compared to fast mode (Luvisetto et al., 2004). The type of $\beta$ subunit modulates the prevalence of these modes, with fast and slow gating mediated by $\beta_{3 \mathrm{a}}$ and $\beta_{4 \mathrm{a}}$ subunits, respectively (Luvisetto et al., 2004), the latter of which is expressed more robustly by brain pericytes (He et al., 2018; Vanlandewijck et al., 2018). $\mathrm{Ca}_{\mathrm{v}} 2.1$ channels are inhibited by GPCR activity through several distinct mechanisms-direct binding of the $G$ protein $\beta \gamma$ dimer can augment VDI, while voltage-independent mechanisms such as phosphorylation, depletion of essential lipids, and trafficking mechanisms also play important roles (Zamponi and Currie, 2013).

T-type $\left(\mathrm{Ca}_{\mathrm{v}} 3.1\right.$ and $\left.\mathrm{Ca}_{\mathrm{v}} 3.2\right)$ channels are activated at more negative potentials, around $-60 \mathrm{mV}$, with rapid gating kinetics and small single channel amplitudes (Iftinca and Zamponi, 2009; Rossier, 2016). At membrane potentials of -65 to $-55 \mathrm{mV}$, these channels exhibit window currents in which the channels open but do not inactivate completely, permitting ongoing $\mathrm{Ca}^{2+}$ entry (Perez-Reyes, 2003). These channels can be modulated by the activity of a broad range of GPCRs, including those with G $\alpha$ subunits that couple to PKA, PKC, and PKG, along with direct effects of G $\beta \gamma$ subunits (Iftinca and Zamponi, 2009).

Both L- and T-type VDCCs are expressed in cerebral SMCs (Hill-Eubanks et al., 2011; Harraz and Welsh, 2013; Harraz et al., 2014). Here, L-type channels provide $\mathrm{Ca}^{2+}$ for contraction (Nelson et al., 1990), whereas T-type channels provide negative feedback by coupling $\mathrm{Ca}^{2+}$ entry to RyR activity. Subsequent $\mathrm{Ca}^{2+}$ release via RyRs in turn activates large-conductance $\mathrm{Ca}^{2+}$. activated $\mathrm{K}^{+}(\mathrm{BK})$ channels to hyperpolarize the membrane (Harraz and Welsh, 2013; Harraz et al., 2014). T- and P/Q-type 
channel currents have not yet been observed in native pericytes, but L-type VDCC currents have been measured in the retina (Sakagami et al., 1999). Variance in the magnitude of L-type VDCC $\mathrm{Ca}^{2+}$ currents across the microvascular network has functional consequences for the degree of $\mathrm{Ca}^{2+}$ entry via these channels (Matsushita et al., 2010; Burdyga and Borysova, 2014). In the retina, L-type VDCC currents are 7.5-fold higher in SMCs as compared to capillary pericytes, suggesting that $\mathrm{V}_{\mathrm{m}}$ changes influence intracellular $\mathrm{Ca}^{2+}$ levels to a greater degree at the level of arterioles (Matsushita et al., 2010). Indeed, extracellular $\mathrm{K}^{+}$at $10 \mathrm{mM}$ (a concentration that evokes $\mathrm{K}_{\mathrm{ir}^{-}}$ mediated hyperpolarization) and $97.5 \mathrm{mM}$ (which depolarizes the membrane to drive VDCC activity) significantly decreased and increased intracellular $\mathrm{Ca}^{2+}$ in arteriolar SMCs, respectively, but had only a marginal effect on capillary pericyte $\mathrm{Ca}^{2+}$ (Matsushita et al., 2010). Thorough characterization of native brain capillary pericyte VDCC currents and their densities is needed to advance our understanding of the contribution of these channels to pericyte $\mathrm{Ca}^{2+}$ handling.

\section{PERICYTE $\mathrm{Cl}^{-}$CHANNELS}

$\mathrm{Cl}^{-}$channels are found in the plasma membrane and that of intracellular organelles and have been implicated in the regulation of cell excitability and volume, acidification of intracellular organelles, control of muscle tone, and synaptic transmission (Jentsch et al., 1999; Nilius and Droogmans, 2003). While they are permeable to other anions (such as iodide, bromide, or nitrate), they are referred to as $\mathrm{Cl}^{-}$channels since this is the most abundant permeating anion species (Jentsch et al., 2002). Capillary pericytes express the CaCC formerly known as TMEM16A or anoctamin (Ano)1, and several members of the voltage-dependent chloride channel (ClC) family-ClC2,-3,-4,-6, and-7 (He et al., 2018; Vanlandewijck et al., 2018). The latter four of these are $\mathrm{Cl}^{-} / \mathrm{H}^{+}$antiporters and are not considered further here. Capillary pericytes also express other anoctamins that have been implicated in lipid scrambling: Ano4 and Ano6, as well as the poorly understood Ano10 (He et al., 2018; Vanlandewijck et al., 2018). Reports indicate that Ano6 may act as a $\mathrm{Ca}^{2+}$-activated $\mathrm{Cl}^{-}$and non-selective cation channel with scramblase activity (Suzuki et al., 2010; Yang et al., 2012; Grubb et al., 2013) and Ano4 was recently shown to be a $\mathrm{Ca}^{2+}$. dependent non-specific cation channel with similar scrambling capabilities (Reichhart et al., 2019).

\section{CaCC Channels Couple Intracellular $\mathrm{Ca}^{2+}$ Increases to Depolarizing $\mathrm{Cl}^{-}$Efflux}

The CaCC TMEM16A is a homodimer of two pores and ten transmembrane domains, cytosolic N- and C-termini, and an extracellular domain (Dang et al., 2017; Paulino et al., 2017). $\mathrm{Ca}^{2+}$ binding to a transmembrane region of the pore induces a conformational rearrangement that gates the channel and leads to $\mathrm{Cl}^{-}$permeation, generating a current that is outwardly rectifying with a slope conductance of $\sim 8 \mathrm{pS}$ (Yang et al., 2008; Xiao et al., 2011; Paulino et al., 2017). $\mathrm{Ca}^{2+}$ and voltage gating are closely coupled, with a stretch of 8 amino acids controlling both
$\mathrm{Ca}^{2+}$ sensitivity and voltage-dependence of the channel (Xiao et al., 2011). Indeed, a remarkable feature of this channel is the voltage-dependence of $\mathrm{Ca}^{2+}$ sensitivity, with an $\mathrm{EC}_{50}$ of $2.6 \mu \mathrm{M}$ at $-60 \mathrm{mV}$ and $400 \mathrm{nM}$ at $+60 \mathrm{mV}$. At physiological voltages, the channel is maximally activated by around $10 \mu \mathrm{M}$ intracellular $\mathrm{Ca}^{2+}$ but concentrations exceeding this lower activation. Strong depolarization (above $\sim 100 \mathrm{mV}$ ), in contrast, opens the channel even in the absence of $\mathrm{Ca}^{2+}$, despite the lack of a classic voltage sensor in the CaCC structure (Yang et al., 2008; Xiao et al., 2011). The kinetics of activation are slow at positive potentials, but are sharpened by an elevation of $\mathrm{Ca}^{2+}$, and at negative potentials channels display deactivation (Nilius and Droogmans, 2003). This interplay between $\mathrm{V}_{\mathrm{m}}$ and intracellular $\mathrm{Ca}^{2+}$ makes the $\mathrm{CaCC}$ an attractive candidate for regulation of $\mathrm{V}_{\mathrm{m}}$ in response to elevations intracellular $\mathrm{Ca}^{2+}$.

Since CaCC is sensitive to micromolar-range intracellular $\mathrm{Ca}^{2+}$ at typical resting potentials, it seems plausible that it is stimulated by local $\mathrm{Ca}^{2+}$ elevations (as opposed to global increases) such as those occurring through nearby TRPs, VDCCs, Orai channels, or $\mathrm{IP}_{3}$ Rs. In keeping with this notion, cerebral SMC CaCCs are activated by TRPC6-mediated $\mathrm{Ca}^{2+}$ entry which drives vasoconstriction (Wang et al., 2016). Coupling of $\mathrm{IP}_{3} \mathrm{R}$ activity to CaCCs has also been reported in response to purinergic receptor activation, wherein CaCC-containing membrane domains are closely localized with ER regions via a physical linkage between this protein and $\mathrm{IP}_{3} \mathrm{R} 1$, facilitating exclusive communication between the two and exposing the $\mathrm{CaCC}$ to high $\mathrm{Ca}^{2+}$ concentrations during its release from the ER (Jin et al., 2013; Cabrita et al., 2017).

Underscoring their important role in the vasculature, targeted disruption of CaCCs from contractile vascular SMCs, mural cells and pericytes lowers systemic blood pressure (Heinze et al., 2014), whereas conversely CaCC overexpression drives hypertension (Wang et al., 2015). In vascular SMCs, the driving force for depolarizing $\mathrm{Cl}^{-}$currents comes from $\mathrm{Cl}^{-} / \mathrm{HCO}^{-}$ exchange and $\mathrm{Na}^{+} / \mathrm{K}^{+} / \mathrm{Cl}^{-}$cotransport which enable high intracellular $\mathrm{Cl}^{-}$concentrations (30-50 mM; Owen, 1984; Chipperfield and Harper, 2000; Kitamura and Yamazaki, 2001). Capillary pericytes in the brain express mRNA for genes encoding two of the SLC4 family $\mathrm{Cl}^{-} / \mathrm{HCO}^{-}$exchangers (Slc4a2, Slc4a3) and the NKCC1 Na ${ }^{+} / \mathrm{K}^{+} / \mathrm{Cl}^{-}$cotransporter (Slc12a2) (He et al., 2018; Vanlandewijck et al., 2018), which raise the potential for similarly high intracellular $\mathrm{Cl}^{-}$concentrations. $\mathrm{E}_{\mathrm{Cl}}$ with 30 $50 \mathrm{mM}$ intracellular $\mathrm{Cl}^{-}$and $133 \mathrm{mM}$ extracellular $\mathrm{Cl}^{-}$(Longden et al., 2016) is between approximately -35 and $-25 \mathrm{mV}$-more positive than resting $\mathrm{V}_{\mathrm{m}}$ of pericytes $(\sim-45 \mathrm{mV}$, as measured in the retina; Zhang et al., 2011), therefore under these conditions activation of $\mathrm{CaCC}$ would cause $\mathrm{Cl}^{-}$efflux and membrane depolarization, as seen in SMCs (Kitamura and Yamazaki, 2001; Bulley and Jaggar, 2014). While direct evidence for CaCCs in cortical capillary pericytes is currently lacking, in bladder pericytes $\mathrm{ER} \mathrm{Ca}^{2+}$ release activates $\mathrm{CaCCs}$ and the resulting depolarization propagates to upstream SMCs of pre-capillary arterioles via gap junctions, where they depolarize the membrane to activate L-type VDCCs (Hashitani et al., 2018). In the pericytes of descending vasa recta, angiotensin II causes cytoplasmic $\mathrm{Ca}^{2+}$ oscillations that activate CaCC channels and depolarize $\mathrm{V}_{\mathrm{m}}$ to 
approximately $-30 \mathrm{mV}$ (Zhang et al., 2008; Lin et al., 2010). CaCC current and membrane depolarization have also been recorded in retinal pericytes, where $\mathrm{CaCC}$ activation depends on unidentified non-selective cation channels (Sakagami et al., 1999) and can be evoked by $\mathrm{G}_{\mathrm{q}}$ PCR stimulation with endothelin (Kawamura et al., 2002). Thus, CaCCs in brain pericytes are predicted to depolarize $\mathrm{V}_{\mathrm{m}}$ by coupling to a number of potential $\mathrm{Ca}^{2+}$ sources, including $\mathrm{IP}_{3} \mathrm{Rs}$ and TRP channels.

\section{CIC Channels May Repolarize the Membrane Following Electrical Signaling}

$\mathrm{ClCs}$ are double-barreled homodimeric channels with one ion conduction pore per monomer (Dutzler et al., 2002). Each subunit is made up of $18 \alpha$-helices which display an interesting internal anti-parallel architecture, and many of these helices are shortened and tilted which permits disparate parts of the polypeptide to come together to form the $\mathrm{Cl}^{-}$selectivity filter of the pore (Dutzler et al., 2002). The C-terminus also contains two cystathione- $\beta$-synthase domains, which regulate gating by binding ATP and ADP to decelerate the kinetics of activation and deactivation (Estévez et al., 2004; Stölting et al., 2013). ClC-2 has a unitary conductance of 2-3 pS and displays strong inward rectification. A remarkable biophysical characteristic of this channel is its slow hyperpolarization-mediated activation at potentials negative to around $-40 \mathrm{mV}$, giving rise to currents that are only very slowly inactivating (Nilius and Droogmans, 2003; Bi et al., 2014). In addition to its hyperpolarization activation, it is sensitive to changes in cell volume and extracellular $\mathrm{pH}$ and is also activated by PKA (Nilius and Droogmans, 2003; Bi et al., 2014). As we have suggested previously for hyperpolarizing electrical signals generated in cECs, $\mathrm{ClC}-2$ is an attractive candidate for mediating membrane repolarization (Garcia and Longden, 2020), in that its slow activation kinetics would enable $\mathrm{K}_{\mathrm{ir}}$-mediated electrical signals to be generated and sent upstream before ClC-2 mediated $\mathrm{Cl}^{-}$current fully develops to repolarize the membrane. Accordingly, $\mathrm{ClC}-2$ may fulfill a similar role in pericytes to initiate membrane repolarization in the wake of electrical signals generated by $\mathrm{K}_{\mathrm{ATP}}$ and $\mathrm{K}_{\mathrm{ir}}$ channels.

\section{FURTHER CHANNELS IN PERICYTES}

Capillary pericytes express an array of other ion channels, including the ubiquitous two-pore channels (TPCs), voltagegated $\mathrm{Na}^{+}\left(\mathrm{Na}_{\mathrm{V}}\right)$ channels, P2X receptors, and acid-sensing ion channels (ASICs; Table 1 and Figure 4). Due to their lower expression and dearth of functional data in capillary pericytes, detailed discussion of these channels is beyond the scope of this review, although we touch briefly upon the function of Piezo1 channels and $\mathrm{P} 2 \mathrm{X}$ receptors.

\section{P2X Receptors}

The ubiquitous purine ATP has received attention as a putative gliotransmitter (Pelligrino et al., 2011) and acts as an endogenous agonist at P2Y GPCRs and the cation-selective ionotropic P2X receptors, permeable to $\mathrm{Na}^{+}, \mathrm{K}^{+}$, and $\mathrm{Ca}^{2+}$ (Khakh et al., 2001).
$\mathrm{P} 2 \mathrm{X}$ receptors are trimmers consisting of intracellular $\mathrm{N}$ - and $\mathrm{C}$ termini, a large extracellular domain containing the ATP binding site, and two transmembrane segments that line an integral ion pore (Kawate et al., 2009). Capillary pericytes express mRNA for P2X1 and P2X4 receptors (Table 1), which have a $p \mathrm{Ca}^{2+} / p \mathrm{Na}^{+}$of $\sim 5$ and 4.2, respectively (Khakh et al., 2001). Thus, pericyte P2X receptors could function as sensors transducing ATP released into the local environment into $\mathrm{Ca}^{2+}$ elevations. Several studies have also suggested $\mathrm{P} 2 \mathrm{X} 7$ receptors are functionally expressed in cultured human and freshly isolated rat retinal pericytes (Kawamura et al., 2003; Sugiyama et al., 2005; Platania et al., 2017), though it should be noted that our expression data do not unambiguously support the expression of this $\mathrm{P} 2 \mathrm{X}$ isoform in CNS pericytes.

\section{Piezo1}

Piezo1 is a large (2,521 amino acids in humans) mechanosensitive cation channel, with three identical subunits, thought to have 38 transmembrane segments, that form a central ion conduction pore with surrounding peripheral domains shaped like propeller blades (Coste et al., 2010; Zhao et al., 2016, 2018; Wu et al., 2017). Functional channels have a single channel conductance of $29 \mathrm{pS}$ and a current that rapidly activates and then decays on a millisecond timescale (Coste et al., 2010, 2015; Zhao et al., 2018). In ECs, piezol can be activated by fluid shear stress, and has been implicated in blood flow regulation, vascular development and remodeling, and permeability (Li et al., 2014; Ranade et al., 2014; Friedrich et al., 2019). Piezo1 may play similar roles in capillary pericytes to mechanosensitive TRP channels in detecting changes in blood flow, vessel diameter, or paravascular fluid shear stress.

\section{A BIRDS-EYE VIEW OF PERICYTE G-PROTEIN COUPLED RECEPTORS}

Pericytes express a huge variety of GPCRs (Table 2 and Figure 4) enabling them to transduce a vast array of extracellular stimuli into intracellular responses. As outlined above, many of the signaling pathways triggered by GPCR signaling impinge upon ion channel activity and thus regulate pericyte $\mathrm{V}_{\mathrm{m}}$ and intracellular $\mathrm{Ca}^{2+}$.

Assessment of the general characteristics of the list of GPCRs expressed by pericytes is revealing. The majority of pericyte GPCRs primarily interact with $\mathrm{G}_{\mathrm{i} / \mathrm{o}} \alpha$ subunits. This is closely followed by $\mathrm{G}_{\mathrm{q}}$-coupled GPCRs, then those that are $\mathrm{G}_{\mathrm{s}}$-coupled, and the remainder couple primarily to $G_{12 / 13}$. Perhaps tellingly, expression of the Gnas gene, encoding the $\mathrm{G}_{\mathrm{s}} \alpha$ subunit, is $\sim 5$ times higher than those collectively encoding $\mathrm{G}_{\mathrm{q} / 11} \alpha$ subunits, more than double that of $G_{i / o} \alpha$ subunit genes, and more than 12 times in excess of $\mathrm{G}_{12 / 13}$ genes (He et al., 2018; Vanlandewijck et al., 2018). Thus, while a wider variety of pericyte receptors may couple to depolarizing, $\mathrm{Ca}^{2+}$-elevating processes, it appears that hyperpolarizing $\mathrm{G}_{\mathrm{s}}$ signaling may be a favored intracellular transduction pathway. 
Around $12 \%$ of the receptor subtypes expressed by pericytes are promiscuous/pleiotropic in their G-protein coupling, the degree of which will depend on the expression levels of the signaling elements involved and their local densities and organization within GPCR signaling platforms. One such example is the highly-expressed $\mathrm{A}_{2 \mathrm{~A}}$ adenosine receptor which couples primarily to $G_{s}$, but also interacts with $G_{q}$ and others (Olah, 1997; Fresco et al., 2004). Such promiscuity could represent an inbuilt feedback mechanism to prevent $\mathrm{V}_{\mathrm{m}}$ being locked at hyperpolarized potentials by $\mathrm{K}^{+}$channel activity, by facilitating recruitment of additional transduction pathways to promote repolarization. In contrast, the promiscuity in signaling exhibited among receptors that couple to $G_{q}, G_{i / o}$, and $\mathrm{G}_{12 / 13}$ would serve to reinforce depolarization. For example, the highly expressed $\mathrm{S}_{1} \mathrm{P}_{3}$ and PAR1 receptors frequently exhibit coupling to not just $\mathrm{G}_{\mathrm{i} / \mathrm{o}}$, but also to both $\mathrm{G}_{\mathrm{q}}$ and $\mathrm{G}_{12 / 13} \alpha$ subunits (Tobo et al., 2007; Means and Brown, 2009; Yue et al., 2012).

At the time of writing, a significant portion of GPCRs expressed by pericytes (Table 2) remain orphan receptors with little functional data available. Strikingly, one such orphan, GPRC5C, is the 4th most robustly expressed GPCR in these cells. Given this lack of data, we omit this group from further discussion.

\section{G-PROTEIN COUPLED RECEPTOR STRUCTURE AND SUBCLASSES}

The GPCR family represents the largest family of mammalian proteins (Lagerström and Schiöth, 2008; Katritch et al., 2014) sharing a common 7-transmembrane topology with an extracellular $\mathrm{N}$-terminus and intracellular C-terminus. Gprotein heterotrimers are organized into four principal categories based on the similarity of function and homology in their $\alpha$ subunits: $G_{s}, G_{i / o}, G_{q / 11}$, and $G_{12 / 13}$ (Simon et al., 1991; Dupré et al., 2009). Broadly, the roles of these $\mathrm{G} \alpha$ subunits are to stimulate/inhibit production of cAMP by adenylate cyclase (AC; $G_{s}$ and $G_{i} / o$, respectively), to activate PLC $\left(G_{q / 11}\right)$, and to activate Rho guanine nucleotide exchange factors (GEFs) $\left(G_{12 / 13}\right)$ (Hanlon and Andrew, 2015). The $G \beta \gamma$ subunit also activates downstream signaling elements and plays a role in GPCR mediated intracellular signaling (Dupré et al., 2009). Below, we outline how signaling through these pathways may modulate the activity of pericyte ion channel activity and consequently $\mathrm{V}_{\mathrm{m}}$ and $\mathrm{Ca}^{2+}$ signaling, and we explore what the GPCRs expressed by pericytes might be able to tell us about NVC mechanisms.

\section{PKA AS A $\mathrm{G}_{\mathrm{s}}-$ AND $\mathrm{G}_{\mathrm{i} / \mathrm{o}}$-CONTROLLED MODULATOR OF ION CHANNEL FUNCTION}

In pericytes, $G_{s}$ stimulation and subsequent PKA engagement is likely to drive phosphorylation of a number of ion channel targets including $\mathrm{K}_{\mathrm{ATP}}$, a range of TRP channels, VDCCs, and $\mathrm{IP}_{3} \mathrm{Rs}-$ modulating their activity and thus $\mathrm{V}_{\mathrm{m}}$ and cellular behavior (Figure 9). $\mathrm{G}_{\mathrm{s}} \mathrm{PCR}$ activation leads to association of the $\mathrm{G} \alpha_{\mathrm{s}}$ subunit with a cleft in the $\mathrm{C} 2$ domain of AC, catalyzing the conversion of ATP to cAMP (Sadana and Dessauer, 2009). cAMP then activates PKA by binding to its two regulatory subunits, inducing the dissociation of two catalytic subunits, enabling their subsequent phosphorylation of downstream targets (SassoneCorsi, 2012). In contrast, $\mathrm{G}_{\mathrm{i} / \mathrm{o}}$ activation inhibits $\mathrm{AC}$, opposing $\mathrm{G}_{\mathrm{s}} \mathrm{PCR}$ activity. Here, $\mathrm{G} \alpha_{\mathrm{i} / \mathrm{o}}$ binds to the $\mathrm{C} 1$ domain of $\mathrm{AC}$ to inhibit enzymatic activity, although this is limited to the AC-I, -V, and -VI isoforms (Sadana and Dessauer, 2009).

\section{$\mathrm{G}_{\mathrm{s}}$-cAMP-PKA Signaling Augments Hyperpolarizing $\mathrm{K}^{+}$Currents in Pericytes}

$\mathrm{K}_{\mathrm{ir}}$ channels are likely key determinants of pericyte $\mathrm{V}_{\mathrm{m}}$, and as noted previously $K_{\text {ATP }}$ channel activity is bidirectionally modulated by cAMP levels. At tonic, low concentrations of cAMP, PKA increases vascular $\mathrm{K}_{\mathrm{ATP}}$ channel activity by phosphorylating multiple sites on the pore-forming and regulatory subunits (Quinn et al., 2004; Shi et al., 2007, 2008b). At higher concentrations, cAMP conversely inhibits $\mathrm{K}_{\mathrm{ATP}}$ channel activity in a $\mathrm{Ca}^{2+}$-dependent manner via engagement of the ubiquitous exchange protein activated by cAMP (Epac)1 (Purves et al., 2009). PKA is preferentially activated by cAMP over Epac1, exhibiting a 30-fold lower $\mathrm{EC}_{50}$ ( $\sim 1$ vs. $30 \mu \mathrm{M}$; Purves et al., 2009). Accordingly, it seems that $\mathrm{G}_{\mathrm{s}}$ activity will preferentially favor membrane hyperpolarization through $\mathrm{K}_{\text {ATP }}$ engagement. Consistent with this, activation of $\mathrm{G}_{\mathrm{s}}$-coupled adenosine receptors leads to a dramatic increase in retinal pericyte $\mathrm{K}^{+}$currents ( $\mathrm{Li}$ and Puro, 2001). High-level accumulation of cAMP might in turn be expected to act as an inbuilt concentration-based feedback mechanism to inhibit the channel through Epac1 engagement.

In addition to such concentration-dependent regulation of channel activity, spatial considerations are important in determining the functional outcome of cAMP elevations. The assembly of ACs and phosphodiesterases into membranebound scaffolds organized around A-kinase anchoring proteins (AKAPs) has been suggested to facilitate the generation of microdomains of cAMP (Arora et al., 2013; Lefkimmiatis and Zaccolo, 2014). Such compartmentalization may facilitate specific, local adjustment of, for example, $\mathrm{K}_{\mathrm{ATP}}$ channel activity in a select part of the cell (e.g., a thin-strand process or around a peg-socket junction in the case of pericytes) without impacting ion channels in other regions.

Complementary to the activation by PKA that $\mathrm{K}_{\mathrm{ATP}}$ channels exhibit, $\mathrm{K}_{\mathrm{ir}} 2.2$ is also positively regulated by PKA (Zitron et al., 2004). Moreover, several $K_{v}$ isoforms expressed by pericytes exhibit PKA sensitivity, in that the activity of $\mathrm{K}_{\mathrm{v}}$ 7.4/7.5 heteromers or $\mathrm{K}_{\mathrm{v}} 7.5$ homomers is potentiated by PKA activation (Mani et al., 2016). $\mathrm{K}_{\mathrm{v}} 2.1$ membrane trafficking is also controlled by a PKA-dependent mechanism (Wu et al., 2015). Collectively, these data suggest a key stimulatory role for $\mathrm{G}_{\mathrm{s}}$-cAMP-PKA signaling in the regulation of pericyte $\mathrm{K}^{+}$ 


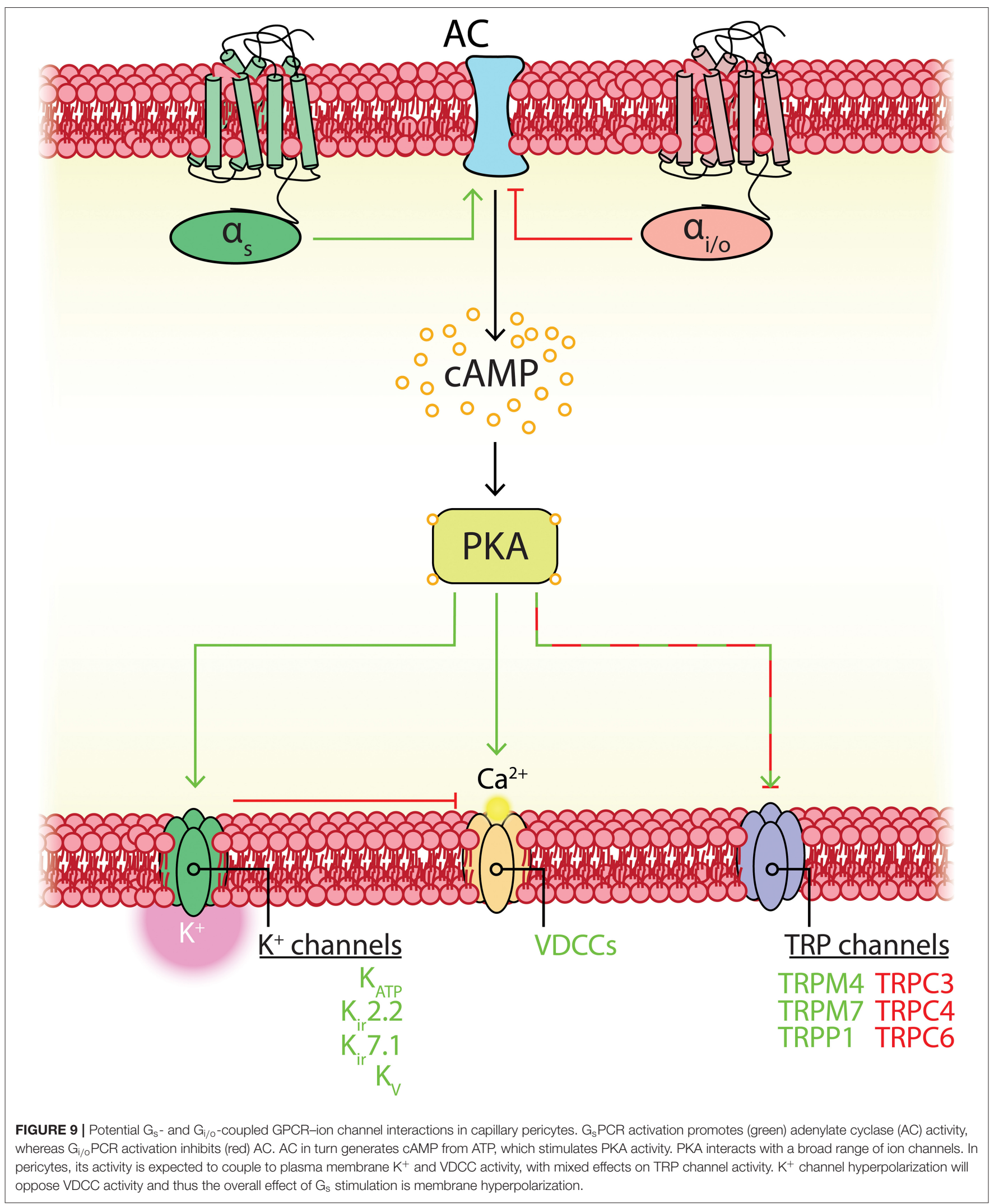


channels, along with potential negative feedback mechanisms to prevent over-activation.

\section{$\mathrm{G}_{\mathrm{s}}$-Mediated Reduction of TRP Channel Activity Complements $\mathrm{K}^{+}$Channel Engagement}

TRP channels are extensively regulated by $\mathrm{G}_{\mathrm{s}}$ activity, and in contrast to $\mathrm{K}^{+}$channels this typically leads to a decrease in activity. Focusing on the TRP isoforms expressed by pericytes, TRPC3, TRPC4, TRPC6, and TRPML1 are all inhibited by PKA phosphorylation (Vergarajauregui et al., 2008; Nishioka et al., 2011; Sung et al., 2011). In contrast, TRPM4 exhibits activation as a result of $\mathrm{G}_{\mathrm{s}}$ stimulation in an Epac1-and $\mathrm{IP}_{3} \mathrm{R}$-mediated $\mathrm{Ca}^{2+}$ release-dependent manner (Mironov and Skorova, 2011), and TRPM7 can also be potentiated by PKA (Takezawa et al., 2004). Phosphorylation of TRPP1 by PKA also increases channel $\mathrm{P}_{\mathrm{o}}$ (Cantero del Rocío et al., 2015).

Thus, regulation of TRP channels via PKA is complex but it appears that this will to lean toward PKA-dependent inhibition of currents in pericytes. This reinforces the notion that engagement of PKA will shift the balance of ion channel activity to favor membrane hyperpolarization via $\mathrm{K}^{+}$channel activity, while reducing $\mathrm{Na}^{+}$and $\mathrm{Ca}^{2+}$ influx via TRP channels.

\section{$\mathrm{G}_{\mathrm{s}}$ Activation May Promote Increases in Intracellular $\mathrm{Ca}^{2+}$}

As noted, augmentation of $\mathrm{Ca}_{\mathrm{v}} 1.2$ is primarily dependent on PKA phosphorylation of Rad to relieve channel inhibition (Liu et al., 2020). PKA phosphoregulation of $\mathrm{Ca}_{\mathrm{v}} 1.2$ is also dependent on the AKAP isoform present in the macromolecular environment of the channel: AKAP15 permits sensitization of the channel whereas calcineurin associated with AKAP79 suppresses PKA-mediated increases in $\mathrm{Ca}_{\mathrm{v}} 1.2$ activity via dephosphorylation (Fuller et al., 2014). scRNAseq data (He et al., 2018; Vanlandewijck et al., 2018) indicate that pericytes express AKAP79 at low levels whilst expressing high levels of AKAP15, suggesting $\mathrm{G}_{\mathrm{s}}$-stimulation in pericytes will favor increases in $\mathrm{Ca}_{\mathrm{v}} 1.2$ channel activity. Along similar lines, an increase in PKA activity induces sensitization of $\mathrm{Ca}_{\mathrm{v}} 1.3$ (Mahapatra et al., 2012), and $\mathrm{Ca}_{\mathrm{v}} 3.1$ currents are augmented in a cAMP/PKAdependent manner (Li et al., 2012). Moreover, the current of $\mathrm{Ca}_{\mathrm{v}} 3.2$ is increased by cAMP, an effect that depends upon AKAP79/150, and its gene expression is also up-regulated by $\mathrm{G}_{\mathrm{s}}$-signaling, suggesting a mechanism for long term T-type VDCC regulation (Liu et al., 2010; Sekiguchi and Kawabata, 2013). Accordingly, PKA activity should increase VDCC channel activity but, due to its voltage-dependence, in the broader context of the pericyte ion channel repertoire this must be weighed against simultaneous increases in activity of multiple $\mathrm{K}^{+}$ channels which will hyperpolarize $V_{\mathrm{m}}$ and keep VDCCs closed.

$\mathrm{IP}_{3}$ Rs also possess phosphorylation sites for PKA (Ferris et al., 1991a; Vanderheyden et al., 2009) and can also be directly influenced by cAMP (Tovey et al., 2010), allowing for direct crosstalk between cAMP and $\mathrm{Ca}^{2+}$ release pathways. Indeed, phosphorylation by PKA induces an increase in sensitivity of the receptor for $\mathrm{IP}_{3}$, promoting $\mathrm{IP}_{3}$-induced $\mathrm{Ca}^{2+}$ release, while
Epac1 activation also potentiates $\mathrm{Ca}^{2+}$ release (Vanderheyden et al., 2009; Mironov and Skorova, 2011).

Drawing all of these threads together, the complement of PKA targets and their relative expression levels in pericytes suggests that the $\mathrm{G}_{\mathrm{s}}$-coupled receptors here likely primarily transduce stimuli into $\mathrm{V}_{\mathrm{m}}$ hyperpolarization, but may in some cases also elevate intracellular $\mathrm{Ca}^{2+}$ via release from stores.

\section{The $\mathrm{G}_{\mathrm{s}}$ Receptor Complement of Pericytes Suggest a Range of Potential Mediators for the Regulation of Blood Flow}

Pericytes express a range of receptors that couple to $\mathrm{G}_{\mathrm{s}}$-of particular note are the adenosine $\mathrm{A}_{2 \mathrm{~A}}$ receptor, the PACAP receptor, $\mathrm{PAC}_{1}$, the prostacyclin IP receptor and the $\mathrm{PTH}-$ type 1 receptor (PTHR1). The expression of these suggests the possibility that their endogenous agonists could be released onto pericytes during neuronal activity to evoke membrane hyperpolarization and electrical signaling to increase blood flow (Figure 6).

The vasodilatory effects of adenosine, an abundant metabolic byproduct, have long been appreciated (Drury and SzentGyörgyi, 1929). In the brain, adenosine is released into the extracellular space by widely-expressed nucleoside transporters, or more commonly accumulates through the extracellular catabolism of ATP by ectonucleotidases (Cunha, 2016). Recent in vivo work showing a reliable correlation between extracellular adenosine accumulation and rapid increases in local $\mathrm{O}_{2}$ suggest that adenosine is capable of acting as a neurovascular coupling mediator (Wang and Venton, 2017), and clear links have been established between sensory stimulation, adenosine receptor engagement, and increases in cerebral blood flow (Ko et al., 1990; Dirnagl et al., 1994). The precise cellular and molecular mechanisms underlying this linkage remain to be determined, and actions through pericyte adenosine receptors are a strong candidate for mediating these effects.

Considering prostanoids also, blockade of $\mathrm{G}_{\mathrm{s}}$-coupled IP receptors impairs neuronal activity-evoked vasodilation (Lacroix et al., 2015), which suggests a role for the classic vasodilator prostacyclin-produced in the same metabolic pathway as $\mathrm{PGE}_{2}$-in NVC. This possibility remains little explored, but the expression of IP receptors in pericytes provides a potential target for capillary endothelium-generated prostacyclin.

PACAP is a 27 - or 38 -amino acid neuropeptide that is an extremely potent vasodilatory agent (Koide et al., 2014). PACAP polypeptides are produced throughout the brain where they act as neurotransmitters and also have neurotrophic effects. These peptides are released by both neurons and astrocytes during activity and thus PACAP accumulation in the paravascular space could feasibly activate pericyte $\mathrm{G}_{\mathrm{s}}$-coupled $\mathrm{PAC}_{1}$ receptors (Johnson et al., 2020), warranting further exploration of their potential involvement in NVC.

Finally, PTHR1 binds the endocrine ligand PTH and the paracrine ligand PTH-related protein-1 (PTHrP1) (Vilardaga et al., 2011). Intriguingly, PTH binding to PTHR1 triggers sustained and prolonged cAMP production by retaining the intact ligand-receptor complex even after 
endocytosis (Ferrandon et al., 2009). This could have important implications for pericyte $\mathrm{G}_{\mathrm{s}}$ signaling if $\mathrm{PTH}$ is released during neuronal activity.

\section{$\mathrm{G}_{\mathrm{i} / \mathrm{o}}$-Coupled $\mathrm{P}_{2} \mathrm{Y}_{14}$ Receptor Signaling May Impart Sensitivity to Local Metabolic Substrate Availability}

The purinergic family $\mathrm{P}_{2} \mathrm{Y}_{14}$ receptor is the most robustly expressed GPCR in pericytes. This receptor signals through $\mathrm{G}_{\mathrm{i} / \mathrm{o}}$ and is activated by uridine diphosphate (UDP) and nucleotide sugars-most potently by UDP-glucose (Harden et al., 2010). UDP-glucose is synthesized from glucose and acts as a glucose donor in the synthesis of glycogen, which is present at modest levels in the brain (Leloir et al., 1959; Breckenridge and Crawford, 1960; Öz et al., 2015). This and related nucleotide sugars also act as donors for glycosylation in the ER lumen and Golgi apparatus (Berninsone and Hirschberg, 1998), and as a consequence these molecules are thought to be released under basal and simulated conditions from a broad range of cells, primarily through vesicular transport accompanying glycoconjugate delivery to the cell membrane (Harden et al., 2010; Lazarowski, 2012). The released nucleotide sugars have been hypothesized to act in an autocrine or paracrine manner on local $\mathrm{P}_{2} \mathrm{Y}_{14}$ receptors (Lazarowski and Harden, 2015), and as the hydrolyzation of UDP-glucose is three times slower than that of ATP, this has been suggested to result in long-duration signaling (Lazarowski, 2006). As its synthesis is dependent on glucose, we speculate that UDP-glucose signaling through $\mathrm{P}_{2} \mathrm{Y}_{14}$ may function to notify pericytes of local energy substrate availability: in conditions of ample glucose, UDP-glucose maintains activity of $\mathrm{P}_{2} \mathrm{Y}_{14}$, which through $\mathrm{G}_{\mathrm{i} / \mathrm{o}}$ signaling would counterbalance cAMP generation and prevent PKA activation of $\mathrm{K}_{\mathrm{ATP}}$ and other $\mathrm{K}^{+}$channels. In the event that glucose levels fall, such as during neuronal activity (Hu and Wilson, 1997; Paulson et al., 2010; Li and Freeman, 2015; Pearson-Leary and McNay, 2016) or in situations of metabolic stress, the loss of this negative feedback could be relieved, leading to cAMP elevations and engagement of $\mathrm{K}_{\mathrm{ATP}}$ and other $\mathrm{K}^{+}$ channels to increase blood flow and replenish local glucose.

\section{mGluR $_{3}$ and mGluR $_{7}$ May Impart Glutamate Sensing Capabilities to Pericytes}

The $G_{i / o}$-coupled metabotropic glutamate receptors mGluR $_{3}$ and $\mathrm{mGluR}_{7}$ are both localized in presynaptic terminals of GABAergic and glutamatergic synapses, and $\mathrm{mGluR}_{3}$ is also found in glia (Harrison et al., 2008; Palazzo et al., 2016). Like other mGluRs, these receptors contain a large $\mathrm{N}$-terminal venus flytrap domain with a glutamate binding site that dimerizes with that of neighboring mGluRs. GGluR $_{7}$ has a comparatively low affinity for glutamate and is thus activated only by its accumulation at high extracellular concentrations, but is also activated by elevations of intracellular $\mathrm{Ca}^{2+}$ through $\mathrm{CaM}$ interactions with its C-terminal tail. In neurons activity of these receptors exerts a hyperpolarizing influence that depresses synaptic activity through the lowering of cAMP, activation of G protein-coupled $\mathrm{K}_{\mathrm{ir}}$ (GIRK) channels and the inhibition of VDCCs (Niswender and Conn, 2010). Pericytes do not express
GIRKs, but they do express a range of VDCCs (Table 1). Thus, although the physiological roles of mGluRs in pericytes remain to be ascertained, their expression here implies that any glutamate elevations in the vicinity of pericytes could drive cAMP inhibition via $\mathrm{mGluR}_{3}$ and $\mathrm{mGluR}_{7}$ activation, and a reduction in $\mathrm{Ca}^{2+}$ entry via VDCCs.

\section{PKC TARGETS: $G_{q}$-DEPENDENT MODULATION OF PERICYTE ION CHANNELS}

Activation of the $\mathrm{G}_{\mathrm{q}} \alpha$ subunit stimulates phospholipase C (PLC), which mediates the conversion of membrane phospholipids to DAG and $\mathrm{IP}_{3}$, inducing $\mathrm{PKC}$ activation and $\mathrm{Ca}^{2+}$ release, respectively, which may affect a broad range of ion channels (Figure 10). We focus below on the ramifications of PKC signaling.

\section{$\mathrm{G}_{\mathrm{q}}$-DAG-PKC Signaling Will Promote Depolarizing Currents in Pericytes}

Activated PKC phosphorylates a diverse range of ion channels and is thus capable of exerting considerable influence on $\mathrm{V}_{\mathrm{m}}$. PKCs are divided into three subfamilies depending on their activation requirements: conventional $\mathrm{PKC}$ require DAG, $\mathrm{Ca}^{2+}$ and a phospholipid for activation; novel PKCs require DAG but are independent of $\mathrm{Ca}^{2+}$; atypical PKCs require neither of these (Newton, 2010). CNS capillary pericytes express PKC isoforms from each of these subfamilies (Table 3 ).

All three $\mathrm{IP}_{3} \mathrm{R}$ isoforms can be phosphorylated by PKC. PKC phosphorylation of $\mathrm{IP}_{3} \mathrm{R} 1$ is potentiated by prior phosphorylation by PKA and increases $\mathrm{Ca}^{2+}$ release (Ferris et al., 1991a,b; Vermassen et al., 2004; Vanderheyden et al., 2009). In contrast, $\mathrm{IP}_{3} \mathrm{R} 2$ and $\mathrm{IP}_{3} \mathrm{R} 3$ are each inhibited by $\mathrm{Ca}^{2+}$-sensitive, conventional PKCs (Arguin et al., 2007; Caron et al., 2007).

$\mathrm{K}_{\mathrm{ir}}$ channels are also extensively regulated by $\mathrm{PKC}$, where phosphorylation inhibits $\mathrm{K}_{\mathrm{ir}} 6.1$-containing $\mathrm{K}_{\mathrm{ATP}}$ channels, contrasting starkly with the stimulatory effects of PKA. This phosphorylation is graded-multiple serine residues (ser$354,-379,-385,-397$, and -397 in the $\mathrm{K}_{\mathrm{ir}} 6.1$ C-terminal domain) can be phosphorylated, and the degree of inhibition is proportional to the number of these sites that receive a phosphoryl group from PKC (Shi et al., 2008b). In pericytes this graded response to $\mathrm{PKC}$ for the highly expressed $\mathrm{K}_{\mathrm{ATP}}$ channel could provide a means to fine tune activity, by permitting the degree of local $\mathrm{G}_{\mathrm{q}}$ signaling to oppose the stimulatory effects or PKA or ATP depletion. PKC also regulates the membrane density of $\mathrm{K}_{\mathrm{ir}} 6.1$, in that the $\mathrm{PKC} \varepsilon$ isoform induces internalization of the receptor in a caveolin-dependent manner (Jiao et al., 2008), providing another avenue to decrease $\mathrm{K}_{\mathrm{ATP}}$ channel activity. Likewise, $\mathrm{K}_{\mathrm{ir}} 2.2$ has multiple sites that inhibit channel current upon phosphorylation by $\mathrm{PKC}$, but the graded $\mathrm{PKC}$ phosphorylation observed for $\mathrm{K}_{\mathrm{ir}} 6.1$ is absent (Kim et al., 2015; Scherer et al., 2016).

TRP channels are subject to complex regulation by $\mathrm{G}_{\mathrm{q}}$ activity, with important roles for DAG, detailed above, and 





TABLE 3 | Expression of PKC isoforms in brain capillary pericytes, and their modes of activation and regulation.

\begin{tabular}{|c|c|c|c|c|c|c|c|}
\hline PKC isoform & Gene name & $\begin{array}{c}\text { Average } \\
\text { counts/cell } \\
\text { (annotated as } \\
\text { a pericyte) }\end{array}$ & Class & $\mathrm{Ca}^{2+}$ activation & DAG activation & $\begin{array}{c}\text { Phospholipid } \\
\text { activation }\end{array}$ & $\begin{array}{c}\text { Regulation by } \\
\text { arachidonic } \\
\text { acid }\end{array}$ \\
\hline$P K C-\alpha$ & Prkca & 6.57 & Conventional & Yes & Yes & Yes & + \\
\hline PKC- $\beta 1$ & Prkcb & 17,15 & Conventional & Yes & Yes & Yes & + \\
\hline PKC- $\beta 2$ & Prkcb & & Conventional & Yes & Yes & Yes & + \\
\hline PKC- $\gamma$ & Prkcg & 13.19 & Conventional & Yes & Yes & Yes & + \\
\hline PKC- $\delta$ & Prkcd & 5.93 & Novel & No & Yes & No & - \\
\hline PKC- $\varepsilon$ & Prkce & 6.65 & Novel & No & Yes & No & Insensitive \\
\hline$P K C-\eta$ & Prkch & 1.25 & Novel & No & Yes & No & + \\
\hline PKC- $\theta$ & Prkcq & 0.04 & Novel & No & Yes & No & Insensitive \\
\hline PKC-ı & Prkci & 22.30 & Atypical & Insensitive & Insensitive & Yes & Insensitive \\
\hline PKC- $\zeta$ & Prkcz & 0.06 & Atypical & Insensitive & Insensitive & Yes & Insensitive \\
\hline
\end{tabular}

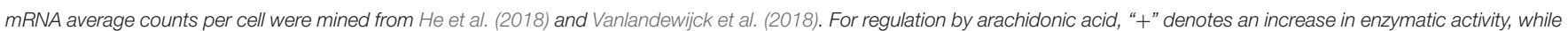
"-" represents a decrease in enzymatic activity.

PKC. TRPC3 and TRPC6 in particular are inhibited by PKC despite activation by other elements of the $\mathrm{G}_{\mathrm{q}}$ signaling cascade (Bousquet et al., 2010; Earley and Brayden, 2015), and TRPC1 is in contrast activated by PKC (Xiao et al., 2017). TRPM4 can be phosphorylated by PKC to sensitize the receptor to $\mathrm{Ca}^{2+}$ (Nilius et al., 2005), which augments $\mathrm{Na}^{+}$entry in response to subsequent local $\mathrm{Ca}^{2+}$ elevations.

$\mathrm{Ca}_{\mathrm{v}} 1.2$ currents are enhanced by phosphorylation at Ser1928 by $\mathrm{PKC}$ isoforms from each subfamily (PKC $\alpha, \mathrm{PKC} \varepsilon$, and $\mathrm{PKC} \zeta$ ), permitting a broad range of conditions to regulate VDCC activity (Yang et al., 2005). As pericytes express members of all three subfamilies of PKC, regulation of $\mathrm{Ca}_{\mathrm{v}} 1.2$ activity may be similarly robust in these cells. $\mathrm{Ca}_{\mathrm{v}} 1.2$ surface expression is also increased within minutes of $\mathrm{G}_{\mathrm{q}}$ stimulation via a PKC-dependent increase in channel trafficking to the plasma membrane (Raifman et al., 2017). In contrast, $\mathrm{Ca}_{\mathrm{v}} 1.3$ is negatively regulated by both conventional and atypical PKC isoforms (PKC $\beta 2$ and the PKC $\varepsilon$, respectively), both of which are expressed in CNS pericytes (Table 3). As for T-type channels, $\mathrm{Ca}_{\mathrm{v}} 3.1$ activity is stimulated by PKC phosphorylation, independently of trafficking (Park et al., 2006), and $\mathrm{Ca}_{\mathrm{v}} 3.2$ is negatively regulated by $\mathrm{Ca}^{2+}$-independent $\mathrm{PKC} \eta$ phosphorylation (Zhang Y. et al., 2018), although PKC $\eta$ is absent in pericytes.

PKC $\alpha$ also activates CaCCs to promote $\mathrm{Cl}^{-}$efflux, where phosphorylation shifts the $\mathrm{EC}_{50}$ of intracellular $\mathrm{Ca}^{2+}$ from 349 to $63 \mathrm{nM}$ for channel activation at $-80 \mathrm{mV}$ (Dutta et al., 2016).

Pulling these threads together, it seems that PKC activation as a result of $G_{q}$ activity in pericytes will contrast with the effects of $\mathrm{G}_{\mathrm{s}}$-cAMP-PKA signaling by enhancing activity of depolarizing ion channels such as VDCCs, TRP channels, and CaCCs while inhibiting hyperpolarizing channels such as $K_{\text {ATP }}$ and $K_{i r}$. Given that $\mathrm{G}_{\mathrm{q}}$ activity also induces the release of $\mathrm{Ca}^{2+}$ from intracellular stores via $\mathrm{IP}_{3} \mathrm{Rs} \mathrm{Ca}^{2+}$-sensitive $\mathrm{PKC}$ activation may act as a further amplification loop to increase the signal:noise ratio of $\mathrm{G}_{\mathrm{q}}$ signaling and promote $\mathrm{Ca}^{2+}$ accumulation and depolarization.

\section{Thromboxane and $\mathrm{ET}_{\mathrm{A}}$ Receptors Are $\mathrm{G}_{\mathbf{q}}$-Coupled Mediators of SMC Constriction That Are Robustly Expressed by Capillary Pericytes}

The $\mathrm{G}_{\mathrm{q}}$-coupled thromboxane (TP) receptor is well-known to induce vasoconstriction by SMCs (Dorn and Becker, 1993) and contractile mural cells of 1 st -4 th order vessels (Mishra et al., 2016). The TP receptor's endogenous agonists include a range of eicosanoid lipids that are generated from arachidonic acid (AA), which is initially mobilized from membrane phospholipid pools by the action of $\mathrm{Ca}^{2+}$-dependent phospholipase $\mathrm{A}_{2}$ ( $\mathrm{PLA}_{2}$; Balsinde et al., 2002). Subsequently, cyclooxygenase or prostaglandin $\mathrm{H}_{2}\left(\mathrm{PGH}_{2}\right)$ synthase enzymes convert AA to $\mathrm{PGH}_{2}$, a potent agonist of the TP receptor. Further processing of $\mathrm{PGH}_{2}$ yields thromboxane- $\mathrm{A}_{2}\left(\mathrm{TxA}_{2}\right)$, a still more potent agonist (Bos et al., 2004; Woodward et al., 2011). Alternatively, AA can be shuttled down a cytochrome P450 $\omega$-hydroxylase pathway to generate the TP agonist 20-HETE (Miyata and Roman, 2005). The contractile influence of 20-HETE has been suggested to play a major role in determining the diameter of cerebral arterioles and thus controlling brain blood flow (Attwell et al., 2010), and the activation of TP receptors has also been suggested to cause mild, slow contractions of capillary pericytes (Fernández-Klett et al., 2010). It is unknown whether pericyte TP receptors are basally active to produce this effect in vivo, but subtle changes in capillary diameter induced by this process could regulate local blood flow over the long term, dependent on the local levels of these agonists.

The $\mathrm{ET}_{\mathrm{A}}$ receptor shares broad similarities with the $\mathrm{TP}$ receptor. Its principal transduction pathway is also $\mathrm{G}_{\mathrm{q}}$-although coupling to other $G$ proteins such as $G_{12 / 13}$ has been notedand similar to the TP receptor, its activation evokes robust SMC contractions (Sokolovsky, 1995; Horinouchi et al., 2013; Davenport et al., 2016). The agonist of the $\mathrm{ET}_{\mathrm{A}}$ receptor, Endothelin-1, is constitutively released by ECs, SMCs, neurons and astrocytes (Russell and Davenport, 1999; Thorin and Webb, 
2010; Freeman et al., 2014). In culture, release of endothelin-1 from ECs has been noted to drive changes in pericyte morphology through reorganization of F-actin and intermediate filaments (Dehouck et al., 1997), suggesting that ECs could regulate their coverage by pericyte processes through $\mathrm{ET}_{\mathrm{A}}$ signaling. In the context of Alzheimer's disease, aberrant $\mathrm{ET}_{\mathrm{A}}$ signaling caused by amyloid $\beta$ accumulation results in capillary constriction by overlying pericytes which may limit oxygen and glucose delivery to the parenchyma (Nortley et al., 2019).

As described above, signaling through these receptors is expected to oppose $\mathrm{G}_{\mathrm{s}}$-cAMP-PKA signaling while promoting membrane depolarization and elevation of $\mathrm{Ca}^{2+}$.

\section{Crosstalk and Control of G Protein Signaling Pathways}

The preceding discussion illustrates that many channels expressed by pericytes are differentially regulated by PKA and PKC phosphorylation, and thus their activity will depend in part on the balance of activity between these pathways. Crosstalk between these pathways also occurs at the level of effectors, in addition to ultimate phosphorylation targets. For example, the $\mathrm{G}_{\mathrm{q}}$ and $\mathrm{G}_{\mathrm{i} / \mathrm{o}}$ pathways oppose the $\mathrm{G}_{\mathrm{s}}$ pathway at the level of $\mathrm{AC}$, which can be $\mathrm{Ca}^{2+}$ sensitive and modulated by PKC, dependent on isoform (Chern, 2000). Indeed, the most highly expressed $\mathrm{AC}$ isoform in brain pericytes is ACVI (Table 4), which is regulated by $\mathrm{PKC}, \mathrm{G}_{\mathrm{i} / \mathrm{o}}, \mathrm{Ca}^{2+}$, and $\mathrm{G} \beta \gamma$ (Chern, 2000; Sadana and Dessauer, 2009). This regulation is mirrored for $\mathrm{G}_{\mathrm{s}}$ acting on the $\mathrm{G}_{\mathrm{q}}$ pathway, where PKA can directly inhibit the activity of PLC via phosphorylation (Nalli et al., 2014). Accordingly, $\mathrm{G}_{\mathrm{s}^{-}}$ and $\mathrm{G}_{\mathrm{q}}$-coupled receptors functionally oppose one another at multiple levels of their transduction pathways, which will help push the membrane potential toward either hyperpolarization or depolarization, respectively.

Another layer of control is provided by regulators of GPCR signaling (RGS) - small proteins that regulate the duration and intensity of GPCR signaling by driving GTPase activity of the $\mathrm{G} \alpha$ subunit and accelerating the hydrolysis of GTP, thereby

TABLE 4 | Expression of isoforms of adenylate cyclase (AC) by CNS pericytes.

\begin{tabular}{lcc}
\hline AC isoform & Gene name & $\begin{array}{c}\text { Average counts/cell } \\
\text { (annotated as a pericyte) }\end{array}$ \\
\hline AC-I & Adcy1 & 0.79 \\
AC-II & Adcy2 & 0.31 \\
AC-III & Adcy3 & 15.18 \\
AC-IV & Adcy4 & 11.33 \\
AC-V & Adcy5 & 8.27 \\
AC-VI & Adcy6 & 89.98 \\
AC-VII & Adcy7 & 1.34 \\
AC-VIII & Adcy8 & 0.05 \\
AC-IX & Adcy9 & 55.32 \\
AC-X & Adcy10 & 0.34 \\
\end{tabular}

mRNA average counts per cell were mined from He et al. (2018) and Vanlandewijck et al. (2018). inactivating their target (Ross and Wilkie, 2000; Kach et al., 2012). Capillary pericytes express high levels of RGS4 and 5 (Bondjers et al., 2003; He et al., 2018; Vanlandewijck et al., 2018) that act as GTPase activating proteins for $\mathrm{G}_{\mathrm{i} / \mathrm{o}}$ and $\mathrm{G}_{\mathrm{q} / 11}$ subunits, while seemingly sparing $\mathrm{G}_{\mathrm{s}}$ (Berman et al., 1996; Watson et al., 1996; Hepler et al., 1997; Huang et al., 1997; Cho et al., 2003; Gunaje et al., 2011). Intriguingly, RGS4 is known to be phosphorylated by PKA and PKG, which stimulate its activity, accelerating the deactivation of $\mathrm{G}_{\mathrm{q} / 11}$ and inhibiting the hydrolysis of phosphoinositide to $\mathrm{IP}_{3}$ (Huang et al., 2007). Therefore, RGS engagement in pericytes may complement and amplify the hyperpolarizing effects of $\mathrm{G}_{\mathrm{s}}$ signaling by stifling the depolarizing influences of $\mathrm{G}_{\mathrm{i} / \mathrm{o}}$ and $\mathrm{G}_{\mathrm{q} / 11}$.

\section{RhoA TARGETS: $\mathrm{G}_{12 / 13}$-SIGNALING}

Capillary pericytes express several $\mathrm{G}_{12 / 13}$-coupled receptors, including a range of lysophospholipid receptors with important roles in lipid signaling, the promiscuous protease activated receptor PAR1, and several orphan receptors (Table 2). $\mathrm{G}_{12 / 13}$ activation couples to a number of interacting partners including cadherins, AKAPs, non-receptor tyrosine kinases and protein phosphatases, though its interaction with Ras homolog family member A (RhoA) is the best characterized (Worzfeld et al., 2008). In SMCs, RhoA engagement of its downstream effector Rho-associated kinase is known to contribute to a range of receptor-mediated contractile responses (Swärd et al., 2003).

RhoA is also frequently observed to be activated downstream of ion channel engagement, including TRPC6 and TRPM7 channels (Canales et al., 2019) and VDCCs (Fernández-Tenorio et al., 2011). RhoA modulating ion channel activity is less frequently reported, but RhoA may indirectly modulate $\mathrm{V}_{\mathrm{m}}$ on slow time scales by promoting the endocytosis and translocation of channels such as $\mathrm{K}_{\mathrm{v}} 1.2, \mathrm{IP}_{3} \mathrm{Rs}$, and TRPC1 (Mehta et al., 2003; Mayor and Pagano, 2007; Stirling et al., 2009) and possibly $\mathrm{K}_{\mathrm{ATP}}$ channels (Foster and Coetzee, 2015). Effects of RhoA on $\mathrm{K}_{\mathrm{ir}} 2.1$ channel activity have also been reported, although the mechanistic details of this interaction have not been fully clarified (Jones, 2003).

\section{G $\beta \gamma$ SIGNALING AND PERICYTE FUNCTION}

Initially, the $G \beta \gamma$ subunit was viewed as a negative regulator of the $\mathrm{G} \alpha$ subunit, serving to increase signal:noise ratio and specificity of signaling by preventing aberrant $\mathrm{G} \alpha$ activity in the absence of an agonist, but has since been found to be an active effector in its own right (Dupré et al., 2009), and may play important roles in pericyte physiology. G $\beta \gamma$ interacts with a range of canonical effectors (for example PLC $\beta$, AC, GIRKs; Chern, 2000; Smrcka, 2008) along with a growing list of non-canonical effectors such as mitochondrial ATP synthase, a range of nuclear transcription factors, cytoskeletal regulators involved in motility, and constituents of the extracellular signal regulated kinase (ERK) pathway. These interactions implicate $\mathrm{G} \beta \gamma$ in signaling roles as diverse as regulation of transcriptional 
activity, modulation of mRNA processing, control of nuclear import/export, cell motility, and oxidative phosphorylation (Khan et al., 2016). In addition to regulation of AC VI (Sadana and Dessauer, 2009) - the most highly expressed pericyte AC isoform (Table 4) - G $\beta \gamma$ signaling may also exert direct effects on pericyte $V_{m}$ through activation of $K_{v} 7.4$ (Stott et al., 2015). In contrast $\mathrm{Ca}_{\mathrm{v}} 2.1, \mathrm{Ca}_{\mathrm{v}} 3.2$, and TRPM3 can be inhibited through G $\beta \gamma$-dependent mechanisms (Hu et al., 2009; Zamponi and Currie, 2013; Alkhatib et al., 2019).

\section{PERICYTE GPCRs THAT COUPLE TO MULTIPLE G PROTEINS}

The previously discussed GPCRs are largely selective in their G protein coupling, allowing for precise intracellular signaling in response to a range of stimuli. However, many GPCRs that are highly expressed in pericytes are capable of signaling through multiple $\mathrm{G}$ proteins. This may represent pleiotropyphysiological activation of different $G$ proteins in response to differing signals-or promiscuity, i.e., engaging in non-preferred $\mathrm{G}$ protein interactions due to high levels of receptor expression or excessive stimulation (Maudsley et al., 2005). Here, we review examples of highly-expressed pericyte GPCRs with a tendency to couple to multiple $\mathrm{G}$ proteins.

\section{S1P Receptors}

Sphingosine-1-phosphate (S1P) is a lipid mediator formed through the action of ceramidase on lipids of the plasma membrane (Ksiazek et al., 2015). S1P is constitutively released by erythrocytes and its plasma concentration strongly correlates with hematocrit (Selim et al., 2011; Ksiazek et al., 2015). The transporter-mediated release of S1P from ECs has also been documented (Kerage et al., 2014) along with the export of the enzyme that catalyzes its formation, sphingosine kinase (Ancellin et al., 2002). This leads to S1P signaling in the vasculature, which is particularly important for maintenance of the $\mathrm{BBB}$ (Janiurek et al., 2019), vasoconstriction (Salomone et al., 2010), angiogenesis, and regulation of vascular tone at the level of arterioles (Kerage et al., 2014).

Pericytes are ideally positioned to sense the release of S1P from local ECs. The actions of S1P are mediated through a family of receptors that act through $\mathrm{G}_{\mathrm{i} / \mathrm{o}}, \mathrm{G}_{\mathrm{q}}$, and $\mathrm{G}_{12 / 13}$ signaling, with $\mathrm{S}_{1} \mathrm{P}_{2}$ and the robustly expressed $\mathrm{S}_{1} \mathrm{P}_{3}$ coupling to each of these (Means and Brown, 2009). Accordingly, S1P sensed by pericytes is expected to promote PLC engagement, $\mathrm{Ca}^{2+}$ elevations, a fall in cAMP, and depolarization, but further information as to the physiological roles of signaling through these receptors awaits experimental attention. As pericytes are critical for the maintenance of blood-brain barrier tightness (Armulik et al., 2010), it is possible that S1P signaling contributes to this process. $\mathrm{S} 1 \mathrm{P}$ signaling also strengthens contact between ECs and pericytes in culture through a mechanism involving the trafficking and activation of the adhesion molecule $\mathrm{N}$-cadherin by ECs (Paik et al., 2004), and it is thus possible that this is mirrored in pericytes to contribute to this interaction and maintain pegsocket junctions.

\section{PAR1 May Regulate Pericyte Thin-Strand Processes}

Protease-activated receptor (PAR) 1 is a member of the PAR family and is stimulated by external proteases such as thrombin and trypsin. The proteolytic action of these enzymes on the extracellular domain of the receptor reveal an $\mathrm{N}$ terminal tethered ligand sequence, exposure of which results in irreversible activity of the receptor that is halted only by its internalization (Soh et al., 2010). PARs are broadly expressed in the neurovascular unit, found in neurons, glia, ECs and SMCs, as well as pericytes. PAR1 couples to $\mathrm{G}_{\mathrm{q}}, \mathrm{G}_{\mathrm{i} / \mathrm{o}}$, and $\mathrm{G}_{12 / 13}$, and while the release or activation of agonists for these receptors is typically associated with injury or inflammatory responses (Ma and Dorling, 2012; Yue et al., 2012), they have also been implicated in cell proliferation and differentiation, synaptic plasticity (Noorbakhsh et al., 2003), and driving vasodilation (Villari et al., 2017). Interestingly, thrombin signaling regulates morphology of fine processes in astrocytes through RhoA, and similar effects have been noted in neurons (Noorbakhsh et al., 2003). In line with this, it is possible that PAR1 signaling regulates the dynamics of pericyte process extension and retraction on capillaries (Berthiaume et al., 2018).

\section{FRIZZLED AND ADHESION GPCRs IN PERICYTES}

Finally, pericytes also express a range of members of the frizzled family of GPCRs. These are receptors for Wnt proteins, and G-protein coupling is of less importance in this group. Instead, canonical frizzled signaling occurs through the $\beta$-catenin pathway (MacDonald et al., 2009), but G protein coupling through signaling platforms assembled around the FZD-associated phosphoprotein Disheveled is also possible. The latter facilitates activation of $\mathrm{G}_{\mathrm{q}}$ - and $\mathrm{G}_{\mathrm{i} / \mathrm{o}}$-proteins to produce $\mathrm{Ca}^{2+}$ elevations and PKC engagement (Schulte, 2010; Kilander et al., 2014). Further research is required to infer the functional implications of pericyte expression of frizzled receptors, but developmental and homeostatic roles seem likely, as these are major aspects of Wnt signaling (Yang, 2012). Low levels of the adhesion class cadherin EGF lag seven pass receptors (CELSR)2 are also seen in pericytes.

\section{CONTROL OF PERICYTE $V_{m}$ BY PERICYTE ION CHANNELS AND GPCRS-CONCLUSIONS AND FUTURE PERSPECTIVES}

The ion channels and GPCRs expressed by capillary pericytes represent a toolkit for the dynamic control of pericyte membrane potential and function. Among a panoply of roles for these signaling elements, the robust expression of genes encoding $\mathrm{K}^{+}$channels and $\mathrm{G}_{\mathrm{s}}$ PCRs and their second messenger components implies an important role for pericyte membrane hyperpolarization, which we suggest contributes to long-range electrical signaling to control blood flow (Figure 6). Importantly, 
disturbances in blood flow and the processes that regulate it are increasingly appreciated to play a key role in a variety of pathological conditions. These include dementias such as Alzheimer's disease (AD) (Alsop et al., 2000; Iadecola, 2004; Nicolakakis and Hamel, 2011; Iturria-Medina et al., 2016), small vessel disease of the brain (Dabertrand et al., 2015; Capone et al., 2016; Huneau et al., 2018), psychological conditions such as schizophrenia (Mathew et al., 1988; Zhu et al., 2017) and chronic stress (Longden et al., 2014; Han et al., 2019), plus diabetes (Mogi and Horiuchi, 2011; Vetri et al., 2012), hypertension (Girouard and Iadecola, 2006; Capone et al., 2012), and stroke (Girouard and Iadecola, 2006; Koide et al., 2012; Balbi et al., 2017), and pericytes appear to be exceptionally sensitive to pathological perturbations (Winkler et al., 2011).

The ion channels and GPCRs that are highly expressed by brain pericytes thus have the potential to be pharmacological targets for vascular disorders, metabolic diseases, and neurodegenerative and neurological disorders (wherein for example $\mathrm{K}_{\mathrm{ATP}}$ channels, $\mathrm{IP}_{3} \mathrm{Rs}$, VDCCs, TRP channels, and GPCRs such as $\mathrm{A}_{2 \mathrm{~A}}$ and $\mathrm{ET}_{\mathrm{A}}$ receptors have been implicated, to name but a few; Hübner and Jentsch, 2002; Jacobson and Gao, 2006; Nilius et al., 2007; Ohkita et al., 2012; Aziz et al., 2014; Mikoshiba, 2015). Thus, furthering our understanding of the mechanisms through which pericytes contribute to blood flow control in the brain is a critical step in the search for ways in which to prevent decline or restore function in these disease contexts. The data we have discussed underscore that we are at an early stage in our understanding of how pericyte ion channels and GPCRs contribute to these functions, and warrant further studies to reveal novel mechanisms and therapeutic targets.

In the future, it will be important to determine the precise effects of both hyperpolarization and depolarization on pericyte functional outputs, for which optogenetic technologies or

\section{REFERENCES}

Adams, P. J., Garcia, E., David, L. S., Mulatz, K. J., Spacey, S. D., and Snutch, T. P. (2009). $\mathrm{Ca}_{v} 2.1 \mathrm{P} / \mathrm{Q}$-type calcium channel alternative splicing affects the functional impact of familial hemiplegic migraine mutations: implications for calcium channelopathies. Channels 3, 110-121. doi: 10.4161/chan.3. 2.7932

Adelman, J. P., Maylie, J., and Sah, P. (2012). Small-conductance Ca $\mathrm{Ca}^{2+}$ activated $\mathrm{K}^{+}$channels: form and function. Annu. Rev. Physiol. 74, 245-269. doi: 10.1146/annurev-physiol-020911-153336

Alarcon-Martinez, L., Yilmaz-Ozcan, S., Yemisci, M., Schallek, J., Kil,iç, K., Can, A., et al. (2018). Capillary pericytes express $\alpha$-smooth muscle actin, which requires prevention of filamentous-actin depolymerization for detection. Elife 7:e34861. doi: 10.7554/eLife.34861.017

Albert, A. P. (2011). "Gating mechanisms of canonical transient receptor potential channel proteins: role of phosphoinositols and diacylglycerol," in Transient Receptor Potential Channels. Advances in Experimental Medicine and Biology, ed M. Islam (Dordrecht: Springer), 391-411. doi: 10.1007/978-94-007-0265-3_22

Alexander, S. P. H., Christopoulos, A., Davenport, A. P., Kelly, E., Mathie, A., Peters, J. A., et al. (2019). The concise guide to pharmacology 2019/20: G protein-coupled receptors. Br. J. Pharmacol. 176, S21-S141. doi: 10.1111/bph.14748

Al-Karagholi, M. A.-M., Ghanizada, H., Nielsen, C. A. W., Ansari, A., Gram, C., Younis, S., et al. (2020). Cerebrovascular effects of glibenclamide investigated traditional electrophysiological approaches (Zhang et al., 2011) can be leveraged. At a deeper level, questions regarding the organization of pericyte ion channels and GPCRs await exploration-are these organized into macromolecular signaling complexes to facilitate privileged communication between complementary molecular players? Are these elements concentrated at sites to optimize cell-cell communication, such as peg-socket junctions, or distributed more broadly throughout the cell? What are the mechanisms that modulate the fidelity and gain of signaling (control of gene expression, protein trafficking, cell surface expression levels, and so on) and how are these affected in cerebrovascular disorders? The present survey of pericyte ion channels and GPCRs provides a map that can be used to guide these deeper explorations.

\section{AUTHOR CONTRIBUTIONS}

All authors listed have made a substantial, direct and intellectual contribution to the work, and approved it for publication.

\section{FUNDING}

Support for this work was provided by the NIH National Institute on Aging and National Institute of Neurological Disorders and Stroke (1R01AG066645 and 1DP2NS121347, to TL), the American Heart Association (17SDG33670237 and 19IPLOI34660108 to TL), and the Swedish Cancer Society (to $\mathrm{CB}$ ).

\section{ACKNOWLEDGMENTS}

The authors thank B. Huang for data organization and proofreading the manuscript.

using high-resolution magnetic resonance imaging in healthy volunteers. $J$. Cereb. Blood Flow Metab. doi: 10.1177/0271678X20959294. [Epub ahead of print].

Alkhatib, O., da Costa, R., Gentry, C., Quallo, T., Bevan, S., and Andersson, D. A. (2019). Promiscuous G-protein-coupled receptor inhibition of transient receptor potential melastatin 3 ion channels by G $\beta \gamma$ subunits. J. Neurosci. 39, 7840-7852. doi: 10.1523/JNEUROSCI.0882-19.2019

Alsop, D. C., Detre, J. A., and Grossman, M. (2000). Assessment of cerebral blood flow in Alzheimer's disease by spinlabeled magnetic resonance imaging. Ann. Neurol. 47, 93-100. doi: 10.1002/1531-8249(200001)47:1<93::AID-ANA15>3.0.CO;2-8

An, M. T., and Zamponi, G. W. (2005). "Voltage-dependent inactivation of voltage gated calcium channels," in Voltage-Gated Calcium Channels. Molecular Biology Intelligence Unit, ed G. W. Zamponi (Boston, MA: Springer), 194-204. doi: 10.1007/0-387-27526-6_12

Ancellin, N., Colmont, C., Su, J., Li, Q., Mittereder, N., Chae, S. S., et al. (2002). Extracellular export of sphingosine kinase-1 enzyme. Sphingosine 1-phosphate generation and the induction of angiogenic vascular maturation. J. Biol. Chem. 277, 6667-6675. doi: 10.1074/jbc.M102841200

Aoki, M., Aoki, H., Ramanathan, R., Hait, N. C., and Takabe, K. (2016). Sphingosine-1-phosphate signaling in immune cells and inflammation: roles and therapeutic potential. Mediators Inflamm. 2016:8606878. doi: 10.1155/2016/8606878

Arguin, G., Regimbald-Dumas, Y., Fregeau, M. O., Caron, A. Z., and Guillemette, G. (2007). Protein kinase C phosphorylates the inositol 1,4,5-trisphosphate 
receptor type 2 and decreases the mobilization of $\mathrm{Ca}^{2+}$ in pancreatoma AR4-2J cells. J. Endocrinol. 192, 659-668. doi: 10.1677/JOE-06-0179

Armstrong, J. F., Faccenda, E., Harding, S. D., Pawson, A. J., Southan, C., Sharman, J. L., et al. (2020). The iuphar/bps guide to pharmacology in 2020: extending immunopharmacology content and introducing the iuphar/mmv guide to malaria pharmacology. Nucleic Acids Res. 48, D1006-D1021. doi: 10.1093/nar/gkz951

Armulik, A., Abramsson, A., and Betsholtz, C. (2005). Endothelial/pericyte interactions. Circ. Res. 97, 512-523. doi: 10.1161/01.RES.0000182903.16652.d7

Armulik, A., Genové, G., Mäe, M., Nisancioglu, M. H., Wallgard, E., Niaudet, C., et al. (2010). Pericytes regulate the blood-brain barrier. Nature 468, 557-561. doi: 10.1038/nature09522

Arora, K., Sinha, C., Zhang, W., Ren, A., Moon, C. S., Yarlagadda, S., et al. (2013). Compartmentalization of cyclic nucleotide signaling: a question of when, where, and why? Pflugers Arch. 465, 1397-1407. doi: 10.1007/s00424-013-1280-6

Asmar, M., Asmar, A., Simonsen, L., Dela, F., Holst, J. J., and Bülow, J. (2019). GIPinduced vasodilation in human adipose tissue involves capillary recruitment. Endocr. Connect. 8, 806-813. doi: 10.1530/EC-19-0144

Attwell, D., Buchan, A. M., Charpak, S., Lauritzen, M., MacVicar, B. A., and Newman, E. A. (2010). Glial and neuronal control of brain blood flow. Nature 468, 232-243. doi: 10.1038/nature09613

Attwell, D., Mishra, A., Hall, C. N., O'Farrell, F. M., and Dalkara, T. (2016). What is a pericyte? J. Cereb. Blood Flow Metab. 36, 451-455. doi: $10.1177 / 0271678 X 15610340$

Aydin, F., Rosenblum, W. I., and Povlishock, J. T. (1991). Myoendothelial junctions in human brain arterioles. Stroke 22, 1592-1597. doi: 10.1161/01.STR.22.12.1592

Aziz, Q., Thomas, A. M., Gomes, J., Ang, R., Sones, W. R., Li, Y., et al. (2014). The ATP-sensitive potassium channel subunit, $K_{\text {ir }} 6.1$, in vascular smooth muscle plays a major role in blood pressure control. Hypertension 64, 523-529. doi: 10.1161/HYPERTENSIONAHA.114.03116

Baker, M. R., Fan, G., and Serysheva, I. I. (2017). Structure of $\mathrm{IP}_{3}$ R channel: high-resolution insights from cryo-EM. Curr. Opin. Struct. Biol. 46, 38-47. doi: 10.1016/j.sbi.2017.05.014

Balbi, M., Koide, M., Wellman, G. C., and Plesnila, N. (2017). Inversion of neurovascular coupling after subarachnoid hemorrhage in vivo. J. Cereb. Blood Flow Metab. 37, 3625-3634. doi: 10.1177/0271678X16686595

Ballanyi, K., Doutheil, J., and Brockhaus, J. (1996). Membrane potentials and microenvironment of rat dorsal vagal cells in vitro during energy depletion. J. Physiol. 495, 769-784. doi: 10.1113/jphysiol.1996.sp021632

Balsinde, J., Winstead, M. V., and Dennis, E. A. (2002). Phospholipase $\mathrm{A}_{2}$ regulation of arachidonic acid mobilization. FEBS Lett. 531, 2-6. doi: 10.1016/S0014-5793(02)03413-0

Bayliss, W. M. (1902). On the local reactions of the arterial wall to changes of internal pressure. J. Physiol. 28, 220-231. doi: 10.1113/jphysiol.1902.sp000911

Beech, D. J., Zhang, H., Nakao, K., and Bolton, T. B. (1993). K channel activation by nucleotide diphosphates and its inhibition by glibenclamide in vascular smooth muscle cells. Br. J. Pharmacol. 110, 573-582. doi: 10.1111/j.1476-5381.1993.tb13849.x

Berman, D. M., Wilkie, T. M., and Gilman, A. G. (1996). GAIP and RGS4 are GTPase-activating proteins for the $\mathrm{G}_{\mathrm{i}}$ subfamily of $\mathrm{G}$ protein $\alpha$ subunits. Cell 86, 445-452. doi: 10.1016/S0092-8674(00)80117-8

Berninsone, P., and Hirschberg, C. B. (1998). Nucleotide sugars, nucleotide sulfate, and ATP transporters of the endoplasmic reticulum and Golgi apparatus. Ann. N. Y. Acad. Sci. 842, 91-99. doi: 10.1111/j.1749-6632.1998.tb09636.x

Berridge, M. (2016). The inositol trisphosphate/calcium signaling pathway in health and disease. Physiol. Rev. 96, 1261-1296. doi: 10.1152/physrev.00006.2016

Berridge, M. J., Lipp, P., and Bootman, M. D. (2000). The versatility and universality of calcium signalling. Nat. Rev. Mol. Cell Biol. 1, 11-21. doi: 10.1038/35036035

Berthiaume, A. A., Grant, R. I., McDowell, K. P., Underly, R. G., Hartmann, D. A., Levy, M., et al. (2018). Dynamic remodeling of pericytes in vivo maintains capillary coverage in the adult mouse brain. Cell Rep. 22, 8-16. doi: 10.1016/j.celrep.2017.12.016

Bezprozvanny, L., Watras, J., and Ehrlich, B. E. (1991). Bell-shaped calciumresponse curves of $\operatorname{Ins}(1,4,5) \mathrm{P}_{3^{-}}$and calcium-gated channels from endoplasmic reticulum of cerebellum. Nature 351, 751-754. doi: 10.1038/35 $1751 \mathrm{a} 0$

Bhattacharjee, A., Joiner, W. J., Wu, M., Yang, Y., Sigworth, F. J., and Kaczmarek, L. K. (2003). Slick (Slo2.1), a rapidly-gating sodium-activated potassium channel inhibited by ATP. J. Neurosci. 23, 11681-11691. doi: 10.1523/JNEUROSCI.23-37-11681.2003

Bi, M. M., Hong, S., Zhou, H. Y., Wang, H. W., Wang, L. N., and Zheng, Y. J. (2014). Chloride channelopathies of ClC-2. Int. J. Mol. Sci. 15, 218-249. doi: 10.3390/ijms15010218

Blinder, P., Tsai, P. S., Kaufhold, J. P., Knutsen, P. M., Suhl, H., and Kleinfeld, D. (2013). The cortical angiome: an interconnected vascular network with noncolumnar patterns of blood flow. Nat. Neurosci. 16, 889-897. doi: $10.1038 / \mathrm{nn} .3426$

Bondjers, C., He, L., Takemoto, M., Norlin, J., Asker, N., Hellström, M., et al. (2006). Microarray analysis of blood microvessels from PDGF-B and PDGF$\mathrm{R} \beta$ mutant mice identifies novel markers for brain pericytes. FASEB J. 20, E1005-E1013. doi: 10.1096/fj.05-4944fje

Bondjers, C., Kalén, M., Hellström, M., Scheidl, S. J., Abramsson, A. Renner, O., et al. (2003). Transcription profiling of platelet-derived growth factor-B-deficient mouse embryos identifies RGS5 as a novel marker for pericytes and vascular smooth muscle cells. Am. J. Pathol. 162, 721-729. doi: 10.1016/S0002-9440(10)63868-0

Bonev, A. D., and Nelson, M. T. (1996). Vasoconstrictors inhibit ATP-sensitive $\mathrm{K}^{+}$ channels in arterial smooth muscle through protein kinase C. J. Gen. Physiol. 108, 315-323. doi: 10.1085/jgp.108.4.315

Bootman, M. D., and Bultynck, G. (2020). Fundamentals of cellular calcium signaling: a primer. Cold Spring Harb. Perspect. Biol. 12:a038802. doi: 10.1101/cshperspect.a038802

Borea, P. A., Gessi, S., Merighi, S., Vincenzi, F., and Varani, K. (2018). Pharmacology of adenosine receptors: the state of the art. Physiol. Rev. 98, 1591-1625. doi: 10.1152/physrev.00049.2017

Borysova, L., Wray, S., Eisner, D. A., and Burdyga, T. (2013). How calcium signals in myocytes and pericytes are integrated across in situ microvascular networks and control microvascular tone. Cell Calcium 54, 163-174. doi: 10.1016/j.ceca.2013.06.001

Bos, C. L., Richel, D. J., Ritsema, T., Peppelenbosch, M. P., and Versteeg, H. H. (2004). Prostanoids and prostanoid receptors in signal transduction. Int. J. Biochem. Cell Biol. 36, 1187-1205. doi: 10.1016/j.biocel.2003.08.006

Bousquet, S. M., Monet, M., and Boulay, G. (2010). Protein kinase C-dependent phosphorylation of transient receptor potential canonical 6 (TRPC6) on serine 448 causes channel inhibition. J. Biol. Chem. 285, 40534-40543. doi: 10.1074/jbc.M110.160051

Breckenridge, B. M., and Crawford, E. J. (1960). Glycogen synthesis from uridine diphosphate glucose in brain. J. Biol. Chem. 235, 3054-3057.

Bulley, S., and Jaggar, J. H. (2014). $\mathrm{Cl}^{-}$channels in smooth muscle cells. Pflügers Arch. 466, 861-872. doi: 10.1007/s00424-013-1357-2

Burdakov, D., Petersen, O. H., and Verkhratsky, A. (2005). Intraluminal calcium as a primary regulator of endoplasmic reticulum function. Cell Calcium 38, 303-310. doi: 10.1016/j.ceca.2005.06.010

Burdyga, T., and Borysova, L. (2014). Calcium signalling in pericytes. J. Vasc. Res 51, 190-199. doi: 10.1159/000362687

Burke, M. A., Mutharasan, R. K., and Ardehali, H. (2008). The sulfonylurea receptor, an atypical ATP-binding cassette protein, and its regulation of the $\mathrm{K}_{\text {ATP }}$ channel. Circ. Res. 102, 164-176. doi: 10.1161/CIRCRESAHA.107.165324

Cabrita, I., Benedetto, R., Fonseca, A., Wanitchakool, P., Sirianant, L., Skryabin, B. V., et al. (2017). Differential effects of anoctamins on intracellular calcium signals. FASEB J. 31, 2123-2134. doi: 10.1096/fj.201600797RR

Cai, C., Fordsmann, J. C., Jensen, S. H., Gesslein, B., Lønstrup, M., Hald, B. O., et al. (2018). Stimulation-induced increases in cerebral blood flow and local capillary vasoconstriction depend on conducted vascular responses. Proc. Natl. Acad. Sci. U.S.A. 115, E5796-E5804. doi: 10.1073/pnas.1707702115

Calcraft, P. J., Arredouani, A., Ruas, M., Pan, Z., Cheng, X., Hao, X., et al. (2009). NAADP mobilizes calcium from acidic organelles through two-pore channel. Nature 459, 596-600. doi: 10.1038/nature08030

Canales, J., Morales, D., Blanco, C., Rivas, J., Diaz, N., Angelopoulos, I., et al. (2019). A $\operatorname{tr}(\mathrm{i}) \mathrm{p}$ to cell migration: new roles of trp channels in mechanotransduction and cancer. Front. Physiol. 10:757. doi: $10.3389 /$ fphys.2019.00757 
Cantero del Rocío, M., Velázquez, I. F., Streets, A. J., Ong, A. C. M., and Cantiello, H. F. (2015). The cAMP signaling pathway and direct protein kinase a phosphorylation regulate polycystin-2 (TRPP2) channel function. J. Biol. Chem. 290, 23888-23896. doi: 10.1074/jbc.M115.661082

Cao, C., Goo, J. H., Lee-Kwon, W., and Pallone, T. L. (2006). Vasa recta pericytes express a strong inward rectifier $\mathrm{K}^{+}$conductance. Am. J. Physiol. Regul. Integr. Comp. Physiol. 290, R1601-R1607. doi: 10.1152/ajpregu.00877.2005

Capone, C., Dabertrand, F., Baron-Menguy, C., Chalaris, A., Ghezali, L., Domenga-Denier, V., et al. (2016). Mechanistic insights into a TIMP3-sensitive pathway constitutively engaged in the regulation of cerebral hemodynamics. Elife 5:e17536. doi: 10.7554/eLife.17536.042

Capone, C., Faraco, G., Peterson, J. R., Coleman, C., Anrather, J., Milner, T. A., et al. (2012). Central cardiovascular circuits contribute to the neurovascular dysfunction in angiotensin II hypertension. J. Neurosci. 32, 4878-4886. doi: 10.1523/JNEUROSCI.6262-11.2012

Carlson, E. (1989). Fenestrated subendothelial basement membranes in human retinal capillaries. Investig. Opthalmology Vis. Sci. 30, 1923-1932.

Caron, A. Z., Chaloux, B., Arguin, G., and Guillemette, G. (2007). Protein kinase $\mathrm{C}$ decreases the apparent affinity of the inositol 1,4,5-trisphosphate receptor type 3 in RINm5F cells. Cell Calcium 42, 323-331. doi: 10.1016/j.ceca.2007. 01.002

Carvalho, J., Chennupati, R., Li, R., Günther, S., Kaur, H., Zhao, W., et al. (2020). Orphan G protein-coupled receptor GPRC5B controls smooth muscle contractility and differentiation by inhibiting prostacyclin receptor signaling. Circulation 141, 1168-1183. doi: 10.1161/CIRCULATIONAHA.119.043703

Catterall, W. A., Perez-Reyes, E., Snutch, T. P., and Striessnig, J. (2005). International Union of Pharmacology. XLVIII. Nomenclature and structurefunction relationships of voltage-gated calcium channels. Pharmacol. Rev. 57, 411-425. doi: 10.1124/pr.57.4.5

Chasseigneaux, S., Moraca, Y., Cochois-Guégan, V., Boulay, A. C., Gilbert, A., Crom, S., et al. (2018). Isolation and differential transcriptome of vascular smooth muscle cells and mid-capillary pericytes from the rat brain. Sci. Rep. 8:12272. doi: 10.1038/s41598-018-30739-5

Chaudhuri, D., Issa, J. B., and Yue, D. T. (2007). Elementary mechanisms producing facilitation of $\mathrm{Ca}_{\mathrm{v}} 2.1$ (P/Q-type) channels. J. Gen. Physiol. 129, 385-401. doi: 10.1085/jgp.200709749

Chen, X., Wang, Q., Ni, F., and Ma, J. (2010). Structure of the fulllength Shaker potassium channel $\mathrm{K}_{\mathrm{v}} 1.2$ by normal-mode-based X-ray crystallographic refinement. Proc. Natl. Acad. Sci. U.S.A. 107, 11352-11357. doi: 10.1073/pnas.1000142107

Cheng, H. Y., Dong, A., Panchatcharam, M., Mueller, P., Yang, F., Li, Z., et al. (2012). Lysophosphatidic acid signaling protects pulmonary vasculature from hypoxia-induced remodeling. Arterioscler. Thromb. Vasc. Biol. 32, 24-32. doi: 10.1161/ATVBAHA.111.234708

Cheng, K. T., Liu, X., Ong, H. L., and Ambudkar, I. S. (2008). Functional requirement for Orail in store-operated TRPC1-STIM1 channels. J. Biol. Chem. 283, 12935-12940. doi: 10.1074/jbc.C800008200

Cheng, K. T., Ong, H. L., Liu, X., and Ambudkar, I. S. (2013). Contribution and regulation of TRPC channels in store-operated $\mathrm{Ca}^{2+}$ entry. Curr. Top. Membr. 71, 149-179. doi: 10.1016/B978-0-12-407870-3.00007-X

Chern, Y. (2000). Regulation of adenylyl cyclase in the central nervous system. Cell. Signal. 12, 195-204. doi: 10.1016/S0898-6568(99)0 0084-4

Chesler, M., and Kaila, K. (1992). Modulation of $\mathrm{pH}$ by neuronal activity. Trends Neurosci. 15, 396-402. doi: 10.1016/0166-2236(92)90191-A

Cheung, W., Andrade-Gordon, P., Derian, C. K., and Damiano, B. P. (1998). Receptor-activating peptides distinguish thrombin receptor (PAR-1) and protease activated receptor 2 (PAR-2) mediated hemodynamic responses in vivo. Can. J. Physiol. Pharmacol. 76, 16-25. doi: 10.1139/y97-176

Chipperfield, A. R., and Harper, A. A. (2000). Chloride in smooth muscle. Prog. Biophys. Mol. Biol. 74, 175-221. doi: 10.1016/S0079-6107(00) 00024-9

Cho, H., Kozasa, T., Bondjers, C., Betsholtz, C., and Kehrl, J. H. (2003). Pericyte-specific expression of Rgs5: implications for PDGF and EDG receptor signaling during vascular maturation. FASEB J. 17, 440-442. doi: 10.1096/fj.020340fje

Cipolla, M. (2009). "Chapter 2: Anatomy and Ultrastructure," in The Cerebral Circulation (San Rafael, CA: Morgan \& Claypool Life Sciences).
Cipolla, M., Li, R., and Vitullo, L. (2004). Perivascular innervation of penetrating brain parenchymal arterioles. J. Cardiovasc. Pharmacol. 44, 1-8. doi: 10.1097/00005344-200407000-00001

Clapham, D. E. (2003). TRP channels as cellular sensors. Nature 426, 517-524 doi: $10.1038 /$ nature 02196

Corda, G., and Sala, A. (2017). Non-canonical WNT/PCP signalling in cancer: Fzd6 takes centre stage. Oncogenesis 6:e364. doi: 10.1038/oncsis.2017.69

Cortijo, C., Gouzi, M., Tissir, F., and Grapin-Botton, A. (2012). Planar cell polarity controls pancreatic beta cell differentiation and glucose homeostasis. Cell Rep. 2, 1593-1606. doi: 10.1016/j.celrep.2012.10.016

Coste, B., Mathur, J., Schmidt, M., Earley, T. J., Ranade, S., Petrus, M. J., et al. (2010). Piezo1 and Piezo2 are essential components of distinct mechanically activated cation channels. Science 330, 55-60. doi: 10.1126/science.1193270

Coste, B., Murthy, S. E., Mathur, J., Schmidt, M., Mechioukhi, Y., Delmas, P., et al. (2015). Piezol ion channel pore properties are dictated by C-terminal region. Nat. Commun. 6:7223. doi: 10.1038/ncomms8223

Crnkovic, S., Egemnazarov, B., Jain, P., Seay, U., Gattinger, N., Marsh, L. M., et al. (2014). NPY/Y1 receptor-mediated vasoconstrictory and proliferative effects in pulmonary hypertension. Br. J. Pharmacol. 171, 3895-3907. doi: $10.1111 /$ bph. 12751

Cuevas, P., Gutierrez-Diaz, J. A., Reimers, D., Dujovny, M., Diaz, F. G., and Ausman, J. I. (1984). Pericyte endothelial gap junctions in human cerebral capillaries. Anat. Embryol. 170, 155-159. doi: 10.1007/BF00319000

Cunha, R. A. (2016). How does adenosine control neuronal dysfunction and neurodegeneration? J. Neurochem. 139, 1019-1055. doi: 10.1111/jnc.13724

Cvetković, D., Babwah, A. V., and Bhattacharya, M. (2013). Kisspeptin/KISSIR system in breast cancer. J. Cancer 4, 653-661. doi: 10.7150/jca.7626

Dabertrand, F., Krøigaard, C., Bonev, A. D., Cognat, E., Dalsgaard, T., DomengaDenier, V., et al. (2015). Potassium channelopathy-like defect underlies earlystage cerebrovascular dysfunction in a genetic model of small vessel disease. Proc. Natl. Acad. Sci. U.S.A. 112, E796-E805. doi: 10.1073/pnas.1420765112

Dang, S., Feng, S., Tien, J., Peters, C. J., Bulkley, D., Lolicato, M., et al. (2017). CryoEM structures of the TMEM16A calcium-activated chloride channel. Nature 552, 426-429. doi: 10.1038/nature25024

D’Avanzo, N., Cheng, W. W. L., Doyle, D. A., and Nichols, C. G. (2010). Direct and specific activation of human inward rectifier $\mathrm{K}^{+}$channels by membrane phosphatidylinositol 4,5-Bisphosphate. J. Biol. Chem. 285, 37129-37132. doi: $10.1074 /$ jbc.C110.186692

Davenport, A. P., Hyndman, K. A., Dhaun, N., Southan, C., Kohan, D. E., Pollock, J. S., et al. (2016). Endothelin. Pharmacol. Rev. 68, 357-418. doi: $10.1124 /$ pr.115.011833

De Henau, O., Degroot, G. N., Imbault, V., Robert, V., De Poorter, C., McHeik, S., et al. (2016). Signaling properties of chemerin receptors CMKLR1, GPR1 and CCRL2. PLoS ONE 11:e0164179. doi: 10.1371/journal.pone.0164179

de Oliveira, P. G., Ramos, M. L. S., Amaro, A. J., Dias, R. A., and Vieira, S. I. (2019). $\mathrm{G}_{\mathrm{i} / \mathrm{o}}$-protein coupled receptors in the aging brain. Front. Aging Neurosci. 11:89. doi: 10.3389/fnagi.2019.00089

Dehouck, M. P., Vigne, P., Torpier, G., Breittmayer, J. P., Cecchelli, R., and Frelin, C. (1997). Endothelin-1 as a mediator of endothelial cell-pericyte interactions in bovine brain capillaries. J. Cereb. Blood Flow Metab. 17, 464-469. doi: 10.1097/00004647-199704000-00012

Denninger, J. W., and Marletta, M. A. (1999). Guanylate cyclase and the NO/cGMP signaling pathway. Biochim. Biophys. Acta Bioenerg. 1411, 334-350. doi: 10.1016/S0005-2728(99)00024-9

Díaz-Flores, L., Gutiérrez, R., Madrid, J. F., Varela, H., Valladares, F., Acosta, E., et al. (2009). Pericytes. Morphofunction, interactions and pathology in a quiescent and activated mesenchymal cell niche. Histol. Histopathol. 24, 909-969. doi: 10.14670/HH-24.909

Dick, I. E., Tadross, M. R., Liang, H., Tay, L. H., Yang, W., and Yue, D. T. (2008). A modular switch for spatial $\mathrm{Ca}^{2+}$ selectivity in the calmodulin regulation of $\mathrm{Ca}_{\mathrm{v}}$ channels. Nature 451, 830-834. doi: 10.1038/nature06529

Dickson, E. J., and Hille, B. (2019). Understanding phosphoinositides: rare, dynamic, and essential membrane phospholipids. Biochem. J. 476, 1-23. doi: 10.1042/BCJ20180022

Dijksterhuis, J. P., Petersen, J., and Schulte, G. (2014). WNT/Frizzled signalling: Receptor-ligand selectivity with focus on FZD-G protein signalling and its physiological relevance: IUPHAR review 3. Br. J. Pharmacol. 171, 1195-1209. doi: $10.1111 /$ bph. 12364 
Dirnagl, U., Niwa, K., Lindauer, U., and Villringer, A. (1994). Coupling of cerebral blood flow to neuronal activation: role of adenosine and nitric oxide. Am. J. Physiol. Hear. Circ. Physiol. 267, H296-H301. doi: 10.1152/ajpheart.1994.267.1.H296

Dorn, G. W. II., and Becker, M. W. (1993). Thromboxane $A_{2}$ stimulated signal transduction in vascular smooth muscle. J. Pharmacol. Exp. Ther. 265, 447-456.

Drury, A. N., and Szent-Györgyi, A. (1929). The physiological activity of adenine compounds with especial reference to their action upon the mammalian heart. J. Physiol. 68, 213-237. doi: 10.1113/jphysiol.1929.sp002608

Duprat, F., Lesage, F., Fink, M., Reyes, R., Heurteaux, C., and Lazdunski, M. (1997). TASK, a human background $\mathrm{K}^{+}$channel to sense external $\mathrm{pH}$ variations near physiological pH. EMBO J. 16, 5464-5471. doi: 10.1093/emboj/16.17.5464

Dupré, D. J., Robitaille, M., Rebois, R. V., and Hébert, T. E. (2009). The role of G $\beta \gamma$ subunits in the organization, assembly, and function of GPCR signaling complexes. Annu. Rev. Pharmacol. Toxicol. 49, 31-56. doi: 10.1146/annurev-pharmtox-061008-103038

Dutta, A. K., Khimji, A. K., Liu, S., Karamysheva, Z., Fujita, A., Kresge, C., et al. (2016). PKC $\alpha$ regulates TMEM16A-mediated $\mathrm{Cl}^{-}$secretion in human biliary cells. Am. J. Physiol. Gastrointest. Liver Physiol. 310, G34-G42. doi: 10.1152/ajpgi.00146.2015

Dutzler, R., Campbell, E. B., Cadene, M., Chait, B. T., and MacKinnon, R. (2002). $\mathrm{X}$-ray structure of a ClC chloride channel at $3.0 \AA$ reveals the molecular basis of anion selectivity. Nature 415, 287-294. doi: 10.1038/415287a

Duvernoy, H. M., Delon, S., and Vannson, J. L. (1981). Cortical blood vessels of the human brain. Brain Res. Bull. 7, 519-579. doi: 10.1016/0361-9230(81)90007-1

Dyer, L. A., and Patterson, C. (2010). Development of the endothelium: An emphasis on heterogeneity. Semin. Thromb. Hemost. 36, 227-235. doi: $10.1055 / \mathrm{s}-0030-1253446$

Earley, S., and Brayden, J. E. (2010). Transient receptor potential channels and vascular function. Clin. Sci. 119, 19-36. doi: 10.1042/CS20090641

Earley, S., and Brayden, J. E. (2015). Transient receptor potential channels in the vasculature. Physiol. Rev. 95, 645-690. doi: 10.1152/physrev.00026.2014

Eberth, C. (1871). Handbuch der lehre von der gewegen des menschen und der tiere Vol. 1. Leipzig: Engelmann

Enkvetchakul, D., and Nichols, C. G. (2003). Gating mechanism of $\mathrm{K}_{\mathrm{ATP}}$ channels: function fits form. J. Gen. Physiol. 122, 471-480. doi: 10.1085/jgp.200 308878

Estévez, R., Pusch, M., Ferrer-Costa, C., Orozco, M., and Jentsch, T. J. (2004). Functional and structural conservational of CBS domains from CLC chloride channels. J. Physiol. 557, 363-378. doi: 10.1113/jphysiol.2003.058453

Evans, N. J., Bayliss, A. L., Reale, V., and Evans, P. D. (2016). Characterisation of signalling by the endogenous GPER1 (GPR30) receptor in an embryonic mouse hippocampal cell line (mHippoE-18). PLoS ONE 11:e0152138. doi: 10.1371/journal.pone.0152138

Fan, G., Baker, M. L., Wang, Z., Baker, M. R., Sinyagovskiy, P. A., Chiu, W., et al. (2015). Gating machinery of $\operatorname{Ins}_{3} \mathrm{R}$ channels revealed by electron cryomicroscopy. Nature 527, 336-341. doi: 10.1038/nature15249

Fan, Z., and Makielski, J. C. (1997). Anionic phospholipids activate ATP-sensitive potassium channels. J. Biol. Chem. 272, 5388-5395. doi: 10.1074/jbc.272.9.5388

Fernández-Klett, F., Offenhauser, N., Dirnagl, U., Priller, J., and Lindauer, U. (2010). Pericytes in capillaries are contractile in vivo, but arterioles mediate functional hyperemia in the mouse brain. Proc. Natl. Acad. Sci. U.S.A. 107, 22290-22295. doi: 10.1073/pnas.1011321108

Fernández-Tenorio, M., Porras-González, C., Castellano, A., Del Valle-Rodríguez, A., López-Barneo, J., and Ureña, J. (2011). Metabotropic regulation of RhoA/Rho-associated kinase by L-type $\mathrm{Ca}^{2+}$ channels: new mechanism for depolarization-evoked mammalian arterial contraction. Circ. Res. 108, 1348-1357. doi: 10.1161/CIRCRESAHA.111.240127

Ferrandon, S., Feinstein, T. N., Castro, M., Wang, B., Bouley, R., Potts, J. T., et al. (2009). Sustained cyclic AMP production by parathyroid hormone receptor endocytosis. Nat. Chem. Biol. 5, 734-742. doi: 10.1038/nchembio.206

Ferris, C. D., Cameron, A. M., Bredt, D. S., Huganir, R. L., and Snyder, S. H. (1991a). Inositol 1,4,5-trisphosphate receptor is phosphorylated by cyclic AMPdependent protein kinase at serines 1755 and 1589. Biochem. Biophys. Res. Commun. 175, 192-198. doi: 10.1016/S0006-291X(05)81219-7

Ferris, C. D., Huganir, R. L., Bredt, D. S., Cameron, A. M., and Snyder, S. H. (1991b). Inositol trisphosphate receptor: phosphorylation by protein kinase $\mathrm{C}$ and calcium calmodulin-dependent protein kinases in reconstituted lipid vesicles. Proc. Natl. Acad. Sci. U.S.A. 88, 2232-2235. doi: $10.1073 /$ pnas.88.6.2232

Filosa, J. A., Bonev, A. D., Straub, S. V., Meredith, A. L., Wilkerson, M. K., Aldrich, R. W., et al. (2006). Local potassium signaling couples neuronal activity to vasodilation in the brain. Nat. Neurosci. 9, 1397-1403. doi: 10.1038/nn1779

Finch, E., Turner, T., and Goldin, S. (1991). Calcium as a coagonist of inositol 1,4,5-trisphosphate-induced calcium release. Science 252, 443-446. doi: $10.1126 /$ science. 2017683

Findlay, I. (1987). The effects of magnesium upon adenosine triphosphatesensitive potassium channels in a rat insulin-secreting cell line. J. Physiol. 391, 611-629. doi: 10.1113/jphysiol.1987.sp016759

Findlay, I. (1988). Effects of ADP upon the ATP-sensitive $\mathrm{K}^{+}$channel in rat ventricular myocytes. J. Membr. Biol. 101, 83-92. doi: 10.1007/BF01872823

Fisher, I., Jenkins, M. L., Tall, G. G., Burke, J. E., and Smrcka, A. V. (2020). Activation of phospholipase C $\beta$ by $G \beta \gamma$ and $G \alpha_{q}$ involves Cterminal rearrangement to release auto-inhibition. Structure 28, 1-10. doi: 10.1101/810994

Foskett, J. K., White, C., Cheung, K. H., and Mak, D. O. (2007). Inositol trisphosphate receptor $\mathrm{Ca}^{2+}$ release channels. Physiol. Rev. 87, 593-658. doi: 10.1152/physrev.00035.2006

Foster, M. N., and Coetzee, W. A. (2015). $\mathrm{K}_{\mathrm{ATP}}$ channels in the cardiovascular system. Physiol. Rev. 96, 177-252. doi: 10.1152/physrev.00003.2015

Freeman, B. D., Machado, F. S., Tanowitz, H. B., and Desruisseaux, M. S. (2014). Endothelin-1 and its role in the pathogenesis of infectious diseases. Life Sci. 118, 110-119. doi: 10.1016/j.lfs.2014.04.021

Fresco, P., Diniz, C., and Gonçalves, J. (2004). Facilitation of noradrenaline release by activation of adenosine $A_{2 A}$ receptors triggers both phospholipase $C$ and adenylate cyclase pathways in rat tail artery. Cardiovasc. Res. 63, 739-746. doi: 10.1016/j.cardiores.2004.05.015

Friedrich, E. E., Hong, Z., Xiong, S., Zhong, M., Di, A., Rehman, J., et al. (2019). Endothelial cell Piezol mediates pressure-induced lung vascular hyperpermeability via disruption of adherens junctions. Proc. Natl. Acad. Sci. U.S.A. 116, 12980-12985. doi: 10.1073/pnas.1902165116

Fujiwara, T., and Uehara, Y. (1984). The cytoarchitecture of the wall and the innervation pattern of the microvessels in the rat mammary gland: A scanning electron microscopic observation. Am. J. Anat. 170, 39-54. doi: 10.1002/aja.1001700104

Fuller, M. D., Fu, Y., Scheuer, T., and Catterall, W. A. (2014). Differential regulation of $\mathrm{Ca}_{\mathrm{v}} 1.2$ channels by cAMP-dependent protein kinase bound to A-kinase anchoring proteins 15 and 79/150. J. Gen. Physiol. 143, 315-324. doi: 10.1085/jgp.201311075

Gannon, K. P., Vanlandingham, L. G., Jernigan, N. L., Grifoni, S. C., Hamilton, G., and Drummond, H. A. (2008). Impaired pressure-induced constriction in mouse middle cerebral arteries of ASIC2 knockout mice. Am. J. Physiol. Hear. Circ. Physiol. 294, H1793-H1803. doi: 10.1152/ajpheart.01380.2007

Garcia, D. C. G., and Longden, T. A. (2020). "Ion channels in capillary endothelium," in Current Topics in Membranes. Ion Channels and Calcium Signaling in the Microcirculation, ed W. F. Jackson (Cambridge, MA: Academic Press), 261-300. doi: 10.1016/bs.ctm.2020.01.005

Giamarchi, A., and Delmas, P. (2007). "Activation mechanisms and functional roles of TRPP2 cation channels," in TRP Ion Channel Function in Sensory Transduction and Cellular Signaling Cascades, eds W. Liedtke and S. Heller (Boca Raton FL: CRC Press/Taylor \& Francis).

Girouard, H., and Iadecola, C. (2006). Neurovascular coupling in the normal brain and in hypertension, stroke, and Alzheimer disease. J. Appl. Physiol. 100, 328-335. doi: 10.1152/japplphysiol.00966.2005

Gonzales, A. L., Klug, N. R., Moshkforoush, A., Lee, J. C., Lee, F. K., Shui, B., et al. (2020). Contractile pericytes determine the direction of blood flow at capillary junctions. Proc. Natl. Acad. Sci. U.S.A. 117, 27022-27033. doi: $10.1073 /$ pnas.1922755117

Gonzales, A. L., Yang, Y., Sullivan, M. N., Sanders, L., Dabertrand, F., HillEubanks, D. C., et al. (2014). A PLC $\gamma 1$-dependent, force-sensitive signaling network in the myogenic constriction of cerebral arteries. Sci. Signal. 7:ra49. doi: 10.1126/scisignal.2004732

Gould, I. G., Tsai, P., Kleinfeld, D., and Linninger, A. (2017). The capillary bed offers the largest hemodynamic resistance to the cortical blood supply. J. Cereb. Blood Flow Metab. 37, 52-68. doi: 10.1177/0271678X166 71146 
Grant, R. I., Hartmann, D. A., Underly, R. G., Berthiaume, A. A., Bhat, N. R., and Shih, A. Y. (2019). Organizational hierarchy and structural diversity of microvascular pericytes in adult mouse cortex. J. Cereb. Blood Flow Metab. 39, 411-425. doi: 10.1177/0271678X17732229

Gribble, F. M., Tucker, S. J., and Ashcroft, F. M. (1997). The essential role of the walker A motifs of SUR1 in K-ATP channel activation by Mg-ADP and diazoxide. EMBO J. 16, 1145-1152. doi: 10.1093/emboj/16.6.1145

Gribble, F. M., Tucker, S. J., Haug, T., and Ashcroft, F. M. (1998). MgATP activates the $\beta$ cell $\mathrm{K}_{\mathrm{ATP}}$ channel by interaction with its SUR1 subunit. Proc. Natl. Acad. Sci. U.S.A. 95, 7185-7190. doi: 10.1073/pnas.95.12.7185

Grimm, C., Kraft, R., Schultz, G., and Harteneck, C. (2005). Activation of the melastatin-related cation channel TRPM3 by D-erythro-sphingosine [Corrected]. Mol. Pharmacol. 67, 798-805. doi: 10.1124/mol.104.006734

Grubb, S., Cai, C., Hald, B. O., Khennouf, L., Murmu, R. P., Jensen, A. G. K., et al. (2020). Precapillary sphincters maintain perfusion in the cerebral cortex. Nat. Commun. 11:395. doi: 10.1038/s41467-020-14330-z

Grubb, S., Poulsen, K. A., Juul, C. A., Kyed, T., Klausen, T. K., Larsen, E. H., et al. (2013). TMEM16F (Anoctamin 6), an anion channel of delayed $\mathrm{Ca}^{2+}$ activation. J. Gen. Physiol. 141, 585-600. doi: 10.1085/jgp.201210861

Grutzendler, J., and Nedergaard, M. (2019). Cellular control of brain capillary blood flow: in vivo imaging veritas. Trends Neurosci. 42, 528-536. doi: 10.1016/j.tins.2019.05.009

Guimarães, S., and Moura, D. (2001). Vascular adrenoceptors: an update. Pharmacol. Rev. 53, 319-356.

Gunaje, J. J., Bahrami, A. J., Schwartz, S. M., Daum, G., and Mahoney, W. M. (2011). PDGF-dependent regulation of regulator of $G$ protein signaling-5 expression and vascular smooth muscle cell functionality. Am. J. Physiol. Cell Physiol. 301, C478-C489. doi: 10.1152/ajpcell.00348.2010

Gurney, A. M., Osipenko, O. N., MacMillan, D., McFarlane, K. M., Tate, R. J., and Kempsill, F. E. J. (2003). Two-pore domain K channel, TASK1, in pulmonary artery smooth muscle cells. Circ. Res. 93, 957-964. doi: 10.1161/01.RES.0000099883.68414.61

Haas, T. L., and Duling, B. R. (1997). Morphology favors an endothelial cell pathway for longitudinal conduction within arterioles. Microvasc. Res. 53, 113-120. doi: 10.1006/mvre.1996.1999

Hall, C. N., Reynell, C., Gesslein, B., Hamilton, N. B., Mishra, A., Sutherland, B. A., et al. (2014). Capillary pericytes regulate cerebral blood flow in health and disease. Nature 508, 55-60. doi: 10.1038/nature13165

Hamada, K., Miyatake, H., Terauchi, A., and Mikoshiba, K. (2017). IP $3^{-}$ mediated gating mechanism of the $\mathrm{IP}_{3}$ receptor revealed by mutagenesis and X-ray crystallography. Proc. Natl. Acad. Sci. U.S.A. 114, 4661-4666. doi: $10.1073 /$ pnas.1701420114

Hamel, E. (2006). Perivascular nerves and the regulation of cerebrovascular tone. J. Appl. Physiol. 100, 1059-1064. doi: 10.1152/japplphysiol.00954.2005

Han, K., Min, J., Lee, M., Kang, B.-M., Park, T., Hahn, J., et al. (2019). Neurovascular coupling under chronic stress is modified by altered GABAergic interneuron activity. J. Neurosci. 39, 10081-10095. doi: 10.1523/JNEUROSCI.1357-19.2019

Hanlon, C. D., and Andrew, D. J. (2015). Outside-in signaling - a brief review of GPCR signaling with a focus on the Drosophila GPCR family. J. Cell Sci. 128, 3533-3542. doi: 10.1242/jcs. 175158

Hansen, S. B., Tao, X., and MacKinnon, R. (2011). Structural basis of $\mathrm{PIP}_{2}$ activation of the classical inward rectifier $\mathrm{K}^{+}$channel $\mathrm{K}_{\mathrm{ir}}$ 2.2. Nature 477, 495-498. doi: 10.1038/nature10370

Harden, T. K., Sesma, J. I., Fricks, I. P., and Lazarowski, E. R. (2010). Signalling and pharmacological properties of the $\mathrm{P}_{2} \mathrm{Y}_{14}$ receptor. Acta Physiol. 199, 149-160. doi: 10.1111/j.1748-1716.2010.02116.x

Harraz, O. F., Abd El-Rahman, R. R., Bigdely-Shamloo, K., Wilson, S. M., Brett, S. E., Romero, M., et al. (2014). $\mathrm{Ca}_{\mathrm{v}} 3.2$ channels and the induction of negative feedback in cerebral arteries. Circ. Res. 115, 650-661. doi: 10.1161/CIRCRESAHA.114.304056

Harraz, O. F., Hill-Eubanks, D., and Nelson, M. T. (2020). PIP 2 : a critical regulator of vascular ion channels hiding in plain sight. Proc. Natl. Acad. Sci. U.S.A. doi: 10.1073/pnas.2006737117. [Epub ahead of print].

Harraz, O. F., Longden, T. A., Dabertrand, F., Hill-Eubanks, D., and Nelson, M. T. (2018). Endothelial $\mathrm{G}_{\mathrm{q}} \mathrm{PCR}$ activity controls capillary electrical signaling and brain blood flow through $\mathrm{PIP}_{2}$ depletion. Proc.
Natl. Acad. Sci. U.S.A. 115, E3569-E3577. doi: 10.1073/pnas.18002 01115

Harraz, O. F., and Welsh, D. G. (2013). T-Type $\mathrm{Ca}^{2+}$ channels in cerebral arteries: approaches, hypotheses, and speculation. Microcirculation 20, 299-306. doi: $10.1111 / \mathrm{micc} .12038$

Harrison, P. J., Lyon, L., Sartorius, L. J., Burnet, P. W. J., and Lane, T. A. (2008). The group II metabotropic glutamate receptor 3 (mGluR3, mGlu3, GRM3): expression, function and involvement in schizophrenia. J. Psychopharmacol. 22, 308-322. doi: 10.1177/02698811080 89818

Hartmann, D. A., Underly, R. G., Grant, R. I., Watson, A. N., Lindner, V., and Shih, A. Y. (2015). Pericyte structure and distribution in the cerebral cortex revealed by high-resolution imaging of transgenic mice. Neurophotonics 2:041402. doi: 10.1117/1.NPh.2.4.041402

Hashitani, H., Mitsui, R., Miwa-Nishimura, K., and Lam, M. (2018). Role of capillary pericytes in the integration of spontaneous $\mathrm{Ca}^{2+}$ transients in the suburothelial microvasculature in situ of the mouse bladder. J. Physiol. 596, 3531-3552. doi: 10.1113/JP275845

He, L., Vanlandewijck, M., Mäe, M., Andrae, J., Ando, K., Gaudio, F., et al. (2018). Single cell RNAseq of mouse brain and lung vascular and vessel-associated cell types. Sci. Data 5:180160. doi: 10.1038/sdata.2018.160

Heinze, C., Seniuk, A., Sokolov, M. V., Huebner, A. K., Klementowicz, A. E., Szijárt,ó, I. A., et al. (2014). Disruption of vascular $\mathrm{Ca}^{2+}$-activated chloride currents lowers blood pressure. J. Clin. Invest. 124, 675-686. doi: 10.1172/JCI70025

Helton, T. D., Xu, W., and Lipscombe, D. (2005). Neuronal L-type calcium channels open quickly and are inhibited slowly. J. Neurosci. 25, 10247-10251. doi: 10.1523/JNEUROSCI.1089-05.2005

Henno, P., Grassin-Delyle, S., Belle, E., Brollo, M., Naline, E., Sage, E., et al. (2017). In smokers, Sonic hedgehog modulates pulmonary endothelial function through vascular endothelial growth factor. Respir. Res. 18:102. doi: 10.1186/s12931-017-0590-1

Hepler, J. R., Berman, D. M., Gilman, A. G., and Kozasa, T. (1997). RGS4 and GAIP are GTPase-activating proteins for $\mathrm{G}_{\mathrm{q}} \alpha$ and block activation of phospholipase C $\beta$ by $\gamma$-thio-GTP-G $\mathrm{q}_{\mathrm{q}} \alpha$. Proc. Natl. Acad. Sci. U.S.A. 94, 428-432. doi: 10.1073/pnas.94.2.428

Hibino, H., Inanobe, A., Furutani, K., Murakami, S., Findlay, I., and Kurachi, Y. (2010). Inwardly rectifying potassium channels: their structure, function, and physiological roles. Physiol. Rev. 90, 291-366. doi: 10.1152/physrev.00021.2009

Hieble, J. P., and Ruffolo, R. R. Jr. (1997). Recent advances in the identification of $\alpha_{1}$ - and $\alpha_{2}$-adrenoceptor subtypes: therapeutic implications. Expert Opin. Investig. Drugs 6, 367-387. doi: 10.1517/13543784.6.4.367

Hill, R. A., Tong, L., Yuan, P., Murikinati, S., Gupta, S., and Grutzendler, J. (2015). Regional blood flow in the normal and ischemic brain is controlled by arteriolar smooth muscle cell contractility and not by capillary pericytes. Neuron 87, 95-110. doi: 10.1016/j.neuron.2015.06.001

Hille, B., Dickson, E. J., Kruse, M., Vivas, O., and Suh, B. C. (2015). Phosphoinositides regulate ion channels. Biochim. Biophys. Acta 1851, 844-856. doi: 10.1016/j.bbalip.2014.09.010

Hill-Eubanks, D. C., Gonzales, A. L., Sonkusare, S. K., and Nelson, M. T. (2014) Vascular TRP channels: performing under pressure and going with the flow. Physiology 29, 343-360. doi: 10.1152/physiol.00009.2014

Hill-Eubanks, D. C., Werner, M. E., Heppner, T. J., and Nelson, M. T. (2011). Calcium signaling in smooth muscle. Cold Spring Harb. Perspect. Biol. 3:a004549. doi: 10.1101/cshperspect.a004549

Hofmann, T., Obukhov, A. G., Schaefer, M., Harteneck, C., Gudermann, T., and Schultz, G. (1999). Direct activation of human TRPC6 and TRPC3 channels by diacylglycerol. Nature 397, 259-263. doi: 10.1038/16711

Horinouchi, T., Terada, K., Higashi, T., and Miwa, S. (2013). Endothelin receptor signaling: new insight into its regulatory mechanisms. J. Pharmacol. Sci. 123, 85-101. doi: 10.1254/jphs.13R02CR

Hot, B., Valnohova, J., Arthofer, E., Simon, K., Shin, J., Uhlén, M., et al. (2017). $\mathrm{FZD}_{10}-\mathrm{G} \alpha 13$ signalling axis points to a role of $\mathrm{FZD}_{10}$ in CNS angiogenesis. Cell. Signal. 32, 93-103. doi: 10.1016/j.cellsig.2017.01.023

Hu, C., DePuy, S. D., Yao, J., McIntire, W. E., and Barrett, P. Q. (2009). Protein kinase A activity controls the regulation of T-type $\mathrm{Ca}_{\mathrm{v}} 3.2$ channels by $\mathrm{G} \beta \gamma$ dimers. J. Biol. Chem. 284, 7465-7473. doi: 10.1074/jbc.M808049200 
Hu, Y., and Wilson, G. S. (1997). Rapid changes in local extracellular rat brain glucose observed with an in vivo glucose sensor. J. Neurochem. 68, 1745-1752. doi: 10.1046/j.1471-4159.1997.68041745.x

Huang, C., Hepler, J. R., Gilman, A. G., and Mumby, S. M. (1997). Attenuation of $\mathrm{G}_{\mathrm{i}}$ - and $\mathrm{G}_{\mathrm{q}}$-mediated signaling by expression of RGS4 or GAIP in mammalian cells. Proc. Natl. Acad. Sci. U.S.A. 94, 6159-6163. doi: 10.1073/pnas.94.12.6159

Huang, G. N., Zeng, W., Kim, J. Y., Yuan, J. P., Han, L., Muallem, S., et al. (2006). STIM1 carboxyl-terminus activates native SOC, $\mathrm{I}_{\text {crac }}$ and TRPC1 channels. Nat. Cell Biol. 8, 1003-1010. doi: 10.1038/ncb1454

Huang, J., Zhou, H., Mahavadi, S., Sriwai, W., and Murthy, K. S. (2007). Inhibition of $\mathrm{G} \alpha_{\mathrm{q}}$-dependent PLC- $\beta 1$ activity by PKG and PKA is mediated by phosphorylation of RGS4 and GRK2. Am. J. Physiol. Cell Physiol. 292, C200-C208. doi: 10.1152/ajpcell.00103.2006

Huang, Y., and Thathiah, A. (2015). Regulation of neuronal communication by G protein-coupled receptors. FEBS Lett. 589, 1607-1619. doi: 10.1016/j.febslet.2015.05.007

Hübner, C. A., and Jentsch, T. J. (2002). Ion channel diseases. Hum. Mol. Genet. 11, 2435-2445. doi: 10.1093/hmg/11.20.2435

Huneau, C., Houot, M., Joutel, A., Béranger, B., Giroux, C., Benali, H., et al. (2018). Altered dynamics of neurovascular coupling in cadasil. Ann. Clin. Transl. Neurol. 5, 788-802. doi: 10.1002/acn3.574

Iadecola, C. (2004). Neurovascular regulation in the normal brain and in Alzheimer's disease. Nat. Rev. Neurosci. 5, 347-360. doi: 10.1038/nrn1387

Iadecola, C. (2017). The neurovascular unit coming of age: a journey through neurovascular coupling in health and disease. Neuron 96, 17-42. doi: 10.1016/j.neuron.2017.07.030

Iftinca, M. C., and Zamponi, G. W. (2009). Regulation of neuronal T-type calcium channels. Trends Pharmacol. Sci. 30, 32-40. doi: 10.1016/j.tips.2008.10.004

Iino, M. (1990). Biphasic $\mathrm{Ca}^{2+}$ dependence of inositol 1,4,5-trisphosphate-induced Ca release in smooth muscle cells of the guinea pig taenia caeci. J. Gen. Physiol. 95, 1103-1122. doi: 10.1085/jgp.95.6.1103

Inada, H., Kawabata, F., Ishimaru, Y., Fushiki, T., Matsunami, H., and Tominaga, M. (2008). Off-response property of an acid-activated cation channel complex PKD1L3-PKD2L1. EMBO Rep. 9, 690-697. doi: 10.1038/embor.2008.89

Ishizaki, E., Fukumoto, M., and Puro, D. G. (2009). Functional $K_{\text {ATP }}$ channels in the rat retinal microvasculature: topographical distribution, redox regulation, spermine modulation and diabetic alteration. J. Physiol. 587, 2233-2253. doi: 10.1113/jphysiol.2009.169003

Iturria-Medina, Y., Sotero, R. C., Toussaint, P. J., Mateos-Pérez, J. M., Evans, A. C., and Alzheimer's Disease Neuroimaging Initiative (2016). Early role of vascular dysregulation on late-onset Alzheimer's disease based on multifactorial data-driven analysis. Nat. Commun. 21:11934. doi: 10.1038/ncomms11934

Iwai, M., Michikawa, T., Bosanac, I., Ikura, M., and Mikoshiba, K. (2007). Molecular basis of the isoform-specific ligand-binding affinity of inositol 1,4,5-trisphosphate receptors. J. Biol. Chem. 282, 12755-12764. doi: $10.1074 /$ jbc.M609833200

Jackson, W. F. (2018). $\mathrm{K}_{\mathrm{v}}$ channels and the regulation of vascular smooth muscle tone. Microcirculation 25:e12421. doi: 10.1111/micc.12421

Jacobson, K. A., and Gao, Z. G. (2006). Adenosine receptors as therapeutic targets. Nat. Rev. Drug Discov. 5, 247-264. doi: 10.1038/nrd1983

Janiurek, M. M., Soylu-Kucharz, R., Christoffersen, C., Kucharz, K., and Lauritzen, M. (2019). Apolipoprotein M-bound sphingosine-1-phosphate regulates blood-brain barrier paracellular permeability and transcytosis. Elife 8:e49405. doi: 10.1101/684894

Jentsch, T. J., Friedrich, T., Schriever, A., and Yamada, H. (1999). The CLC chloride channel family. Pflügers Arch. 437, 783-795. doi: 10.1007/s004240050847

Jentsch, T. J., Stein, V., Weinreich, F., and Zdebik, A. A. (2002). Molecular structure and physiological function of chloride channels. Physiol. Rev. 82, 503-568. doi: 10.1152/physrev.00029.2001

Jeon, J. P., Hong, C., Park, E. J., Jeon, J. H., Cho, N. H., Kim, I. G., et al. (2012). Selective $\mathrm{G} \alpha_{\mathrm{i}}$ subunits as novel direct activators of transient receptor potential canonical (TRPC) 4 and TRPC5 channels. J. Biol. Chem. 287, 17029-17039. doi: 10.1074/jbc.M111.326553

Jiang, Y., Lee, A., Chen, J., Ruta, V., Cadene, M., Chait, B. T., et al. (2003). $\mathrm{X}$-ray structure of a voltage-dependent $\mathrm{K}^{+}$channel. Nature 423, 33-41. doi: 10.1038/nature01580

Jiao, J., Garg, V., Yang, B., Elton, T. S., and Hu, K. (2008). Protein kinase $\mathrm{C}-\varepsilon$; induces caveolin-dependent internalization of vascular adenosine $5^{\prime}$-triphosphate-sensitive $\mathrm{K}^{+}$channels. Hypertension 52, 499-506. doi: 10.1161/HYPERTENSIONAHA.108.110817

Jin, X., Shah, S., Liu, Y., Zhang, H., Lees, M., Fu, Z., et al. (2013). Activation of the $\mathrm{Cl}^{-}$channel ANO1 by localized calcium signals in nociceptive sensory neurons requires coupling with the $\mathrm{IP}_{3}$ receptor. Sci. Signal. 6, ra73. doi: 10.1126/scisignal.2004184

Johnson, G. C., Parsons, R., May, V., and Hammack, S. E. (2020). The role of pituitary adenylate cyclase-activating polypeptide (PACAP) signaling in the hippocampal dentate gyrus. Front. Cell. Neurosci. 14:111. doi: $10.3389 /$ fncel.2020.00111

Jones, S. V. P. (2003). Role of the small GTPase Rho in modulation of the inwardly rectifying potassium channel $\mathrm{K}_{\mathrm{ir}} 2.1$. Mol. Pharmacol. 64, 987-993. doi: 10.1124/mol.64.4.987

Kach, J., Sethakorn, N., and Dulin, N. O. (2012). A finer tuning of G-protein signaling through regulated control of RGS proteins. Am. J. Physiol. Hear. Circ. Physiol. 303, H19-H35. doi: 10.1152/ajpheart.00764.2011

Kaczynski, P., Kowalewski, M. P., and Waclawik, A. (2016). Prostaglandin $F_{2 \alpha}$ promotes angiogenesis and embryo-maternal interactions during implantation. Reproduction 151, 539-552. doi: 10.1530/REP-15-0496

Kajioka, S., Kitamura, K., and Kuriyama, H. (1991). Guanosine diphosphate activates an adenosine 5 '-triphosphate-sensitive $\mathrm{K}^{+}$channel in the rabbit portal vein. J. Physiol. 444, 397-418. doi: 10.1113/jphysiol.1991.sp018885

Kamouchi, M., and Kitamura, K. (1994). Regulation of ATP-sensitive $\mathrm{K}^{+}$channels by ATP and nucleotide diphosphate in rabbit portal vein. Am. J. Physiol. Hear. Circ. Physiol. 266, H1687-H1698. doi: 10.1152/ajpheart.1994.266.5.H1687

Kamp, T. J., and Hell, J. W. (2000). Regulation of Cardiac L-type calcium channels by protein kinase A and protein kinase C. Circ. Res. 87, 1095-1102. doi: 10.1161/01.RES.87.12.1095

Kapusta, D. R., Dayan, L. A., and Kenigs, V. A. (2002). Nociceptin/orphanin FQ modulates the cardiovascular, but not renal, responses to stress in spontaneously hypertensive rats. Clin. Exp. Pharmacol. Physiol. 29, 254-259. doi: 10.1046/j.1440-1681.2002.03639.x

Katritch, V., Fenalti, G., Abola, E. E., Roth, B. L., Cherezov, V., and Stevens, R. C. (2014). Allosteric sodium in class A GPCR signaling. Trends Biochem. Sci. 39, 233-244. doi: 10.1016/j.tibs.2014.03.002

Katz, B. (1949). Les constantes electriques de la membrane du muscle. Arch. Sci. Physiol. 3, 285-299.

Kawamura, H., Sugiyama, T., Wu, D. M., Kobayashi, M., Yamanishi, S., Katsumura, K., et al. (2003). ATP: a vasoactive signal in the pericytecontaining microvasculature of the rat retina. J. Physiol. 551, 787-799. doi: 10.1113/jphysiol.2003.047977

Kawamura, H., Oku, H., Li, Q., Sakagami, K., and Puro, D. G. (2002). Endothelininduced changes in the physiology of retinal pericytes. Invest. Opthalmol. Vis. Sci. 43, 882-888. Available online at: https://iovs.arvojournals.org/article.aspx? articleid $=2200149$

Kawate, T., Michel, J. C., Birdsong, W. T., and Gouaux, E. (2009). Crystal structure of the ATP-gated P2X4 ion channel in the closed state. Nature 460, 592-598. doi: $10.1038 /$ nature 08198

Kennedy, A. J., Yang, P., Read, C., Kuc, R. E., Yang, L., Taylor, E. J. A., et al. (2016). Chemerin elicits potent constrictor actions via chemokine-like receptor 1 (CMKLR1), not G-protein-coupled receptor 1 (GPR1), in human and rat vasculature. J. Am. Heart Assoc. 5:e004421. doi: 10.1161/JAHA.116.004421

Kerage, D., Brindley, D. N., and Hemmings, D. G. (2014). Review: Novel insights into the regulation of vascular tone by sphingosine 1-phosphate. Placenta 35, S86-S92. doi: 10.1016/j.placenta.2013.12.006

Khakh, B. S., Burnstock, G., Kennedy, C., King, B. F., North, R. A., Séguéla, P., et al. (2001). International union of pharmacology. XXIV. Current status of the nomenclature and properties of P2X receptors and their subunits. Pharmacol. Rev. 53, 107-118.

Khan, S. M., Sung, J. Y., and Hébert, T. E. (2016). G $\beta \gamma$ subunits-different spaces, different faces. Pharmacol. Res. 111, 434-441. doi: 10.1016/j.phrs.2016.06.026

Kilander, M. B. C., Petersen, J., Andressen, K. W., Ganji, R. S., Levy, F. O., Schuster, J., et al. (2014). Disheveled regulates precoupling of heterotrimeric G proteins to Frizzled 6. FASEB J. 28, 2293-2305. doi: 10.1096/fj.13-246363

Kim, K. S., Jang, J. H., Lin, H., Choi, S. W., Kim, H. R., Shin, D. H., et al. (2015). Rise and fall of $\mathrm{K}_{\mathrm{ir}} 2.2$ current by TLR4 signaling in human monocytes: PKC-dependent trafficking and PI3K-mediated PIP $_{2}$ decrease. J. Immunol. 195, 3345-3354. doi: 10.4049/jimmunol.1500056 
Kisler, K., Nelson, A. R., Rege, S. V., Ramanathan, A., Wang, Y., Ahuja, A., et al. (2017). Pericyte degeneration leads to neurovascular uncoupling and limits oxygen supply to brain. Nat. Neurosci. 20, 406-441. doi: 10.1038/nn.4489

Kitamura, K., and Yamazaki, J. (2001). Chloride channels and their functional roles in smooth muscle tone in the vasculature. Jpn. J. Pharmacol. 85, 351-357. doi: $10.1254 /$ jjp. 85.351

Kleppisch, T., and Nelson, M. T. (1995). Adenosine activates ATP-sensitive potassium channels in arterial myocytes via $\mathrm{A}_{2}$ receptors and cAMPdependent protein kinase. Proc. Natl. Acad. Sci. U.S.A. 92, 12441-12445. doi: $10.1073 /$ pnas.92.26.12441

Ko, K. R., Ngai, A. C., and Winn, H. R. (1990). Role of adenosine in regulation of regional cerebral blood flow in sensory cortex. Am. J. Physiol. Hear. Circ. Physiol. 259, H1703-H1708. doi: 10.1152/ajpheart.1990.259.6.H1703

Kochukov, M. Y., Balasubramanian, A., Abramowitz, J., Birnbaumer, L., and Marrelli, S. P. (2014). Activation of endothelial transient receptor potential C3 channel is required for small conductance calcium-activated potassium channel activation and sustained endothelial hyperpolarization and vasodilation of cerebral artery. J. Am. Heart Assoc. 3:e000913. doi: 10.1161/JAHA.114. 000913

Kofuji, P., and Newman, E. A. (2004). Potassium buffering in the central nervous system. Neuroscience 129, 1045-1056. doi: 10.1016/j.neuroscience.2004.06.008

Koide, M., Bonev, A. D., Nelson, M. T., and Wellman, G. C. (2012). Inversion of neurovascular coupling by subarachnoid blood depends on large-conductance $\mathrm{Ca}^{2+}$-activated $\mathrm{K}^{+}$(BK) channels. Proc. Natl. Acad. Sci. U.S.A. 109, E1387E1395. doi: 10.1073/pnas.1121359109

Koide, M., Syed, A. U., Braas, K. M., May, V., and Wellman, G. C. (2014). Pituitary adenylate cyclase activating polypeptide (PACAP) dilates cerebellar arteries through activation of large-conductance $\mathrm{Ca}^{2+}$-activated (BK) and ATP-sensitive ( $\left.\mathrm{K}_{\mathrm{ATP}}\right) \mathrm{K}^{+}$channels. J. Mol. Neurosci. 54, 443-450. doi: 10.1007/s12031-014-0301-Z

Koide, M., Moshkforoush, A., Tsoukias, N. M., Hill-Eubanks, D. C., Wellman, G. C., Nelson, M. T., et al. (2018). The yin and yang of $K_{V}$ channels in cerebral small vessel pathologies. Microcirculation 25, 1-10. doi: 10.1111/micc.12436

Kovacs, R. J., and Nelson, M. T. (1991). ATP-sensitive $\mathrm{K}^{+}$channels from aortic smooth muscle incorporated into planar lipid bilayers. Am. J. Physiol. Hear. Circ. Physiol. 261, H604-H609. doi: 10.1152/ajpheart.1991.261.2.H604

Kovacs-Oller, T., Ivanova, E., Bianchimano, P., and Sagdullaev, B. T. (2020). The pericyte connectome: spatial precision of neurovascular coupling is driven by selective connectivity maps of pericytes and endothelial cells and is disrupted in diabetes. Cell Discov. 6:39. doi: 10.1038/s41421-020-0180-0

Koval, M., Molina, S. A., and Burt, J. M. (2014). Mix and match: investigating heteromeric and heterotypic gap junction channels in model systems and native tissues. FEBS Lett. 588, 1193-1204. doi: 10.1016/j.febslet.2014.02.025

Kozielewicz, P., Turku, A., and Schulte, G. (2020). Molecular pharmacology of class F receptor activation. Mol. Pharmacol. 97, 62-71. doi: 10.1124/mol.119.117986

Ksiazek, M., Chacińska, M., Chabowski, A., and Baranowski, M. (2015). Sources, metabolism, and regulation of circulating sphingosine-1-phosphate. J. Lipid Res. 56, 1271-1281. doi: 10.1194/jlr.R059543

Kurz, H. (2009). Cell lineages and early patterns of embryonic CNS vascularization. Cell Adhes. Migr. 3, 205-210. doi: 10.4161/cam.3.2.7855

Lacroix, A., Toussay, X., Anenberg, E., Lecrux, C., Ferreirós, N., Karagiannis, A., et al. (2015). COX-2-derived prostaglandin $\mathrm{E}_{2}$ produced by pyramidal neurons contributes to neurovascular coupling in the rodent cerebral cortex. J. Neurosci. 35, 11791-11810. doi: 10.1523/JNEUROSCI.0651-15.2015

Lagerström, M. C., and Schiöth, H. B. (2008). Structural diversity of G protein coupled receptors and significance for drug discovery. Nat. Rev. Drug Discov. 7, 339-357. doi: 10.1038/nrd2518

Lazarowski, E. (2006). Regulated release of nucleotides and UDP sugars from astrocytoma cells. Novartis Found. Symp. 276, 73-84. doi: 10.1002/9780470032244.ch7

Lazarowski, E. R. (2012). Vesicular and conductive mechanisms of nucleotide release. Purinergic Signal. 8, 359-373. doi: 10.1007/s11302-012-9304-9

Lazarowski, E. R., and Harden, T. K. (2015). UDP-sugars as extracellular signaling molecules: cellular and physiologic consequences of $\mathrm{P}_{2} \mathrm{Y}_{14}$ receptor activation. Mol. Pharmacol. 88, 151-160. doi: 10.1124/mol.115.098756

Ledoux, J., Werner, M. E., Brayden, J. E., and Nelson, M. T. (2006). Calciumactivated potassium channels and the regulation of vascular tone. Physiology 21, 69-78. doi: 10.1152/physiol.00040.2005
Lee, A., Scheuer, T., and Catterall, W. A. (2000). $\mathrm{Ca}^{2+} /$ calmodulin-dependent facilitation and inactivation of P/Q-type $\mathrm{Ca}^{2+}$ channels. J. Neurosci. 20, 6830-6838. doi: 10.1523/JNEUROSCI.20-18-06830.2000

Lee, A., Wong, S. T., Gallagher, D., Li, B., Storm, D. R., Scheuer, T., et al. (1999). $\mathrm{Ca}^{2+} /$ calmodulin binds to and modulates P/Q-type calcium channels. Nature 399, 155-159. doi: 10.1038/20194

Lee-Kwon, W., Goo, J. H., Zhang, Z., Silldorff, E. P., and Pallone, T. L. (2007). Vasa recta voltage-gated $\mathrm{Na}^{+}$channel $\mathrm{Na}_{\mathrm{v}} 1.3$ is regulated by calmodulin. Am. J. Physiol. Ren. Physiol. 292, F404-F414. doi: 10.1152/ajprenal.00070.2006

Lefkimmiatis, K., and Zaccolo, M. (2014). cAMP signaling in subcellular compartments. Pharmacol. Ther. 143, 295-304. doi: 10.1016/j.pharmthera.2014.03.008

Leloir, L. F., Olavarría, J. M., Goldemberg, S. H., and Carminatti, H. (1959). Biosynthesis of glycogen from uridine diphosphate glucose. Arch. Biochem. Biophys. 81, 508-520. doi: 10.1016/0003-9861(59)90232-2

Li, B., and Freeman, R. D. (2015). Neurometabolic coupling between neural activity, glucose and lactate in activated visual cortex. J. Neurochem. 135, 742-754. doi: 10.1111/jnc. 13143

Li, J., Hou, B., Tumova, S., Muraki, K., Bruns, A., Ludlow, M. J., et al. (2014). Piezo1 integration of vascular architecture with physiological force. Nature 515, 279-282. doi: 10.1038/nature13701

Li, M., van Esch, B. C. A. M., Henricks, P. A. J., Folkerts, G., and Garssen, J. (2018). The anti-inflammatory effects of short chain fatty acids on lipopolysaccharide- or tumor necrosis factor $\alpha$-stimulated endothelial cells via activation of GPR41/43 and inhibition of HDACs. Front. Pharmacol. 9:533. doi: 10.3389/fphar.2018.00533

Li, N., Wu, J. X., Ding, D., Cheng, J., Gao, N., and Chen, L. (2017). Structure of a pancreatic ATP-sensitive potassium channel. Cell 168, 101-110. doi: 10.1016/j.cell.2016.12.028

Li, Q., and Puro, D. G. (2001). Adenosine activates ATP-sensitive $\mathrm{K}^{+}$currents in pericytes of rat retinal microvessels: role of $A_{1}$ and $A_{2 a}$ receptors. Brain Res. 907, 93-99. doi: 10.1016/S0006-8993(01)02607-5

Li, Y., Wang, F., Zhang, X., Qi, Z., Tang, M., Szeto, C., et al. (2012). $\beta$-adrenergic stimulation increases $\mathrm{Ca}_{\mathrm{v}} 3.1$ activity in cardiac myocytes through protein kinase A. PLoS ONE 7:e39965. doi: 10.1371/journal.pone.0039965

Li, Z., Zhang, W., and Mulholland, M. W. (2015). LGR4 and its role in intestinal protection and energy metabolism. Front. Endocrinol. 6:131. doi: 10.3389/fendo.2015.00131

Lin, H., Pallone, T. L., and Cao, C. (2010). Murine vasa recta pericyte chloride conductance is controlled by calcium, depolarization, and kinase activity. Am. J. Physiol. Regul. Integr. Comp. Physiol. 299, R1317-R1325. doi: 10.1152/ajpregu.00129.2010

Lintschinger, B., Balzer-Geldsetzer, M., Baskaran, T., Graier, W. F., Christoph, R., Zhu, M. X., et al. (2000). Coassembly of Trp1 and Trp3 proteins generates diacylglycerol- and $\mathrm{Ca}^{2+}$-sensitive cation channels. J. Biol. Chem. 275, 27799-27805. doi: 10.1074/jbc.M002705200

Lipscombe, D., Helton, T. D., and Xu, W. (2004). L-type calcium channels: the low down. J. Neurophysiol. 92, 2633-2641. doi: 10.1152/jn.00486.2004

Liu, G., Papa, A., Katchman, A. N., Zakharov, S. I., Roybal, D., Hennessey, J. A., et al. (2020). Mechanism of adrenergic $\mathrm{Ca}_{\mathrm{V}} 1.2$ stimulation revealed by proximity proteomics. Nature $577,695-700$. doi: $10.1038 / \mathrm{s} 41586-020-1947-\mathrm{Z}$

Liu, H., Enyeart, J. A., and Enyeart, J. J. (2010). ACTH induces $\mathrm{Ca}_{\mathrm{v}} 3.2$ current and mRNA by cAMP-dependent and cAMP-independent mechanisms. J. Biol. Chem. 285, 20040-20050. doi: 10.1074/jbc.M110.104190

Liu, Y., Beyer, A., and Aebersold, R. (2016). On the dependency of cellular protein levels on mRNA abundance. Cell 165, 535-550. doi: 10.1016/j.cell.2016. 03.014

Liu, Y., Zhang, Z., Wang, Y., Song, J., Ma, K., Si, J., et al. (2018). Electrophysiological properties of strial pericytes and the effect of aspirin on pericyte $\mathrm{K}^{+}$channels. Mol. Med. Rep. 17, 2861-2868. doi: $10.3892 / \mathrm{mmr} .2017 .8194$

Lock, J. T., and Parker, I. (2020). $\mathrm{IP}_{3}$ mediated global $\mathrm{Ca}^{2+}$ signals arise through two temporally and spatially distinct modes of $\mathrm{Ca}^{2+}$ release. Elife 9:e55008. doi: 10.7554/eLife.55008.sa2

Lolicato, M., Riegelhaupt, P. M., Arrigoni, C., Clark, K. A., and Minor Jr., D. L. (2014). Transmembrane helix straightening and buckling underlies activation of mechanosensitive and thermosensitive $\mathrm{K}_{2} \mathrm{P}$ channels. Neuron 84, 1198-1212. doi: 10.1016/j.neuron.2014.11.017 
Longden, T., Harraz, O., Hennig, G., Shui, B., Lee, F., Lee, J., et al. (2019). Neural activity drives dynamic $\mathrm{Ca}^{2+}$ signals in capillary endothelial cells that shape local brain blood flow. FASEB J. 33:688. doi: 10.1096/fasebj.2019.33.1_supplement.688.8

Longden, T. A., Dabertrand, F., Hill-Eubanks, D. C., Hammack, S. E., and Nelson, M. T. (2014). Stress-induced glucocorticoid signaling remodels neurovascular coupling through impairment of cerebrovascular inwardly rectifying $\mathrm{K}^{+}$channel function. Proc. Natl. Acad. Sci. U.S.A. 111, 7462-7467. doi: $10.1073 /$ pnas.1401811111

Longden, T. A., Dabertrand, F., Koide, M., Gonzales, A. L., Tykocki, N. R., Brayden, J. E., et al. (2017). Capillary $\mathrm{K}^{+}$-sensing initiates retrograde hyperpolarization to locally increase cerebral blood flow. Nat. Neurosci. 20, 717-726. doi: 10.1038/nn.4533

Longden, T. A., Hill-Eubanks, D. C., and Nelson, M. T. (2016). Ion channel networks in the control of cerebral blood flow. J. Cereb. Blood Flow Metab. 36, 492-512. doi: 10.1177/0271678X15616138

Longden, T. A., and Nelson, M. T. (2015). Vascular inward rectifier $\mathrm{K}^{+}$channels as external $\mathrm{K}^{+}$sensors in the control of cerebral blood flow. Microcirculation 22, 183-196. doi: 10.1111/micc. 12190

Luvisetto, S., Fellin, T., Spagnolo, M., Hivert, B., Brust, P. F., Harpold, M. M., et al. (2004). Modal gating of human $\mathrm{Ca}_{\mathrm{v}} 2.1$ (P/Q-type) calcium channels: I. The slow and the fast gating modes and their modulation by $\beta$ subunits. J. Gen. Physiol. 124, 445-461. doi: 10.1085/jgp.200409034

Ma, L., and Dorling, A. (2012). The roles of thrombin and proteaseactivated receptors in inflammation. Semin. Immunopathol. 34, 63-72. doi: 10.1007/s00281-011-0281-9

MacDonald, B., Tamai, K., and He, X. (2009). Wnt/beta-catenin signaling: components, mechanisms, and diseases. Dev. Cell 17, 9-26. doi: 10.1016/j.devcel.2009.06.016

MacDonald, P. E., Joseph, J. W., and Rorsman, P. (2005). Glucose-sensing mechanisms in pancreatic $\beta$-cells. Philos. Trans. R. Soc. London. Ser. B, Biol. Sci. 360, 2211-2225. doi: 10.1098/rstb.2005.1762

Maguire, J. J., and Davenport, A. P. (2015). Endothelin receptors and their antagonists. Semin. Nephrol. 35, 125-136. doi: 10.1016/j.semnephrol.2015.02.002

Mahapatra, S., Marcantoni, A., Zuccotti, A., Carabelli, V., and Carbone, E. (2012). Equal sensitivity of $\mathrm{Ca}_{\mathrm{v}} 1.2$ and $\mathrm{Ca}_{\mathrm{v}} 1.3$ channels to the opposing modulations of PKA and PKG in mouse chromaffin cells. J. Physiol. 590, 5053-5073. doi: 10.1113/jphysiol.2012.236729

Mahon, M. J. (2012). The parathyroid hormone receptorsome and the potential for therapeutic intervention. Curr. Drug Targets 13, 116-128. doi: $10.2174 / 138945012798868416$

Makani, S., and Chesler, M. (2010). Rapid rise of extracellular pH evoked by neural activity is generated by the plasma membrane calcium ATPase. J. Neurophysiol. 103, 667-676. doi: 10.1152/jn.00948.2009

Mani, B. K., Robakowski, C., Brueggemann, L. I., Cribbs, L. L., Tripathi, A., Majetschak, M., et al. (2016). $K_{\mathrm{v}} 7.5$ potassium channel subunits are the primary targets for PKA-Dependent enhancement of vascular smooth muscle $\mathrm{K}_{\mathrm{v}} 7$ currents. Mol. Pharmacol. 89, 323-334. doi: 10.1124/mol.115.101758

Markworth, E., Schwanstecher, C., and Schwanstecher, M. (2000). ATP4mediates closure of pancreatic beta-cell ATP-sensitive potassium channels by interaction with 1 of 4 identical sites. Diabetes 49, 1413-1418. doi: $10.2337 /$ diabetes.49.9.1413

Masago, K., Kihara, Y., Yanagida, K., Hamano, F., Nakagawa, S., Niwa, M., et al. (2018). Lysophosphatidic acid receptor, LPA6, regulates endothelial blood-brain barrier function: implication for hepatic encephalopathy. Biochem. Biophys. Res. Commun. 501, 1048-1054. doi: 10.1016/j.bbrc.2018.05.106

Mathew, R. J., Wilson, W. H., Tant, S. R., Robinson, L., and Prakash, R. (1988). Abnormal resting regional cerebral blood flow patterns and their correlates in schizophrenia. Arch. Gen. Psychiatry 45, 542-549. doi: 10.1001/archpsyc.1988.01800300038004

Mathiisen, T. M., Lehre, K. P., Danbolt, N. C., and Ottersen, O. P. (2010). The perivascular astroglial sheath provides a complete covering of the brain microvessels: an electron microscopic 3D reconstruction. Glia 58, 1094-1103. doi: 10.1002 /glia. 20990

Matsushita, K., Fukumoto, M., Kobayashi, T., Kobayashi, M., Ishizaki, E., Minami, M., et al. (2010). Diabetes-induced inhibition of voltage-dependent calcium channels in the retinal microvasculature: role of spermine. Investig. Opthalmology Vis. Sci. 51, 5979-5990. doi: 10.1167/iovs.10-5377

Matsushita, K., and Puro, D. G. (2006). Topographical heterogeneity of $\mathrm{K}_{\mathrm{ir}}$ currents in pericyte-containing microvessels of the rat retina: effect of diabetes. J. Physiol. 573, 483-495. doi: 10.1113/jphysiol.2006.107102

Maudsley, S., Martin, B., and Luttrell, L. M. (2005). The origins of diversity and specificity in G protein-coupled receptor signaling. J. Pharmacol. Exp. Ther. 314, 485-494. doi: 10.1124/jpet.105.083121

May, V., Lutz, E., MacKenzie, C., Schutz, K. C., Dozark, K., and Braas, K. M. (2010). Pituitary adenylate cyclase-activating polypeptide (PACAP)/PAC 1HOP1 receptor activation coordinates multiple neurotrophic signaling pathways: akt activation through phosphatidylinositol 3-kinase $\gamma$ and vesicle endocytosis for neuronal survival. J. Biol. Chem. 285, 9749-9761. doi: 10.1074/jbc.M109.043117

Mayor, S., and Pagano, R. E. (2007). Pathways of clathrin-independent endocytosis. Nat. Rev. Mol. Cell Biol. 8, 603-612. doi: 10.1038/nrm2216

Mazzotti, C., Gagliostro, V, Bosisio, D., Del Prete, A., Tiberio, L., Thelen, M. M., et al. (2017). The atypical receptor CCRL2 (C-C Chemokine Receptor-Like 2) does not act as a decoy receptor in endothelial cells. Front. Immunol. 8:1233. doi: 10.3389/fimmu.2017.01233

McGrory, S., Ballerini, L., Doubal, F. N., Staals, J., Allerhand, M., ValdesHernandez, M., et al. (2019). Retinal microvasculature and cerebral small vessel disease in the lothian birth cohort 1936 and mild stroke study. Sci. Rep. 9:6320. doi: 10.1038/s41598-019-42534-x

Means, C. K., and Brown, J. H. (2009). Sphingosine-1-phosphate receptor signalling in the heart. Cardiovasc. Res. 82, 193-200. doi: 10.1093/cvr/cvp086

Mehta, D., Ahmmed, G. U., Paria, B. C., Holinstat, M., Voyno-Yasenetskaya, T., Tiruppathi, C., et al. (2003). RhoA interaction with inositol 1,4,5-trisphosphate receptor and transient receptor potential channel-1 regulates $\mathrm{Ca}^{2+}$ entry: role in signaling increased endothelial permeability. J. Biol. Chem. 278, 33492-33500. doi: 10.1074/jbc.M302401200

Mestre, H., Tithof, J., Du, T., Song, W., Peng, W., Sweeney, A. M., et al. (2018). Flow of cerebrospinal fluid is driven by arterial pulsations and is reduced in hypertension. Nat. Commun. 9:4878. doi: 10.1038/s41467-018-07318-3

Miki, T., Liss, B., Minami, K., Shiuchi, T., Saraya, A., Kashima, Y., et al. (2001). ATP-sensitive $\mathrm{K}^{+}$channels in the hypothalamus are essential for the maintenance of glucose homeostasis. Nat. Neurosci. 4, 507-512. doi: $10.1038 / 87455$

Mikoshiba, K. (2015). Role of $\mathrm{IP}_{3}$ receptor signaling in cell functions and diseases. Adv. Biol. Regul. 57, 217-227. doi: 10.1016/j.jbior.2014.10.001

Miller, A. N., and Long, S. B. (2012). Crystal structure of the human two-pore domain potassium channel $\mathrm{K}_{2 \mathrm{P}} 1$. Science 335, 432-436. doi: $10.1126 /$ science. 1213274

Mironov, S. L., and Skorova, E. Y. (2011). Stimulation of bursting in preBötzinger neurons by Epac through calcium release and modulation of TRPM4 and K-ATP channels. J. Neurochem. 117, 295-308. doi: 10.1111/j.1471-4159.2011.07202.x

Mishra, A., Reynolds, J. P., Chen, Y., Gourine, A. V., Rusakov, D. A., and Attwell, D. (2016). Astrocytes mediate neurovascular signaling to capillary pericytes but not to arterioles. Nat. Neurosci. 19, 1619-1627. doi: 10.1038/nn.4428

Miyata, N., and Roman, R. J. (2005). Role of 20-hydroxyeicosatetraenoic acid (20-HETE) in vascular system. J. Smooth Muscle Res. 41, 175-193. doi: $10.1540 /$ jsmr.41.175

Mogi, M., and Horiuchi, M. (2011). Neurovascular coupling in cognitive impairment associated with diabetes mellitus. Circ. J. 75, 1042-1048. doi: 10.1253/circj.CJ-11-0121

Muraki, K., Iwata, Y., Katanosaka, Y., Ito, T., Ohya, S., Shigekawa, M., et al. (2003). TRPV2 is a component of osmotically sensitive cation channels in murine aortic myocytes. Circ. Res. 93, 829-838. doi: 10.1161/01.RES.0000097263.10220.0C

Muszkat, M., Kurnik, D., Solus, J., Sofowora, G. G., Xie, H. G., Jiang, L., et al. (2005). Variation in the $\alpha_{2 B}$-adrenergic receptor gene (ADRA2B) and its relationship to vascular response in vivo. Pharmacogenet. Genomics 15, 407-414. doi: 10.1097/01213011-200506000-00006

Nalli, A. D., Kumar, D. P., Al-Shboul, O., Mahavadi, S., Kuemmerle, J. F., Grider, J. R., et al. (2014). Regulation of G $\beta \gamma_{i}$-dependent PLC- $\beta 3$ activity in smooth muscle: inhibitory phosphorylation of PLC- $\beta 3$ by PKA and PKG and stimulatory phosphorylation of $\mathrm{Ga}_{\mathrm{i}}$-GTPase-activating protein RGS2 
by PKG. Cell Biochem. Biophys. 70, 867-880. doi: 10.1007/s12013-0149992-6

Narayanan, D., Bulley, S., Leo, M. D., Burris, S. K., Gabrick, K. S., Boop, F. A., et al. (2013). Smooth muscle cell transient receptor potential polycystin-2 (TRPP2) channels contribute to the myogenic response in cerebral arteries. J. Physiol. 591, 5031-5046. doi: 10.1113/jphysiol.2013.258319

Nelson, M. T., Patlak, J. B., Worley, J. F., and Standen, N. B. (1990). Calcium channels, potassium channels, and voltage dependence of arterial smooth muscle tone. Am. J. Physiol. Cell Physiol. 259, C3-C18. doi: 10.1152/ajpcell.1990.259.1.C3

Nelson, M. T., and Quayle, J. M. (1995). Physiological roles and properties of potassium channels in arterial smooth muscle. Am. J. Physiol. Cell Physiol. 268, C799-C822. doi: 10.1152/ajpcell.1995.268.4.C799

Newman, E. (1986). High potassium conductance in astrocyte endfeet. Science 233, 453-454. doi: 10.1126/science.3726539

Newman, E. A. (2013). Functional hyperemia and mechanisms of neurovascular coupling in the retinal vasculature. J. Cereb. Blood Flow Metab. 33, 1685-1695. doi: $10.1038 /$ jcbfm.2013.145

Newton, A. C. (2010). Protein kinase C: poised to signal. Am. J. Physiol. Endocrinol. Metab. 298, E395-E402. doi: 10.1152/ajpendo.00477.2009

Nichols, A. S., Floyd, D. H., Bruinsma, S. P., Narzinski, K., and Baranski, T. J. (2013). Frizzled receptors signal through G proteins. Cell. Signal. 25, 1468-1475. doi: 10.1016/j.cellsig.2013.03.009

Nicolakakis, N., and Hamel, E. (2011). Neurovascular function in Alzheimer's disease patients and experimental models. J. Cereb. Blood Flow Metab. 31, 1354-1370. doi: 10.1038/jcbfm.2011.43

Nilius, B., and Droogmans, G. (2003). Amazing chloride channels: an overview. Acta Physiol. Scand. 177, 119-147. doi: 10.1046/j.1365-201X.2003.01060.x

Nilius, B., and Owsianik, G. (2011). The transient receptor potential family of ion channels. Genome Biol. 12:218. doi: 10.1186/gb-2011-12-3-218

Nilius, B., Owsianik, G., Voets, T., and Peters, J. A. (2007). Transient receptor potential cation channels in disease. Physiol. Rev. 87, 165-217. doi: 10.1152/physrev.00021.2006

Nilius, B., Prenen, J., Tang, J., Wang, C., Owsianik, G., Janssens, A., et al. (2005). Regulation of the $\mathrm{Ca}^{2+}$ sensitivity of the nonselective cation channel TRPM4. J. Biol. Chem. 280, 6423-6433. doi: 10.1074/jbc.M411089200

Nishioka, K., Nishida, M., Ariyoshi, M., Jian, Z., Saiki, S., Hirano, M., et al. (2011). Cilostazol suppresses angiotensin II-induced vasoconstriction via protein kinase A-mediated phosphorylation of the transient receptor potential canonical 6 channel. Arterioscler. Thromb. Vasc. Biol. 31, 2278-2286. doi: 10.1161/ATVBAHA.110.221010

Niswender, C. M., and Conn, P. J. (2010). Metabotropic glutamate receptors: physiology, pharmacology, and disease. Annu. Rev. Pharmacol. Toxicol. 50, 295-322. doi: 10.1146/annurev.pharmtox.011008.145533

Noorbakhsh, F., Vergnolle, N., Hollenberg, M. D., and Power, C. (2003). Proteinase-activated receptors in the nervous system. Nat. Rev. Neurosci. 4, 981-990. doi: 10.1038/nrn1255

Nortley, R., Mishra, A., Jaunmuktane, Z., Kyrargyri, V., Madry, C., Gong, H., et al. (2019). Amyloid? oligomers constrict human capillaries in Alzheimer's disease via signalling to pericytes. Science 365:300. doi: 10.1126/science.aav9518

Ohkita, M., Tawa, M., Kitada, K., and Matsumura, Y. (2012). Pathophysiological roles of endothelin receptors in cardiovascular diseases. J. Pharmacol. Sci. 119, 302-313. doi: 10.1254/jphs.12R01CR

Olah, M. E. (1997). Identification of $A_{2 a}$ adenosine receptor domains involved in selective coupling to $\mathrm{G}_{\mathrm{s}}$ : analysis of chimeric $\mathrm{A}_{1} / \mathrm{A}_{2 \mathrm{a}}$ adenosine receptors. $J$. Biol. Chem. 272, 337-344. doi: 10.1074/jbc.272.1.337

Orkand, R. K., Nicholls, J. G., and Kuffler, S. W. (1966). Effect of nerve impulses on the membrane potential of glial cells in the central nervous system of amphibia. J. Neurophysiol. 29, 788-806. doi: 10.1152/jn.1966.29.4.788

Owen, N. E. (1984). Regulation of $\mathrm{Na} / \mathrm{K} / \mathrm{Cl}$ cotransport in vascular smooth muscle cells. Biochem. Biophys. Res. Commun. 125, 500-508. doi: 10.1016/0006-291X(84)90568-0

Öz, G., DiNuzzo, M., Kumar, A., Moheet, A., and Seaquist, E. R. (2015). Revisiting glycogen content in the human brain. Neurochem. Res. 40, 2473-2481. doi: 10.1007/s11064-015-1664-4

Ozen, G., Benyahia, C., Amgoud, Y., Patel, J., Abdelazeem, H., Bouhadoun, A., et al. (2020). Interaction between $\mathrm{PGI}_{2}$ and ET-1 pathways in vascular smooth muscle from Group-III pulmonary hypertension patients. Prostaglandins Other Lipid Mediat. 146:106388. doi: 10.1016/j.prostaglandins.2019.106388

Paik, J. H., Skoura, A., Chae, S. S., Cowan, A. E., Han, D. K., Proia, R. L., et al. (2004). Sphingosine 1-phosphate receptor regulation of N-cadherin mediates vascular stabilization. Genes Dev. 18, 2392-2403. doi: 10.1101/gad.1227804

Palazzo, E., Marabese, I., de Novellis, V., Rossi, F., and Maione, S. (2016). Metabotropic glutamate receptor 7: from synaptic function to therapeutic implications. Curr. Neuropharmacol. 14, 504-513. doi: 10.2174/1570159X13666150716165323

Park, J. Y., Kang, H. W., Moon, H. J., Huh, S. U., Jeong, S. W., Soldatov, N. M., et al. (2006). Activation of protein kinase C augments T-type $\mathrm{Ca}^{2+}$ channel activity without changing channel surface density. J. Physiol. 577, 513-523. doi: 10.1113/jphysiol.2006.117440

Patel, C., Narayanan, S. P., Zhang, W., Xu, Z., Sukumari-Ramesh, S., Dhandapani, K. M., et al. (2014). Activation of the endothelin system mediates pathological angiogenesis during ischemic retinopathy. Am. J. Pathol. 184, 3040-3051. doi: 10.1016/j.ajpath.2014.07.012

Patton, N., Aslam, T., MacGillivray, T., Pattie, A., Deary, I. J., and Dhillon, B. (2005). Retinal vascular image analysis as a potential screening tool for cerebrovascular disease: A rationale based on homology between cerebral and retinal microvasculatures. J. Anat. 206, 319-348. doi: 10.1111/j.1469-7580.2005.00395.x

Paulino, C., Kalienkova, V., Lam, A. K. M., Neldner, Y., and Dutzler, R. (2017). Activation mechanism of the calcium-activated chloride channel TMEM16A revealed by cryo-EM. Nature 552, 421-425. doi: 10.1038/nature24652

Paulson, O. B., Hasselbalch, S. G., Rostrup, E., Knudsen, G. M., and Pelligrino, D. (2010). Cerebral blood flow response to functional activation. J. Cereb. Blood Flow Metab. 30, 2-14. doi: 10.1038/jcbfm.2009.188

Paulson, O. B., Strandgaard, S., and Edvinsson, L. (1990). Cerebral autoregulation. Cerebrovasc. Brain Metab. Rev. 2, 161-192.

Pearson-Leary, J., and McNay, E. C. (2016). Novel roles for the insulin-regulated glucose transporter-4 in hippocampally dependent memory. J. Neurosci. 36, 11851-11864. doi: 10.1523/JNEUROSCI.1700-16.2016

Pébay, A., and Wong, R. C. B. (2017). Lipidomics of Stem Cells. Cham: Humana Press. doi: 10.1007/978-3-319-49343-5

Pedersen, S. F., Owsianik, G., and Nilius, B. (2005). TRP channels: an overview. Cell Calcium 38, 233-252. doi: 10.1016/j.ceca.2005.06.028

Pelligrino, D. A., Vetri, F., and Xu, H. L. (2011). Purinergic mechanisms in gliovascular coupling. Semin. Cell Dev. Biol. 22, 229-236. doi: 10.1016/j.semcdb.2011.02.010

Peppiatt, C. M., Howarth, C., Mobbs, P., and Attwell, D. (2006). Bidirectional control of CNS capillary diameter by pericytes. Nature 443, 700-704. doi: 10.1038/nature05193

Perálvarez-Marín, A., Doñate-Macian, P., and Gaudet, R. (2013). What do we know about the transient receptor potential vanilloid 2 (TRPV2) ion channel? FEBS J. 280, 5471-5487. doi: 10.1111/febs.12302

Perez-Reyes, E. (2003). Molecular physiology of low-voltage-activated T-type calcium channels. Physiol. Rev. 83, 117-161. doi: 10.1152/physrev.00018.2002

Peterson, B. Z., DeMaria, C. D., and Yue, D. T. (1999). Calmodulin is the $\mathrm{Ca}^{2+}$ sensor for $\mathrm{Ca}^{2+}$-dependent inactivation of L-type calcium channels. Neuron 22, 549-558. doi: 10.1016/S0896-6273(00)80709-6

Pitt, S. J., Reilly-O'Donnell, B., and Sitsapesan, R. (2016). Exploring the biophysical evidence that mammalian two-pore channels are NAADP-activated calcium-permeable channels. J. Physiol. 594, 4171-4179. doi: 10.1113/JP2 70936

Platania, C. B. M., Giurdanella, G., Di Paola, L., Leggio, G. M., Drago, F., Salomone, S., et al. (2017). P2X 7 receptor antagonism: implications in diabetic retinopathy. Biochem. Pharmacol. 138, 130-139. doi: 10.1016/j.bcp.2017.05.001

Poyner, D. R., Sexton, P. M., Marshall, I., Smith, D. M., Quirion, R., Born, W., et al. (2002). International Union of Pharmacology. XXXII. The mammalian calcitonin gene-related peptides, adrenomedullin, amylin, and calcitonin receptors. Pharmacol. Rev. 54, 233-246. doi: 10.1124/pr.54.2.233

Pozzi, A., Yurchenco, P. D., and Iozzo, R. V. (2017). The nature and biology of basement membranes. Matrix Biol. 57-58, 1-11. doi: 10.1016/j.matbio.2016.12.009

Prakriya, M., and Lewis, R. S. (2015). Store-operated calcium channels. Physiol. Rev. 95, 1383-1436. doi: 10.1152/physrev.00020.2014 
Praticò, D., and Dogné, J. M. (2005). Selective cyclooxygenase-2 inhibitors development in cardiovascular medicine. Circulation 112, 1073-1079. doi: 10.1161/CIRCULATIONAHA.104.524231

Proks, P., de Wet, H., and Ashcroft, F. M. (2010). Activation of the K(ATP) channel by Mg-nucleotide interaction with SUR1. J. Gen. Physiol. 136, 389-405. doi: 10.1085/jgp.201010475

Prossnitz, E. R., and Arterburn, J. B. (2015). International union of basic and clinical pharmacology. XCVII. G protein-coupled estrogen receptor and its pharmacologic modulators. Pharmacol. Rev. 67, 505-540. doi: 10.1124/pr.114.009712

Purves, G. I., Kamishima, T., Davies, L. M., Quayle, J. M., and Dart, C. (2009). Exchange protein activated by cAMP (Epac) mediates cAMP-dependent but protein kinase A-insensitive modulation of vascular ATP-sensitive potassium channels. J. Physiol. 587, 3639-3650. doi: 10.1113/jphysiol.2009. 173534

Quayle, J. M., Nelson, M. T., and Standen, N. B. (1997). ATP-sensitive and inwardly rectifying potassium channels in smooth muscle. Physiol. Rev. 77, 1165-1232. doi: 10.1152/physrev.1997.77.4.1165

Quayle, J. M., Turner, M. R., Burrell, H. E., and Kamishima, T. (2006). Effects of hypoxia, anoxia, and metabolic inhibitors on $\mathrm{K}_{\mathrm{ATP}}$ channels in rat femoral artery myocytes. Am. J. Physiol. Hear. Circ. Physiol. 291, H71-H80. doi: 10.1152/ajpheart.01107.2005

Querques, G., Borrelli, E., Sacconi, R., De Vitis, L., Leocani, L., Santangelo, R., et al. (2019). Functional and morphological changes of the retinal vessels in Alzheimer's disease and mild cognitive impairment. Sci. Rep. 9:63. doi: 10.1038/s41598-018-37271-6

Quignard, J., Harley, E., Duhault, J., Vanhoutte, P., and Félétou, M. (2003). $\mathrm{K}^{+}$channels in cultured bovine retinal pericytes: effects of $\beta$-adrenergic stimulation. J. Cardiovasc. Pharmacol. 42, 379-388. doi: 10.1097/00005344-200309000-00009

Quinn, K. V., Cui, Y., Giblin, J. P., Clapp, L. H., and Tinker, A. (2003). Do anionic phospholipids serve as cofactors or second messengers for the regulation of activity of cloned ATP-sensitive $\mathrm{K}^{+}$channels? Circ. Res. 93, 646-655. doi: 10.1161/01.RES.0000095247.81449.8E

Quinn, K. V., Giblin, J. P., and Tinker, A. (2004). Multisite phosphorylation mechanism for protein kinase A activation of the smooth muscle ATP-sensitive $\mathrm{K}^{+}$channel. Circ. Res. 94, 1359-1366. doi: 10.1161/01.RES.0000128513.34817.c4

Raifman, T. K., Kumar, P., Haase, H., Klussmann, E., Dascal, N., and Weiss, S. (2017). Protein kinase C enhances plasma membrane expression of cardiac L-type calcium channel, Ca $\mathrm{a}_{\mathrm{v}}$ 1.2. Channels 11, 604-615. doi: $10.1080 / 19336950.2017 .1369636$

Ramos, D., Navarro, M., Mendes-Jorge, L., Carretero, A., López-Luppo, M., Nacher, V., et al. (2013). "The use of confocal laser microscopy to analyze mouse retinal blood vessels," in Confocal Laser Microscopy - Principles and Applications in Medicine, Biology, and the Food Sciences, ed N. Lagali (London: IntechOpen), 19-37. doi: 10.5772/56131

Ranade, S. S., Qiu, Z., Woo, S. H., Hur, S. S., Murthy, S. E., Cahalan, S. M., et al. (2014). Piezol, a mechanically activated ion channel, is required for vascular development in mice. Proc. Natl. Acad. Sci. U.S.A. 111, 10347-10352. doi: $10.1073 /$ pnas. 1409233111

Ratelade, J., Klug, N. R., Lombardi, D., Angelim, M. K. S. C., Dabertrand, F., Domenga-Denier, V., et al. (2020). Reducing hypermuscularization of the transitional segment between arterioles and capillaries protects against spontaneous intracerebral hemorrhage. Circulation 141, 2078-2094. doi: 10.1161/CIRCULATIONAHA.119.040963

Reichhart, N., Schöberl, S., Keckeis, S., Alfaar, A. S., Roubeix, C., Cordes, M., et al. (2019). Anoctamin-4 is a bona fide $\mathrm{Ca}^{2+}$-dependent non-selective cation channel. Sci. Rep. 9:2257. doi: 10.1038/s41598-018-37287-y

Robertson, B. E., and Nelson, M. T. (1994). Aminopyridine inhibition and voltage dependence of $\mathrm{K}^{+}$currents in smooth muscle cells from cerebral arteries. Am. J. Physiol. Cell Physiol. 267, C1589-C1597. doi: 10.1152/ajpcell.1994.267.6. C1589

Ross, E. M., and Wilkie, T. M. (2000). GTPase-activating proteins for heterotrimeric $G$ proteins: regulators of $G$ protein signaling (RGS) and RGS-like proteins. Annu. Rev. Biochem. 69, 795-827. doi: 10.1146/annurev. biochem.69.1.795
Rossier, M. F. (2016). T-type calcium channel: a privileged gate for calcium entry and control of adrenal steroidogenesis. Front. Endocrinol. 7:43. doi: $10.3389 /$ fendo.2016.00043

Rouach, N., Koulakoff, A., Abudara, V., Willecke, K., and Giaume, C. (2008). Astroglial metabolic networks sustain hippocampal synaptic transmission. Science 322, 1551-1555. doi: 10.1126/science.1164022

Rouget, C. (1873). Mémoire sur le développement, la structure et les proprietés physiologiques des capillaires sanguins et lymphatiques. Arch. Physiol. Norm. Pathol. 5, 603-663.

Rungta, R. L., Chaigneau, E., Osmanski, B.-F., and Charpa, S. (2018). Vascular compartmentalization of functional hyperemia from the synapse to the pia. Neuron 99, 362-337. doi: 10.1016/j.neuron.2018.06.012

Russell, F. D., and Davenport, A. P. (1999). Secretory pathways in endothelin synthesis. Br. J. Pharmacol. 126, 391-398. doi: 10.1038/sj.bjp.0702315

Sadana, R., and Dessauer, C. W. (2009). Physiological roles for G protein-regulated adenylyl cyclase isoforms: insights from knockout and overexpression studies. NeuroSignals 17, 5-22. doi: 10.1159/000166277

Sakagami, K., Wu, D. M., and Puro, D. G. (1999). Physiology of rat retinal pericytes: modulation of ion channel activity by serum-derived molecules. J. Physiol. 521, 637-650. doi: 10.1111/j.1469-7793.1999.00637.x

Salomone, S., Soydan, G., Ip, P. C. T., Hopson, K. M. P., and Waeber, C. (2010). Vessel-specific role of sphingosine kinase 1 in the vasoconstriction of isolated basilar arteries. Pharmacol. Res. 62, 465-474. doi: 10.1016/j.phrs.2010.09.002

Sasaki, Y., Hoshi, M., Akazawa, C., Nakamura, Y., Tsuzuki, H., Inoue, K., et al. (2003). Selective expression of $\mathrm{G}_{\mathrm{i} / \mathrm{o}}$-coupled ATP receptor P2Y12 in microglia in rat brain. Glia 44, 242-250. doi: 10.1002/glia.10293

Sassone-Corsi, P. (2012). The cyclic AMP pathway. Cold Spring Harb. Perspect. Biol. 4:a011148. doi: 10.1101/cshperspect.a011148

Sawyer, I., Smillie, S. J., Bodkin, J. V., Fernandes, E., O’Byrne, K. T., and Brain, S. D. (2011). The vasoactive potential of kisspeptin-10 in the peripheral vasculature. PLoS ONE 6:e14671. doi: 10.1371/journal.pone.0014671

Scherer, D., Seyler, C., Xynogalos, P., Scholz, E. P., Thomas, D., Backs, J., et al. (2016). Inhibition of cardiac $\mathrm{K}_{\mathrm{ir}}$ current $\left(\mathrm{I}_{\mathrm{K} 1}\right)$ by protein kinase C critically depends on PKC $\beta$ and $\mathrm{K}_{\mathrm{ir}} 2.2$. PLoS ONE 11:e0156181. doi: 10.1371/journal.pone.0156181

Schlingmann, K. P., Waldegger, S., Konrad, M., Chubanov, V., and Gudermann, T. (2007). TRPM6 and TRPM7-gatekeepers of human magnesium metabolism. Biochim. Biophys. Acta 1772, 813-821. doi: 10.1016/j.bbadis.2007.03.009

Schulte, G. (2010). International Union of Basic and Clinical Pharmacology. LXXX. The class frizzled receptors. Pharmacol. Rev. 62, 632-667. doi: $10.1124 /$ pr.110.002931

Schwartz, E., Adamany, A. M., and Blumenfeld, O. O. (1981). Isolation and characterization of the internal elastic lamina from calf thoracic aorta. Exp. Mol. Pathol. 34, 299-306. doi: 10.1016/0014-4800(81)90047-2

Seino, S., and Miki, T. (2003). Physiological and pathophysiological roles of ATP-sensitive $\mathrm{K}^{+}$channels. Prog. Biophys. Mol. Biol. 81, 133-176. doi: 10.1016/S0079-6107(02)00053-6

Sekiguchi, F., and Kawabata, A. (2013). T-type calcium channels: functional regulation and implication in pain signaling. J. Pharmacol. Sci. 122, 244-250. doi: 10.1254/jphs.13R05CP

Selim, S., Sunkara, M., Salous, A. K., Leung, S. W., Berdyshev, E. V., Bailey, A., et al. (2011). Plasma levels of sphingosine 1-phosphate are strongly correlated with haematocrit, but variably restored by red blood cell transfusions. Clin. Sci. 121, 565-572. doi: $10.1042 / C S 20110236$

Sharif-Naeini, R., Folgering, J. H. A., Bichet, D., Duprat, F., Lauritzen, I., Arhatte, M., et al. (2009). Polycystin-1 and -2 dosage regulates pressure sensing. Cell 139, 587-596. doi: 10.1016/j.cell.2009.08.045

Sherwood, T. W., Frey, E. N., and Askwith, C. C. (2012). Structure and activity of the acid-sensing ion channels. Am. J. Physiol. Cell Physiol. 303, C699-C710. doi: 10.1152/ajpcell.00188.2012

Shi, Y., Chen, X., Wu, Z., Shi, W., Yang, Y., Cui, N., et al. (2008a). cAMPdependent protein kinase phosphorylation produces interdomain movement in SUR2B leading to activation of the vascular $\mathrm{K}_{\mathrm{ATP}}$ channel. J. Biol. Chem. 283, 7523-7530. doi: 10.1074/jbc.M709941200

Shi, Y., Cui, N., Shi, W., and Jiang, C. (2008b). A short motif in $\mathrm{K}_{\mathrm{ir}} 6.1$ consisting of four phosphorylation repeats underlies the vascular $\mathrm{K}_{\mathrm{ATP}}$ channel inhibition by protein kinase C. J. Biol. Chem. 283, 2488-2494. doi: 10.1074/jbc.M708769200 
Shi, Y., Wu, Z., Cui, N., Shi, W., Yang, Y., Zhang, X., et al. (2007). PKA phosphorylation of SUR2B subunit underscores vascular $\mathrm{K}_{\mathrm{ATP}}$ channel activation by beta-adrenergic receptors. Am. J. Physiol. Regul. Integr. Comp. Physiol. 293, R1205-R1214. doi: 10.1152/ajpregu.00337.2007

Shih, A. Y., Rühlmann, C., Blinder, P., Devor, A., Drew, P. J., Friedman, B., et al. (2015). Robust and fragile aspects of cortical blood flow in relation to the underlying angioarchitecture. Microcirculation 22, 204-218. doi: $10.1111 /$ micc. 12195

Shima, Y., Kawaguchi, S. Y., Kosaka, K., Nakayama, M., Hoshino, M., Nabeshima, Y., et al. (2007). Opposing roles in neurite growth control by two seven-pass transmembrane cadherins. Nat. Neurosci. 10, 963-969. doi: 10.1038/nn1933

Shyng, S. L., Ferrigni, T., and Nichols, C. G. (1997). Regulation of $\mathrm{K}_{\mathrm{ATP}}$ channel activity by diazoxide and MgADP. Distinct functions of the two nucleotide binding folds of the sulfonylurea receptor. J. Gen. Physiol. 110, 643-654. doi: 10.1085/jgp.110.6.643

Shyng, S. L., and Nichols, C. G. (1998). Membrane phospholipid control of nucleotide sensitivity of $\mathrm{K}_{\mathrm{ATP}}$ channels. Science 282, 1138-1141. doi: $10.1126 /$ science. 282.5391 .1138

Silva, A. S., and Zanesco, A. (2010). Physical exercise, $\beta$-adrenergic receptors, and vascular response. J. Vasc. Bras. 9, 47-56. doi: 10.1590/S1677-54492010000200007

Simon, M. I., Strathmann, M. P., and Gautam, N. (1991). Diversity of G proteins in signal transduction. Science 252, 802-808. doi: 10.1126/science.1902986

Singh, A., Gebhart, M., Fritsch, R., Sinnegger-Brauns, M. J., Poggiani, C., Hoda, J. C., et al. (2008). Modulation of voltage- and $\mathrm{Ca}^{2+}$-dependent gating of $\mathrm{Ca}_{\mathrm{v}} 1.3$ L-type calcium channels by alternative splicing of a C-terminal regulatory domain. J. Biol. Chem. 283, 20733-20744. doi: 10.1074/jbc.M802254200

Singh, J., Wen, X., and Scales, S. J. (2015). The orphan G protein-coupled receptor Gpr175 (Tpra40) enhances Hedgehog signaling by modulating cAMP levels. J. Biol. Chem. 290, 29663-29675. doi: 10.1074/jbc.M115.665810

Smith, I. F., and Parker, I. (2009). Imaging the quantal substructure of single $\mathrm{IP}_{3} \mathrm{R}$ channel activity during $\mathrm{Ca}^{2+}$ puffs in intact mammalian cells. Proc. Natl. Acad. Sci. U.S.A. 106, 6404-6409. doi: 10.1073/pnas.0810799106

Smrcka, A. V. (2008). G protein $\beta \gamma$ subunits: Central mediators of $G$ protein-coupled receptor signaling. Cell. Mol. Life Sci. 65, 2191-2214. doi: 10.1007/s00018-008-8006-5

Soboloff, J., Spassova, M. A., Tang, X. D., Hewavitharana, T., Xu, W., and Gill, D. L. (2006). Orail and STIM reconstitute store-operated calcium channel function. J. Biol. Chem. 281, 20661-20665. doi: 10.1074/jbc.C600126200

Soh, U. J., Dores, M. R., Chen, B., and Trejo, J. (2010). Signal transduction by protease-activated receptors. Br. J. Pharmacol. 160, 191-203. doi: 10.1111/j.1476-5381.2010.00705.x

Sokolovsky, M. (1995). Endothelin receptor subtypes and their role in transmembrane signaling mechanisms. Pharmacol. Ther. 68, 435-471. doi: 10.1016/0163-7258(95)02015-2

Souza Bomfim, G. H., Costiniti, V., Li, Y., Idaghdour, Y., and Lacruz, R. S. (2020). TRPM7 activation potentiates SOCE in enamel cells but requires ORAI. Cell Calcium 87:102187. doi: 10.1016/j.ceca.2020.102187

Stirling, L., Williams, M. R., and Morielli, A. D. (2009). Dual roles for RhoA/Rhokinase in the regulated trafficking of a voltage-sensitive potassium channel. Mol. Biol. Cell 20, 2991-3002. doi: 10.1091/mbc.e08-10-1074

Stölting, G., Teodorescu, G., Begemann, B., Schubert, J., Nabbout, R., Toliat, M. R., et al. (2013). Regulation of ClC-2 gating by intracellular ATP. Pflügers Arch. 465, 1423-1437. doi: 10.1007/s00424-013-1286-0

Stott, J. B., Povstyan, O. V., Carr, G., Barrese, V., and Greenwood, I. A. (2015). G-protein $\beta \gamma$ subunits are positive regulators of $\mathrm{K}_{\mathrm{v}} 7.4$ and native vascular $\mathrm{K}_{\mathrm{v}} 7$ channel activity. Proc. Natl. Acad. Sci. U.S.A. 112, 6497-6502. doi: 10.1073/pnas.1418605112

Straub, A., Zeigler, A., and Isakson, B. (2014). The myoendothelial junction: connections that deliver the message. Physiology 29, 242-249. doi: $10.1152 /$ physiol.00042.2013

Straub, S. V., Girouard, H., Doetsch, P. E., Hannah, R. M., Wilkerson, M. K., and Nelson, M. T. (2009). Regulation of intracerebral arteriolar tone by $K_{v}$ channels: effects of glucose and PKC. Am. J. Physiol. Cell Physiol. 297, C788-C796. doi: 10.1152/ajpcell.00148.2009

Striessnig, J., Pinggera, A., Kaur, G., Bock, G., and Tuluc, P. (2014). L-type $\mathrm{Ca}^{2+}$ channels in heart and brain. Wiley Interdiscip. Rev. Membr. Transp. Signal. 3, 15-38. doi: $10.1002 /$ wmts.102
Sugimura, R., He, X. C., Venkatraman, A., Arai, F., Box, A., Semerad, C., et al. (2012). Noncanonical Wnt signaling maintains hematopoietic stem cells in the niche. Cell 150, 351-365. doi: 10.1016/j.cell.2012.05.041

Sugiyama, T., Kawamura, H., Yamanishi, S., Kobayashi, M., Katsumura, K., and Puro, D. G. (2005). Regulation of $\mathrm{P}_{2} \mathrm{X}_{7}$-induced pore formation and cell death in pericyte-containing retinal microvessels. Am. J. Physiol. 288, C568-C576. doi: 10.1152/ajpcell.00380.2004

Sung, T. S., Jeon, J. P., Kim, B. J., Hong, C., Kim, S. Y., Kim, J., et al. (2011). Molecular determinants of PKA-dependent inhibition of TRPC5 channel. Am. J. Physiol. Cell Physiol. 301, C823-C832. doi: 10.1152/ajpcell.00351.2010

Suzuki, J., Umeda, M., Sims, P. J., and Nagata, S. (2010). Calciumdependent phospholipid scrambling by TMEM16F. Nature 468, 834-838. doi: 10.1038 /nature09583

Swärd, K., Mita, M., Wilson, D. P., Deng, J. T., Susnjar, M., and Walsh, M. P. (2003). The role of RhoA and Rho-associated kinase in vascular smooth muscle contraction. Curr. Hypertens. Rep. 5, 66-72. doi: 10.1007/s11906-003-0013-1

Tadross, M. R., Johny, M., Ben, and Yue, D. T. (2010). Molecular endpoints of $\mathrm{Ca}^{2+} /$ calmodulin- and voltage-dependent inactivation of $\mathrm{Ca}_{\mathrm{v}} 1.3$ channels. J. Gen. Physiol. 135, 197-215. doi: 10.1085/jgp.200910308

Tadross, M. R., and Yue, D. T. (2010). Systematic mapping of the state dependence of voltage- and $\mathrm{Ca}^{2+}$-dependent inactivation using simple openchannel measurements. J. Gen. Physiol. 135, 217-227. doi: 10.1085/jgp.2009 10309

Takezawa, R., Schmitz, C., Demeuse, P., Scharenberg, A. M., Penner, R., and Fleig, A. (2004). Receptor-mediated regulation of the TRPM7 channel through its endogenous protein kinase domain. Proc. Natl. Acad. Sci. U.S.A. 101, 6009-6014. doi: 10.1073/pnas.0307565101

Tanabe, K., Tucker, S. J., Ashcroft, F. M., Proks, P., Kioka, N., Amachi, T., et al. (2000). Direct photoaffinity labeling of $\mathrm{K}_{\mathrm{ir}} 6.2$ by [gamma-(32)P]ATP[gamma]4-azidoanilide. Biochem. Biophys. Res. Commun. 272, 316-319. doi: 10.1006/bbrc. 2000.2780

Tarasov, A., Dusonchet, J., and Ashcroft, F. (2004). Metabolic regulation of the pancreatic beta-cell ATP-sensitive $\mathrm{K}^{+}$channel: a pas de deux. Diabetes 53, S113-S122. doi: 10.2337/diabetes.53.suppl_3.S113

Taylor, M. S., Bonev, A. D., Gross, T. P., Eckman, D. M., Brayden, J. E., Bond, C. T., et al. (2003). Altered expression of small-conductance $\mathrm{Ca}^{2+}$-activated $\mathrm{K}^{+}(\mathrm{SK} 3)$ channels modulates arterial tone and blood pressure. Circ. Res. 93, 124-131. doi: 10.1161/01.RES.0000081980.63146.69

Tejada, M. A., Stople, K., Bomholtz, S. H., Meinild, A.-K., Poulsen, A. N., and Klaerke, D. A. (2014). Cell volume changes regulate slick (Slo2.1), but not slack (Slo2.2) $\mathrm{K}^{+}$channels. PLoS ONE 9:e110833. doi: 10.1371/journal.pone.0110833

Thiriet, M. (2013). Tissue Functioning and Remodeling in the Circulatory and Ventilatory Systems. Verlag; New York, NY: Springer. doi: 10.1007/978-1-4614-5966-8

Thorin, E., and Webb, D. J. (2010). Endothelium-derived endothelin-1. Pflugers Arch. 459, 951-958. doi: 10.1007/s00424-009-0763-y

Tilton, R. G., Kilo, C., and Williamson, J. R. (1979). Pericyte-endothelial relationships in cardiac and skeletal muscle capillaries. Microvasc. Res. 18, 325-335. doi: 10.1016/0026-2862(79)90041-4

Tobo, M., Tomura, H., Mogi, C., Wang, J. Q., Liu, J. P., Komachi, M., et al. (2007). Previously postulated "ligand-independent" signaling of GPR4 is mediated through proton-sensing mechanisms. Cell. Signal. 19, 1745-1753. doi: 10.1016/j.cellsig.2007.03.009

Tovey, S. C., Dedos, S. G., Rahman, T., Taylor, E. J. A., Pantazaka, E., and Taylor, C. W. (2010). Regulation of inositol 1,4,5-trisphosphate receptors by cAMP independent of cAMP-dependent protein kinase. J. Biol. Chem. 285, 12979-12989. doi: 10.1074/jbc.M109.096016

Trost, A., Lange, S., Schroedl, F., Bruckner, D., Motloch, K. A., Bogner, B., et al. (2016). Brain and retinal pericytes: Origin, function and role. Front. Cell. Neurosci. 10:20. doi: 10.3389/fncel.2016.00020

Tsai, P. S., Kaufhold, J. P., Blinder, P., Friedman, B., Drew, P. J., Karten, H. J., et al. (2009). Correlations of neuronal and microvascular densities in murine cortex revealed by direct counting and colocalization of nuclei and vessels. J. Neurosci. 29, 14553-14570. doi: 10.1523/JNEUROSCI.3287-09.2009

Tu, H., Wang, Z., Nosyreva, E., Smedt, H., De, and Bezprozvanny, I. (2005). Functional characterization of mammalian inositol 1,4,5-trisphosphate receptor isoforms. Biophys. J. 88, 1046-1055. doi: 10.1529/biophysj.104. 049593 
Tucker, S. J., Gribble, F. M., Zhao, C., Trapp, S., and Ashcroft, F. M. (1997). Truncation of $\mathrm{K}_{\mathrm{ir}} 6.2$ produces ATP-sensitive $\mathrm{K}^{+}$channels in the absence of the sulphonylurea receptor. Nature 387, 179-183. doi: 10.1038/387179a0

Tung, R. T., and Kurachi, Y. (1991). On the mechanism of nucleotide diphosphate activation of the ATP-sensitive $\mathrm{K}^{+}$channel in ventricular cell of guinea-pig. J. Physiol. 437, 239-256. doi: 10.1113/jphysiol.1991.sp018593

Ullrich, N. D., Voets, T., Prenen, J., Vennekens, R., Talavera, K., Droogmans, G., et al. (2005). Comparison of functional properties of the $\mathrm{Ca}^{2+}$-activated cation channels TRPM4 and TRPM5 from mice. Cell Calcium 37, 267-278. doi: 10.1016/j.ceca.2004.11.001

Upchurch, C., and Leitinger, N. (2019). "Biologically active lipids in vascular biology," in Fundamentals of Vascular Biology. Learning Materials in Biosciences, ed M. Geiger (Cham: Springer), 171-193. doi: 10.1007/978-3-030-12270-6_9

Urtatiz, O., and Van Raamsdonk, C. D. (2016). Gnaq and Gnall in the Endothelin signaling pathway and melanoma. Front. Genet. 7:59. doi: $10.3389 /$ fgene.2016.00059

van de Kreeke, J. A., Nguyen, H. T., Konijnenberg, E., Tomassen, J., den Braber, A., ten Kate, M., et al. (2018). Retinal and cerebral microvasculopathy: Relationships and their genetic contributions. Investig. Ophthalmol. Vis. Sci. 59, 5025-5031. doi: 10.1167/iovs.18-25341

Vanderheyden, V., Devogelaere, B., Missiaen, L., De Smedt, H., Bultynck, G., and Parys, J. B. (2009). Regulation of inositol 1,4,5-trisphosphate-induced $\mathrm{Ca}^{2+}$ release by reversible phosphorylation and dephosphorylation. Biochim. Biophys. Acta 1793, 959-970. doi: 10.1016/j.bbamcr.2008.12.003

Vanlandewijck, M., He, L., Mäe, M. A., Andrae, J., Ando, K., Gaudio, F., et al. (2018). A molecular atlas of cell types and zonation in the brain vasculature. Nature 554, 475-480. doi: 10.1038/nature25739

Veldhuis, N. A., Poole, D. P., Grace, M., McIntyre, P., Bunnett, N. W., and Christopoulos, A. (2015). The G protein-coupled receptor-transient receptor potential channel axis: molecular insights for targeting disorders of sensation and inflammation. Pharmacol. Rev. 67, 36-73. doi: 10.1124/pr.114.009555

Venkatachalam, K., and Montell, C. (2007). TRP Channels. Annu. Rev. Biochem. 76, 387-417. doi: 10.1146/annurev.biochem.75.103004.142819

Venkatachalam, K., Wong, C.-O., and Zhu, M. X. (2015). The role of TRPMLs in endolysosomal trafficking and function. Cell Calcium 58, 48-56. doi: $10.1016 /$ j.ceca.2014.10.008

Vergarajauregui, S., Oberdick, R., Kiselyov, K., and Puertollano, R. (2008). Mucolipin 1 channel activity is regulated by protein kinase A-mediated phosphorylation. Biochem. J. 410, 417-425. doi: 10.1042/BJ20070713

Vermassen, E., Fissore, R. A., Kasri, N. N., Vanderheyden, V., Callewaert, G., Missiaen, L., et al. (2004). Regulation of the phosphorylation of the inositol 1,4,5-trisphosphate receptor by protein kinase C. Biochem. Biophys. Res. Commun. 319, 888-893. doi: 10.1016/j.bbrc.2004.05.071

Vetri, F., Xu, H., Paisansathan, C., and Pelligrino, D. A. (2012). Impairment of neurovascular coupling in type 1 diabetes mellitus in rats is linked to PKC modulation of $\mathrm{BK}_{\mathrm{Ca}}$ and $\mathrm{K}_{\mathrm{ir}}$ channels. Am. J. Physiol. Hear. Circ. Physiol. 302, H1274-H1284. doi: 10.1152/ajpheart.01067.2011

Vilardaga, J. P., Romero, G., Friedman, P. A., and Gardella, T. J. (2011). Molecular basis of parathyroid hormone receptor signaling and trafficking: a family B GPCR paradigm. Cell. Mol. Life Sci. 68, 1-13. doi: 10.1007/s00018-010-0465-9

Villari, A., Giurdanella, G., Bucolo, C., Drago, F., and Salomone, S. (2017). Apixaban enhances vasodilatation mediated by protease-activated receptor 2 in isolated rat arteries. Front. Pharmacol. 8:480. doi: 10.3389/fphar.2017.00480

von Bartheld, C. S., Bahney, J., and Herculano-Houzel, S. (2016). The search for true numbers of neurons and glial cells in the human brain: a review of 150 years of cell counting. J. Comp. Neurol. 524, 3865-3895. doi: 10.1002/cne.24040 von Beckerath, N., Nees, S., Neumann, F. J., Krebs, B., Juchem, G., and Schömig, A. (2000). An inward rectifier and a voltage-dependent $\mathrm{K}^{+}$current in single, cultured pericytes from bovine heart. Cardiovasc. Res. 46, 569-578. doi: 10.1016/S0008-6363(00)00055-9

Wagner, T. F. J., Loch, S., Lambert, S., Straub, I., Mannebach, S., Mathar, I., et al. (2008). Transient receptor potential M3 channels are ionotropic steroid receptors in pancreatic $\beta$ cells. Nat. Cell Biol. 10, 1421-1430. doi: $10.1038 / \mathrm{ncb} 1801$

Wang, B., Li, C., Huai, R., and Qu, Z. (2015). Overexpression of ANO1/TMEM16A, an arterial $\mathrm{Ca}^{2+}$-activated $\mathrm{Cl}^{-}$channel, contributes to spontaneous hypertension. J. Mol. Cell. Cardiol. 82, 22-32. doi: 10.1016/j.yjmcc.2015.02.020
Wang, Q., Leo, M. D., Narayanan, D., Kuruvilla, K. P., and Jaggar, J. H. (2016). Local coupling of TRPC6 to ANO1/TMEM16A channels in smooth muscle cells amplifies vasoconstriction in cerebral arteries. Am. J. Physiol. Cell Physiol. 310, C1001-C1009. doi: 10.1152/ajpcell.00092.2016

Wang, Y., and Venton, B. J. (2017). Correlation of transient adenosine release and oxygen changes in the caudate-putamen. J. Neurochem. 140, 13-23. doi: 10.1111 /jnc. 13705

Watson, N., Linder, M. E., Druey, K. M., Kehrl, J. H., and Blumer, K. J. (1996). RGS family members: GTPase-activating proteins for heterotrimeric G- protein $\alpha$-subunits. Nature 383, 172-175. doi: 10.1038/383172a0

Watts, A. O., Verkaar, F., Van Der Lee, M. M. C., Timmerman, C. A. W., Kuijer, M., Offenbeek, J., et al. (2013). $\beta$-Arrestin recruitment and G protein signaling by the atypical human chemokine decoy receptor CCX-CKR. J. Biol. Chem. 288, 7169-7181. doi: 10.1074/jbc.M112.406108

Weiß, K. T., Fante, M., Köhl, G., Schreml, J., Haubner, F., Kreutz, M., et al. (2017). Proton-sensing $\mathrm{G}$ protein-coupled receptors as regulators of cell proliferation and migration during tumor growth and wound healing. Exp. Dermatol. 26, 127-132. doi: 10.1111/exd.13209

Wheeler, D. G., Groth, R. D., Ma, H., Barrett, C. F., Owen, S. F., Safa, P., et al. (2012). $\mathrm{Ca}_{\mathrm{v}} 1$ and $\mathrm{Ca}_{\mathrm{v}} 2$ channels engage distinct modes of $\mathrm{Ca}^{2+}$ signaling to control CREB-dependent gene expression. Cell 149, 1112-1124. doi: 10.1016/j.cell.2012.03.041

Wihlborg, A. K., Wang, L., Braun, O. Ö., Eyjolfsson, A., Gustafsson, R., Gudbjartsson, T., et al. (2004). ADP receptor P2Y12 is expressed in vascular smooth muscle cells and stimulates contraction in human blood vessels. Arterioscler. Thromb. Vasc. Biol. 24, 1810-1815. doi: 10.1161/01.ATV.0000142376.30582.ed

Winkler, E. A., Bell, R. D., and Zlokovic, B. V. (2011). Central nervous system pericytes in health and disease. Nat. Neurosci. 14, 1398-1405. doi: $10.1038 / \mathrm{nn} .2946$

Woodward, D. F., Jones, R. L., and Narumiya, S. (2011). International union of basic and clinical pharmacology. LXXXIII: classification of prostanoid receptors, updating 15 years of progress. Pharmacol. Rev. 63, 471-538. doi: $10.1124 /$ pr.110.003517

Worzfeld, T., Wettschureck, N., and Offermanns, S. (2008). $\mathrm{G}_{12} / \mathrm{G}_{13}$-mediated signalling in mammalian physiology and disease. Trends Pharmacol. Sci. 29, 582-589. doi: 10.1016/j.tips.2008.08.002

Woszczek, G., Chen, L.-Y., Nagineni, S., Alsaaty, S., Harry, A., Logun, C., et al. (2007). IFN- $\gamma$ induces cysteinyl leukotriene receptor 2 expression and enhances the responsiveness of human endothelial cells to cysteinyl leukotrienes. J. Immunol. 178, 5262-5270. doi: 10.4049/jimmunol.178.8.5262

Wroblewska, B., Santi, M. R., and Neale, J. H. (1998). Nacetylaspartylglutamate activates cyclic AMP-coupled metabotropic glutamate receptors in cerebellar astrocytes. Glia 24, 172-179. doi: 10.1002/(SICI)1098-1136(199810)24:2<172::AID-GLIA2>3.0.CO;2-6

Wu, D. M., Kawamura, H., Sakagami, K., Kobayashi, M., and Puro, D. G. (2003). Cholinergic regulation of pericyte-containing retinal microvessels. Am. J. Physiol. Hear. Circ. Physiol. 284, H2083-H2090. doi: 10.1152/ajpheart.01007.2002

Wu, J., Lewis, A. H., and Grandl, J. (2017). Touch, tension, and transduction - the function and regulation of piezo ion channels. Trends Biochem. Sci. 42, 57-71. doi: 10.1016/j.tibs.2016.09.004

Wu, Y., Shyng, S. L., and Chen, P. C. (2015). Concerted trafficking regulation of $\mathrm{K}_{\mathrm{V}} 2.1$ and $\mathrm{K}_{\mathrm{ATP}}$ channels by leptin in pancreatic $\beta$-cells. J. Biol. Chem. 290, 29676-29690. doi: 10.1074/jbc.M115.670877

Xi, Q., Adebiyi, A., Zhao, G., Chapman, K. E., Waters, C. M., Hassid, A., et al. (2009). $\mathrm{IP}_{3}$ constricts cerebral arteries via $\mathrm{IP}_{3}$ receptor-mediated TRPC3 channel activation and independently of sarcoplasmic reticulum $\mathrm{Ca}^{2+}$ release. Circ. Res. 105:e1. doi: 10.1161/CIRCRESAHA.108.173948

Xiao, Q., Yu, K., Perez-Cornejo, P., Cui, Y., Arreola, J., and Hartzell, H. C. (2011). Voltage- and calcium-dependent gating of TMEM16A/Anol chloride channels are physically coupled by the first intracellular loop. Proc. Natl. Acad. Sci. U.S.A. 108, 8891-8896. doi: 10.1073/pnas.1102147108

Xiao, X., Liu, H. X., Shen, K., Cao, W., and Li, X. Q. (2017). Canonical transient receptor potential channels and their link with cardio/cerebrovascular diseases. Biomol. Ther. 25, 471-481. doi: 10.4062/biomolther.2016.096

$\mathrm{Xu}, \mathrm{W}$, and Lipscombe, D. (2001). Neuronal $\mathrm{Ca}_{\mathrm{V}} 1.3 \alpha_{1}$ L-type channels activate at relatively hyperpolarized membrane potentials and are 
incompletely inhibited by dihydropyridines. J. Neurosci. 21, 5944-5951. doi: 10.1523/JNEUROSCI.21-16-05944.2001

Yamada, M., Isomoto, S., Matsumoto, S., Kondo, C., Shindo, T., Horio, Y., et al. (1997). Sulphonylurea receptor $2 \mathrm{~B}$ and $\mathrm{K}_{\mathrm{ir}} 6.1$ form a sulphonylureasensitive but ATP-insensitive $\mathrm{K}^{+}$channel. J. Physiol. 499, 715-720. doi: 10.1113/jphysiol.1997.sp021963

Yang, G., Xu, J., Li, T., Ming, J., Chen, W., and Liu, L. (2010). Role of $\mathrm{V}_{\text {la }}$ receptor in AVP-induced restoration of vascular hyporeactivity and its relationship to MLCP-MLC 20 phosphorylation pathway. J. Surg. Res. 161, 312-320. doi: 10.1016/j.jss.2009.01.005

Yang, H., Kim, A., David, T., Palmer, D., Jin, T., Tien, J., et al. (2012). TMEM16F forms a $\mathrm{Ca}^{2+}$-activated cation channel required for lipid scrambling in platelets during blood coagulation. Cell 151, 111-122. doi: 10.1016/j.cell.2012. 07.036

Yang, L., Liu, G., Zakharov, S. I., Morrow, J. P., Rybin, V. O., Steinberg, S. F., et al. (2005). Ser1928 is a common site for $\mathrm{Ca}_{\mathrm{v}} 1.2$ phosphorylation by protein kinase C isoforms. J. Biol. Chem. 280, 207-214. doi: 10.1074/jbc.M4105 09200

Yang, Y. (2012). Wnt signaling in development and disease. Cell Biosci. 2:14. doi: 10.1186/2045-3701-2-14

Yang, Y. D., Cho, H., Koo, J. Y., Tak, M. H., Cho, Y., Shim, W. S., et al. (2008). TMEM16A confers receptor-activated calcium-dependent chloride conductance. Nature 455, 1210-1215. doi: 10.1038/nature07313

Yin, J., and Kuebler, W. M. (2010). Mechanotransduction by TRP channels: general concepts and specific role in the vasculature. Cell Biochem. Biophys. 56, 1-18. doi: 10.1007/s12013-009-9067-2

Yu, F. H., and Catterall, W. A. (2003). Overview of the voltage-gated sodium channel family. Genome Biol. 4:207. doi: 10.1186/gb-2003-4-3-207

Yuan, K., Orcholski, M. E., Panaroni, C., Shuffle, E. M., Huang, N. F., Jiang, X., et al. (2015). Activation of the wnt/planar cell polarity pathway is required for pericyte recruitment during pulmonary angiogenesis. Am. J. Pathol. 185, 69-84. doi: 10.1016/j.ajpath.2014.09.013

Yudin, Y., and Rohacs, T. (2018). Inhibitory $\mathrm{G}_{\mathrm{i} / \mathrm{o}}$-coupled receptors in somatosensory neurons: potential therapeutic targets for novel analgesics. Mol. Pain 14:1744806918763646. doi: 10.1177/17448806918763646

Yue, R., Li, H., Liu, H., Li, Y., Wei, B., Gao, G., et al. (2012). Thrombin receptor regulates hematopoiesis and endothelial-to-hematopoietic transition. Dev. Cell 22, 1092-1100. doi: 10.1016/j.devcel.2012.01.025

Zamponi, G. W., and Currie, K. P. M. (2013). Regulation of $\mathrm{Ca}_{\mathrm{v}} 2$ calcium channels by G protein coupled receptors. Biochim. Biophys. Acta 1828, 1629-1643. doi: 10.1016/j.bbamem.2012.10.004

Zamponi, G. W., Striessnig, J., Koschak, A., Dolphin, A. C., and Sibley, D. R. (2015). The physiology, pathology, and pharmacology of voltage-gated calcium channels and their future therapeutic potential. Pharmacol. Rev. 67, 821-870. doi: 10.1124/pr.114.009654

Zeisel, A., Hochgerner, H., Lönnerberg, P., Johnsson, A., Memic, F., van der Zwan, J., et al. (2018). Molecular architecture of the mouse nervous system. Cell 174, 999.e22-1014.e22. doi: 10.1016/j.cell.2018.06.021
Zhang, H. L., and Bolton, T. B. (1996). Two types of ATP-sensitive potassium channels in rat portal vein smooth muscle cells. Br. J. Pharmacol. 118, 105-114. doi: 10.1111/j.1476-5381.1996.tb15372.x

Zhang, Q., Cao, C., Zhang, Z., Wier, W. G., Edwards, A., and Pallone, T. L. (2008). Membrane current oscillations in descending vasa recta pericytes. Am. J. Physiol. Ren. Physiol. 294, F656-F666. doi: 10.1152/ajprenal.00493.2007

Zhang, T., Wu, D. M., Xu, G., and Puro, D. G. (2011). The electrotonic architecture of the retinal microvasculature: modulation by angiotensin II. J. Physiol. 589, 2383-2399. doi: 10.1113/jphysiol.2010.202937

Zhang, Y., Ji, H., Wang, J., Sun, Y., Qian, Z., Jiang, X., et al. (2018). Melatoninmediated inhibition of $\mathrm{Ca}_{\mathrm{v}} 3.2 \mathrm{~T}$-type $\mathrm{Ca}^{2+}$ channels induces sensory neuronal hypoexcitability through the novel protein kinase C-eta isoform. J. Pineal Res. 64:e12476. doi: 10.1111/jpi.12476

Zhang, Y. J., Zhang, L., Ye, Y. L., Fang, S. H., Zhou, Y., Zhang, W. P., et al. (2006). Cysteinyl leukotriene receptors CysLT1 and CysLT2 are upregulated in acute neuronal injury after focal cerebral ischemia in mice. Acta Pharmacol. Sin. 27, 1553-1560. doi: 10.1111/j.1745-7254.2006.00458.x

Zhao, G., Joca, H. C., Nelson, M. T., and Lederer, W. J. (2020). ATP- And voltagedependent electro-metabolic signaling regulates blood flow in heart. Proc. Natl. Acad. Sci. U. S. A. 117, 7461-7470. doi: 10.1073/pnas.1922095117

Zhao, Q., Wu, K., Geng, J., Chi, S., Wang, Y., Zhi, P., et al. (2016). Ion permeation and mechanotransduction mechanisms of mechanosensitive piezo channels. Neuron 89, 1248-1263. doi: 10.1016/j.neuron.2016.01.046

Zhao, Q., Zhou, H., Chi, S., Wang, Y., Wang, J., Geng, J., et al. (2018). Structure and mechanogating mechanism of the Piezol channel. Nature 554, 487-492. doi: 10.1038 /nature25743

Zhu, J., Zhuo, C., Xu, L., Liu, F., Qin, W., and Yu, C. (2017). Altered coupling between resting-state cerebral blood flow and functional connectivity in schizophrenia. Schizophr. Bull. 43, 1363-1374. doi: 10.1093/schbul/sbx051

Zimmerli, D. (2018). Elucidating the Roles of Wnt-Secretion and $\beta$-Catenin's Interaction Partners in Development and Disease. University of Zurich.

Zitron, E., Kiesecker, C., Lück, S., Kathöfer, S., Thomas, D., Kreye, V. A. W., et al. (2004). Human cardiac inwardly rectifying current $\mathrm{I}_{\mathrm{Kir} 2.2}$ is upregulated by activation of protein kinase A. Cardiovasc. Res. 63, 520-527. doi: 10.1016/j.cardiores.2004. 02.015

Conflict of Interest: The authors declare that the research was conducted in the absence of any commercial or financial relationships that could be construed as a potential conflict of interest.

Copyright (๑) 2020 Hariharan, Weir, Robertson, He, Betsholtz and Longden. This is an open-access article distributed under the terms of the Creative Commons Attribution License (CC BY). The use, distribution or reproduction in other forums is permitted, provided the original author(s) and the copyright owner(s) are credited and that the original publication in this journal is cited, in accordance with accepted academic practice. No use, distribution or reproduction is permitted which does not comply with these terms. 